Aspects of bulblet growth of lily in vitro

Naser Askari 


\section{Thesis committee}

\section{Promotor}

Prof. Dr R.G.F. Visser

Professor of Plant Breeding

Wageningen University

\section{Co-promotor}

Dr G.J.M. de Klerk

Senior Researcher, Wageningen UR Plant Breeding

\section{Other members}

Prof. Dr G.H. Immink, Wageningen University

Prof. Dr P.C. Struik, Wageningen University

Dr H.J. Van Telgen, Botany B.V., Horst-Meterik

Dr R.J. Bogers, Bulb Research Center, Lisse

This research was conducted under the auspices of the Graduate School of Experimental Plant Sciences. 


\title{
Aspects of bulblet growth of lily in vitro
}

\author{
Naser Askari
}

\section{Thesis}

submitted in fulfilment of the requirements for the degree of doctor at Wageningen University by the authority of the Rector Magnificus Prof. Dr A.P.J. Mol, in the presence of the Thesis Committee appointed by the Academic Board to be defended in public on Tuesday 5 July 2016 at 1:30 p.m. in the Aula. 
Naser Askari

Aspects of bulblet growth of lily in vitro 130 pages.

$\mathrm{PhD}$ thesis, Wageningen University, Wageningen, NL (2016)

With references, with summary in English

ISBN: 978-94-6257-760-2

DOI: $10.18174 / 375959$ 


\section{Contents}

$\begin{array}{lll}\text { Chapter } 1 & \text { General introduction } & \mathbf{8}\end{array}$

Chapter 2 Stringent treatments to reduce contamination increased

22 growth of lily bulblets regenerating in vitro

Chapter 3 The influence of scale explants on lily bulblet growth in vitro

Chapter 4 The effect of abiotic stresses on lily bulblet growth in vitro 58

Chapter $5 \quad \mathrm{CO}_{2}$ starvation in vitro is lethal at heterotrophic conditions 72

Chapter 6 General discussion 88

References

Summary

116

Acknowledgments

120

About the author

124

List of publications

126

Experimental plant science (EPS) certificate

128 



\section{Chapter 1}

General Introduction 


\section{Lilium L.}

The genus Lilium is one of the ca. 220 genera belonging to the Liliaceae and comprises about 85 species including many ornamental species. Lilies are among the top 10 commercial flowers of the world. They have large flowers with attractive colors (Fig. 1) and an excellent vase life (Beattie and White). Lilium is characterized by an annual thermo-periodism and is widely distributed in the Northern Hemisphere. Lilium is classified into several divisions on the basis of geographical and genetic origin, and the position of the flowers. The species of this genus are taxonomically classified into seven sections (Martagon, Pseudolirium, Lilium, Archelirion, Sinomartagon, Leucolirion and Oxypetalum) (De Jong, 1974).

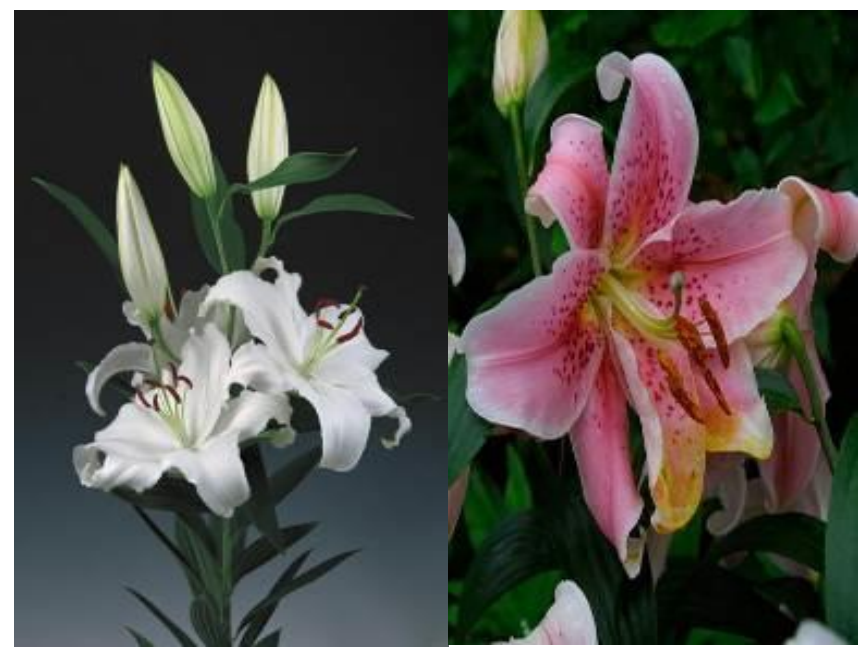

Fig. 1. Lilium cvs Santander (left) and Stargazer (right) that were used for the experiments described in this thesis.

\section{Propagation and micropropagation of lily}

Commercially grown cultivars are propagated by vegetative means to maintain genetic purity. The natural vegetative propagules are small bulblets, either produced above ground on the stems (bulbils) or underground on bulb scales (Kumar et al., 2006). For conventional commercial vegetative propagation, bulblets are produced from scales. Excised scales are kept in a plastic bag in moistened vermiculite and each scale produces 1-4 bulblets. This procedure is called 'scaling' (Fig. 2). Because the 
speed is nonetheless relatively slow, introduction of newly bred cultivars still requires a long period of time (Langens-Gerrits and De Klerk, 1999).

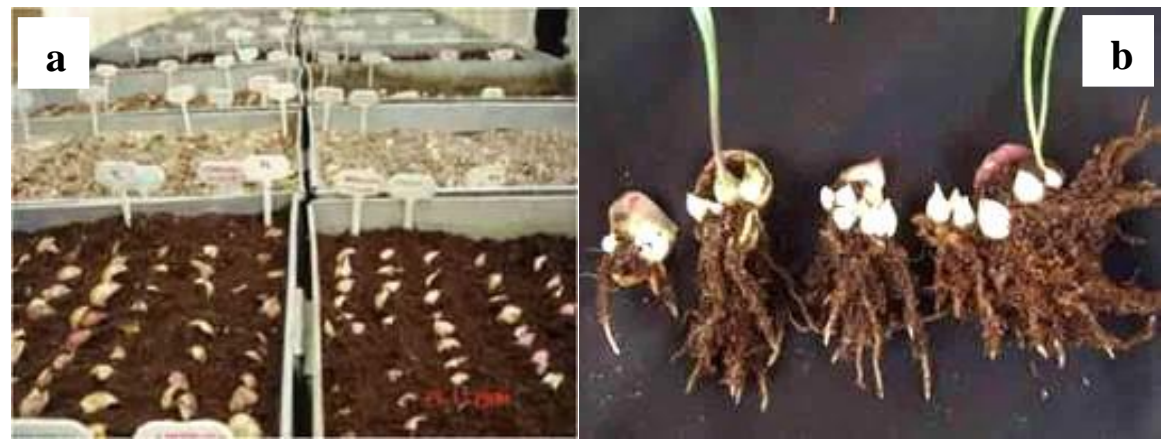

Fig. 2. Propagation of lily via scaling; a) lily scale culture on peat, b) regenerated lily bulblets after 12 weeks.

Micropropagation has the potency to produce large numbers of high quality plantlets in a short period of time (George et al., 2008). Basically, micropropagation in lily is just like scaling but carried out in vitro on an artificial nutrient medium. The major advantages of micropropagation are that small scale-explants can be used, that scales excised from the new bulblets can be used as new starting material so that per year a few propagation cycles can be performed, and that infection by micro-organisms is avoided (Fig. 3).

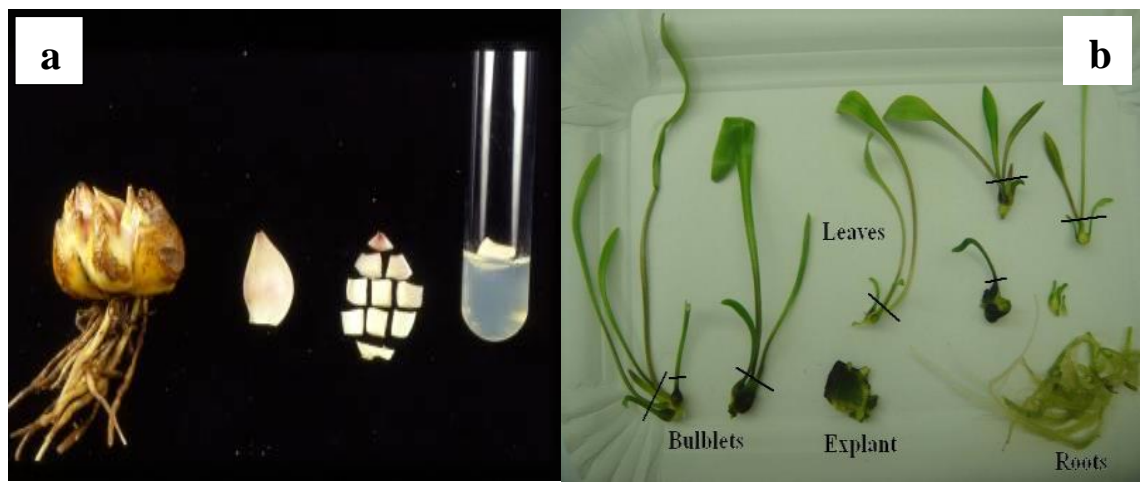

Fig. 3. Lily micropropagation in vitro; a) lily bulb, scale and explants cultured in vitro, b) lily bulblets regenerated in vitro after 12 weeks ( bulblets, leaves, roots and scale explant). 
The drawbacks of micropropagation are the high costs per propagule and the small size of the produced propagules. The latter leads to suboptimal performance after planting in soil. In micropropagation of Lilium, many tissues can be used but bulb scales are the favorite explants (Van Aartrijk and Van der Linde, 1986; Bahr and Compton, 2004; Han et al., 2005). Scales of lily bulbs are swollen petioles. Lily scale fragments cultured in vitro regenerate bulblets consisting of scales that may or may not carry a leaf blade (Jásik and De Klerk, 2006).

\section{Importance of bulb formation in tissue culture}

Bulblets and other storage organs produced in vitro have properties that make them preferable propagules. They can be easily handled, transported and stored and they do not require an extensive acclimatization procedure after transfer to soil (Thakur et al., 2006). In food crops, tissue culture is being used for production of microtubers in potato (Vreugdenhil et al., 1994), bulblets in shallot (Le Guen-Le Saos et al., 2002), garlic (Ravnikar et al., 1993), and onion (Knypl, 1980; Keller, 1993), and tuberous roots in sweet potato (Wang et al., 2006). In ornamentals, bulblets are produced as a last step during micropropagation of tulip (Kuijpers and Langens-Gerrits, 1996), lily (Bahr and Compton, 2004), Narcissus (Staikidou et al., 2005), Hyacinthus (Takayama et al., 1991), Muscari (Saniewski and Puchalski, 1987), Hippeastrum (Ilczuk et al., 2005) and iris (Van der Linde and Schipper, 1992). In some bulbous crops, bulblets are generated 'automatically' under normal tissue culture conditions and no special measures have to be taken (lily, hyacinth), but in other bulbous crops (tulip, iris) only shoots are formed. In the latter case, a special treatment is used to achieve bulb formation from the shoots.

The size of the bulblets produced in vitro has a strong effect on performance after planting. Studies with direct field planting of bulblets produced in vitro have shown that small bulblets emerge slower, less uniform and to a smaller percentage (Lian et al., 2003). Furthermore, the growth after planting is determined by the initial bulb weight. The initial weight influences growth after planting in two ways. The weight of bulblets after a growing season is linearly related with the initial weight (Langens-Gerrits et al., 1996b). In addition, when bulblets are sufficiently large (> 300 
$\mathrm{mg}$ ), they increasingly sprout with a stem instead of a rosette (Langens-Gerrits et al., 2003a). When sprouting with a stem, growth of the bulblets in soil is much better (Fig. 4). The change from sprouting with a rosette to sprouting with a stem is related to a switch in ontogenetic development from juvenile to adult vegetative.

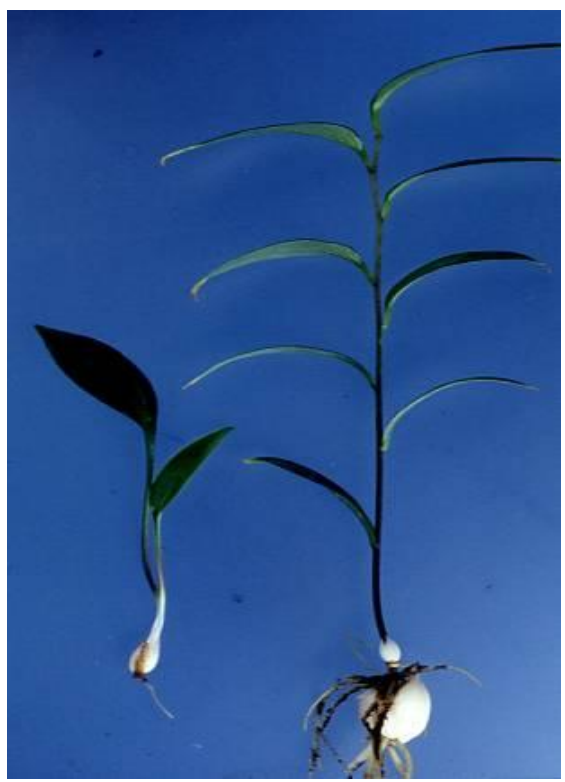

Fig. 4. Lily bulblet growth in soil (left: small bulblet growth without a stem, right: bigger bulblet growth with a stem).

\section{Effect of plant growth regulators on the growth of storage organs}

All classes of hormones were found to have some effect on the formation of tubers and bulbs (Vreugdenhil and Sergeeva, 1999). The major ones are discussed below.

\section{Gibberellins}

Gibberellins inhibit tuberization, cause stolons to elongate rather than to swell, and inhibit starch accumulation and the synthesis of tuber-specific proteins (Xu et al., 1998; Vreugdenhil and Sergeeva, 1999). The effect of the gibberellin-synthesis inhibitors on growth and development of oriental lily hybrids has been examined and with these growth retardants heavy bulblets were obtained (Kumar et al., 2005). The 
effect of growth retardants (like paclobutrazol or ancymidol) was studied in Lilium plantlets growing in liquid culture. A significant increase in leaf chlorophyll, epicuticular wax, plant dry weight and bulb starch contents were found in plantlets treated with growth retardants. A similar increase in the number of leaves, roots and bulbs was also noted (Thakur et al., 2006). Three inhibitors of gibberellin biosynthesis (ancymidol, flurpirimidol, and paclobutrazol) promoted bulb formation and the percentage of bulbing in shallot (Le Guen-Le Saos et al., 2002). In Hippeastrum tissue culture, flurpirimidol not only influenced the propagation rate, but also the size of the newly developed bulblets. Explants cultured in media containing flurprimidol formed much bigger bulblets (Ilczuk et al., 2005).

\title{
Jasmonates (JA)
}

Exogenously applied JA induces or promotes tuber formation in potato, yam, and orchid, as well as bulb formation in garlic and narcissus. The putative role of JA in storage organ formation has been corroborated by reports on increased endogenous levels of JA in bulb and tuber forming plants (Jásik and De Klerk, 2006). In lily, JA promotes relative bulb weight (bulb weight as a percent of plantlet weight). Here it should be noted again that scales of lily bulblets regenerated in vitro may or may not carry a leaf blade. In lily JA strongly inhibited leaf blade formation without promoting absolute bulblet weight. JA significantly enhanced shoot and bulb development in garlic (Ravnikar et al., 1993). In Narcissus triandus, JA plays an important role in the formation and enlargement of bulbs (Santos and Salema, 2000).

\begin{abstract}
Abscisic acid (ABA)
In lily, ABA promotes relative bulb weight (bulb weight as a percent of plantlet weight), but not the absolute weight: ABA strongly inhibits leaf blade formation without promoting absolute bulblet weight. When fluridone, an inhibitor of $\mathrm{ABA}$ synthesis is added, scale formation is inhibited completely, but is restored when ABA is added along with fluridone (Kim et al., 1994).
\end{abstract}




\section{Effect of other factors on the growth of storage organs}

Various other factors have been examined with relation to storage organ formation. First, these factors are dealt with. The next section deals with tissue culture factors that are usually not recognized but may be decisive for adequate bulblet growth.

\section{Temperature}

Both a moderate low temperature $\left(15^{\circ} \mathrm{C}\right)$ and a severe cold treatment $\left(5^{\circ} \mathrm{C}\right)$ have a profound effect. A moderate temperature $\left(15^{\circ} \mathrm{C}\right)$ is required for a phase change. During the development of lily, three ontogenic phases can be distinguished, viz., juvenile, vegetative adult and flowering phase (Langens-Gerrits et al., 2003a). In in vitro cultured lily bulblets, the transition from juvenile to vegetative adult is characterized by the development of a tunica-corpus structure with increased mitotic activity in the apical meristem, followed by stem elongation (Langens-Gerrits et al., 1996a). This step is related to the weight of the bulblets (Matsuo and Arisumi, 1978; Niimi, 1995; Langens-Gerrits et al., 2003a), and also to a moderate low temperature treatment $\left(15^{\circ} \mathrm{C}\right)$ (Ishimori et al., 2007).

In lily bulblets that are planted in the field, the bulblet growth per mg leaf DW (this is the sink activity of the bulblets) is sharply promoted by a preceding cold treatment of bulblets at $5{ }^{\circ} \mathrm{C}$ (De Klerk, 2009). It was concluded that a cold treatment is necessary to stimulate sink strength of the bulblets. In tissue culture of lily bulb formation occurs without a preceding cold treatment. Apparently other bulb-inducers (e.g., the high sucrose concentration in the medium) play a role. On the other hand, bulb growth in vitro is much less than bulb growth in soil (see below) and this may well be caused by the lack of cold treatment. In tulip, a cold treatment is also necessary to obtain bulblet growth (Rice et al., 1983).

\section{Light}

Light intensity and quality also influence the growth of bulblets. The fresh weight of bulblets was significantly greater in dark than in light in L. longiflorum (Leshem et al., 1982). In potato darkening of both roots and shoots strongly promoted tuber formation; the tubers were formed on the darkened part of the plant (Aksenova et 
al., 1994). The influence of varying light treatments (blue, green, yellow, red, far-red and UV irradiation) on shoot and bulb induction was studied in tissue culture of hyacinths in vitro. Blue light stimulated growth and development of adventitious shoots and buds regardless of carbohydrate type, while the highest number of bulbs was obtained under red or white light (Bach and Świderski, 2000).When stem cuttings of potato plants were cultured under red or blue light, red-light-plants were thin, long, with very small leaves, and produced no or only few microtubers (after longer-lasting cultivation). Blue-light-plants remained short, thick, with large, well developed leaves and produced a significant amount of microtubers (Aksenova et al., 1994). With respect to day length, in L. ancifolium, $16 \mathrm{~h} \mathrm{~d}^{-1}$ darkness had the best effect with respect to bulblet formation and enlargement (Zhang et al., 2010).

\section{Explant size}

In lily, the size of the explant (= scale fragment) has a major effect on the size of the regenerated bulblet. The size of the explant has yet another effect: bulblets of the same size that have regenerated from a large or a small explant respectively may differ with respect to the ontogenic age. The bulblets that have regenerated from a large explant are often adult and the ones from a small explant usually juvenile, and they sprout with a stem or with a rosette respectively (Langens-Gerrits et al., 2003a). There are a number of ways how the size can influence the regenerating bulblet, including hormonal or nutritional influences.

\section{Sucrose}

Sucrose does not affect the number of regenerated bulblets, but the size of bulblets increases with increasing concentration of sucrose (Han et al., 2005). During in vitro culture, growth of the bulblets depends on the sucrose concentration (Yamagishi, 1998). It was reported earlier that large bulblets were obtained in vitro on medium with a high concentration of sucrose (Van Aartrijk and Van der Linde, 1986; Langens-Gerrits et al., 2003b). The increase in bulblet size with high concentration of sucrose (60-90 $\mathrm{g}^{-1}$ ) was reported in many Lilium cultivars using different explants (Takayama and Misawa, 1982; Bonnier and Van Tuyl, 1997). The increase in bulblet 
size was mainly due to an increase in starch and total carbohydrates. The ontogenic age of the regenerated bulblets is influenced by the sucrose-mineral ratio in the medium with a high ratio being promotive for the phase change. Especially phosphorus seems to be important but this has not been examined critically (Langens-Gerrits et al., 2003a).

Lilium bulbs accumulate storage polysaccharides. Starch is the major storage polysaccharide in Lilium bulbs. In L. longiflorum, $85 \%$ of the storage polysaccharides are starch and the remainder glucomannan (Matsuo and Mizuno, 1974). Starch is an important reserve carbohydrate found in many plant species in all types of storage organs: seeds, tubers, bulbs and corms. It is deposited as crystalline granules, which consist of two polysaccharides, amylose (20-30\%) and amylopectin (70-80\%). In plant storage organs, starch biosynthesis takes place within the amyloplast (Ji et al., 2003). With respect to the biochemistry, it is widely accepted that plastidic ADPglucosepyrophosphorylase (AGPase) catalyzes the first step. AGPase utilizes glucose1-phosphate (Glc-1-P) and ATP to form ADP-glucose (the substrate for starch synthase) and PPi, which serves as the direct precursor for starch synthesis. To date the AGPase enzyme has been extensively studied in many sink organs of plants (Jaleel et al., 2007; Kato et al., 2007; Mohapatra et al., 2009). In mungbean seeds, a steady sink activity of the enzymes controlling carbon flux entering the seed may be required to achieve a large seed size (Chopra et al., 2007).

\section{Stress}

Under stressful conditions, plants also tend to increase allocation to belowground biomass and storage organs (Puijalon et al., 2008). In correspondence with this, a short period of abiotic stress (heat, cold, anaerobiosis) increases rhizome growth in Alstroemeria by ca. $100 \%$ (Pumisutapon et al., 2012).

\section{Nutrition of the regenerating bulblet; how do medium components reach the bulblet?}

The conditions in tissue culture seem to be optimal: water is abundantly available, high levels of organic and inorganic nutrients are added and the temperature 
is favorable. Nevertheless, the growth of plantlets in tissue culture falls short of expectations and seems at best similar to growth in the field. This has been ascribed to poor long-distance translocation in the explants (De Klerk, 2010). Lily bulblets generated in vitro also show relatively poor growth. Growth in tissue culture is linear and in the field exponential, resulting in much heavier bulblets ex vitro (De Klerk et al 1992). It should be noted that the ex vitro conditions include an adequate, constant temperature and relatively poor lightning. There may be several reasons for the poor growth of bulblets in tissue culture:

- The sink activity is limited; in tissue culture of lily no cold treatment is applied in contrast to e.g. tulip. In the field, a cold treatment increases sink activity in lily (De Klerk, 2009).

- The bulblet requires hormonal factors for proper growth (ABA? JA? antigibberellins?) which are only available in complete plantlets growing in soil.

- The tissue culture microenvironment is stressful, e.g. because sucrose is toxic (Desjardins et al., 2009)

- The supply of nutrients is inadequate.

The latter factor will be elaborated below. First, the supply under natural conditions will be discussed.

\section{Translocation under natural conditions}

\section{Inorganic nutrients}

In plants growing in the field, inorganics are taken up from the soil by the roots. Movement of solutes from the soil into the cell walls of roots occurs by diffusion or by hitching with the mass water flow. The ions move in the apoplast and the symplast up to the xylem parenchyma cells. However, a suberized cell layer in the endodermis, known as the Casparian strip, effectively blocks the entry of water and mineral ions into the stele via the apoplast. To pass through this cell layer, the solutes have to move into the symplast. After passing the Casperian strip, they may again move both in the symplast and the apoplast. The Casperian strip prevents moving backwards. Next, the solutes are loaded into the xylem tracheary cells and are then taken with the water flow in the xylem to the shoot. 


\section{Carbohydrates}

In plants growing in the field there are two main sources of carbohydrates: photosynthetically active leaves and degrading storage organs. Sucrose is the major transport mode for carbohydrates and long-distance transport from source to sink organs occurs in the phloem (Li et al., 2010). In the source, energy is necessary to move carbohydrates from producing cells into the sieve elements in the phloem. This movement is called phloem loading. In the sink, energy is essential for some aspects of movement from sieve elements to sink cells, which store or metabolize the sugar. This movement of photosynthate from sieve elements to sink cells is called phloem unloading (Taiz and Zeiger, 2002). Phloem functions differ according to organ location. At least three parts can be defined: collection phloem in source organs (minor veins), transport phloem (along the path from source to sinks) and release phloem in sink organs (Van Bel, 1993). Sink organs rely heavily on the delivery of carbohydrates through the phloem for growth and development. Besides sucrose, other sugars are found and sometimes may be as abundant as sucrose, depending on species. They include polyols and oligosaccharides of the raffinose family. Other nutrients, such as amino acids and organic acids, are also found (Zimmermann and Ziegler, 1975). The loading of sucrose at the source and unloading at the sink brings about differences in osmotic potential that lead to uptake of water in the sink and release in the source and thereby the water flow in the phloem.

\section{Transport to regenerating bulblets cultured in vitro}

The components that are being translocated into growing bulblets include carbohydrates and inorganic nutrients. Carbohydrates originate from the scale explant and from the medium (Langens-Gerrits et al., 2003b). The percentage bulb growth that can be attributed to uptake of medium-sucrose is constant over the full regeneration period: $45-50 \%$ for large $(3 \times 15 \mathrm{~mm})$ and $65-75 \%$ for small $(3 \times 5 \mathrm{~mm})$ explants.

It is usually taken for granted that medium components reach the target tissue in the explants (usually the growing areas) in adequate amounts. But how are they translocated? Generally, solutes (compounds dissolved in water) may be translocated in two ways: (1) by diffusion and (2) by hitch hiking with the water flow. Diffusion is 
driven by random thermal agitation and is fast over short distance, but very slow over large distances. According to Flick's law of diffusion, diffusion over 1 meter takes 32 years, over $2 \mathrm{~cm}$ one week, and over $50 \mu \mathrm{m} 2.5 \mathrm{sec}$. Therefore, plants use water flow in the vascular tissues for long distance transport (Taiz and Zeiger, 2002). It has been discussed in the previous section how compounds are translocated to growing areas in plants in the field. In micropopagation, the distances between the source, the medium, and the sink (the growing areas) are a few millimeters to a few centimeters. Diffusion over a distance of $4 \mathrm{~mm}$ takes about $9 \mathrm{~h}$ (depending on the diffusion-coefficient) and 2 $\mathrm{cm}$ takes 8 days which is slow. In addition, a second factor that results in low translocation via diffusion is the small diameter of the tissue via which transport occurs. Therefore, to obtain adequate growth in tissue culture most of the long distance transport of nutrients (from the medium to the growing regions of the shoot or from the medium to the developing bulblets) should also occur via the vascular bundles (De Klerk, 2010).

\section{Xylem}

The movement of water in the phloem is driven by transpiration. The tissue culture conditions are very humid so transpiration is expected to be reduced. Transpiration of shoots cultured in vitro has only been measured few times and was found to be $50 \mu 1 . \mathrm{cm}^{-2} \cdot \mathrm{d}^{-1}$ (Tanaka et al., 1991) and $30 \mu 1 . \mathrm{cm}^{-2} \cdot \mathrm{d}^{-1}$ (De Klerk, 2010) This is a small percentage of the transpiration rate in the field. Calculations showed that this is just enough to support growth when the compounds enter the cut surface together with water and move together with the water upwards into the shoot. Experiments with dyes, though, showed that when the cut surface is healed after the wounding reaction, most of the dye stays in the tissue at the cut surface. Similarly inorganic and organic nutrients may be captured at the cut surface. Regenerating lily bulblets that have no leaves because of culture in the dark, will have even less transpiration and still show bulblet growth similar or even higher than light-grown bulblets. We therefore conclude provisionally that xylem transport does not play a major role in the growth of lily bulblets. 


\section{Phloem}

About phloem functioning in tissue culture nothing is known. As noted above, water flow in the phloem -so also the movement of solutes- is brought about by the loading and unloading of sucrose. In lily tissue culture, phloem unloading occurs in the regenerating bulblets and the mechanisms are most probably the same as in bulblets growing under natural conditions. Loading may occur in scale explants or in the leaves where sufficient sucrose might have accumulated by photosynthesis and/or by translocation in the transpiration flow in the xylem. In lily scale explants, the scale itself also functions naturally as a source when being degraded. It is not known in which developmental stage scales in tissue culture are. Scales seem to be both sink and source: They definitely acts as sink during tissue culture since they increase in weight but they also act as source since a significant portion of the carbohydrates translocated to the regenerating bulblet is scale-carbohydrate (Langens-Gerrits et al., 2003b). In potato, ${ }^{14} \mathrm{C}$-glucose is incorporated in starch when the potato is a sink and in sucrose when it is a source (Viola et al., 2007). It is questionable whether sufficient loading occurs in the regenerating bulblet itself, so the scale explant seems to play a major role. It should be remembered that -in agreement with this- the size of the scale explant determined the size of the regenerating bulblet (Langens-Gerrits et al., 2003b).

\section{Scope of the thesis}

Lily is propagated via in vitro methods and the common explant for lily micropropagation is the scale explant. In spite of availability of nutrients, water, light and proper temperature in vitro, the growth of lily bulblets regenerated in vitro is lower than the growth of lily bulblets ex vitro. There is little literature available on the elucidation of the growth of lily in vitro as a model crop for bulbous crops (De Klerk et al., 1992; Langens-Gerrits et al., 1996b; Langens-Gerrits and De Klerk, 1999; Langens-Gerrits et al., 2003b; De Klerk, 2009).

In Chapter 2, we set up a novel method to reduce the contamination percentage of lily scale explants. Lily is a geophyte and underground storage organs of lily are used for micropropagation, so there is a high number of microorganisms which increase contamination percentage during tissue culture of lily. A diluted $\mathrm{NaClO}$ 
solution was added to the rinsing water and subsequently cross-contamination decreased significantly. In addition, excision of scales of lily bulbs submerged in diluted $\mathrm{NaClO}$ also decreased lily contamination by preventing the entering of contaminated fluid percentage. The results described in this chapter showed that the common sterilization procedure is not the proper way to sterilize explants in vitro.

In Chapter 3, a detailed study on the effect of scale explants on growth of lily bulblets in vitro was done. Scale explants as the main explants for tissue culture of lily plays a key role in the growth of lily bulblets in vitro. The size of scale explants influenced the growth of lily bulblets in vitro. Studies on apical and basal scale explants showed that the intensity of vascular bundles and the amount of starch granules influenced the growth of lily bulblet regenerated in vitro. In this chapter, we describe the development of vascular bundles in lily scale explants.

In Chapter 4, several moderate abiotic stresses were found to improve the growth of lily bulblets in vitro. Hot air, hot water, drought and anaerobiosis were studied with respect to their effect on the growth of lily bulblets in vitro. The aim of this chapter was to understand whether moderate stresses can enhance the growth of lily bulblets in vitro.

In Chapter 5, the effect of $\mathrm{CO}_{2}$ removal from the headspace of tissue culture containers on photosynthesis of in vitro grown lily and Arabidopsis is examined. In absence of $\mathrm{CO}_{2}$, the growth and $\mathrm{F}_{\mathrm{v}} / \mathrm{F}_{\mathrm{m}}$ decreased in lily and Arabidopsis cultured explants. Staining with nitro blue tetrazolium, a stain for reactive oxygen species (ROS), showed that tissue cultured plants contained a low, but significant level of ROS. This level was strongly increased when $\mathrm{CO}_{2}$ had been removed, probably due to the lack of electron acceptors in the photosynthetic electron transport chain. ROS were virtually absent in ex vitro grown plants. An overall discussion about all above mentioned chapters is presented in Chapter 6. 


\section{Chapter 2}

\section{Stringent treatments to reduce contamination increased growth of lily bulblets regenerating in vitro}

\footnotetext{
Naser Askari ${ }^{1,2}$, YouGuo Wang ${ }^{3}$, Richard G.F Visser ${ }^{1}$, and Geert-Jan de Klerk ${ }^{1}$

${ }^{1}$ Wageningen UR Plant Breeding, P. O. Box 16, 6700 AA Wageningen, The Netherlands ${ }^{2}$ Department of Plant Sciences, University of Jiroft, P. O. Box 364 , Jiroft, Iran

${ }^{3}$ College of Landscape and Horticulture, Yunnan Agricultural University, Bei ShiQu, Kunming 650201, Yunnan Province, China
}

Parts of this chapter were published as Naser Askari, YouGuo Wang and Geert-Jan de Klerk in Propagation of Ornamental Plants Vol. 14, NO. 2, 2014:49-56 


\begin{abstract}
In tissue culture of Lilium, the standard initiation procedure brings about substantial contamination in two ways. (1) When scales are detached from the mother bulb, microorganisms can enter via the wound. Contamination was strongly enhanced by the negative hydrostatic pressure within the scales by which nonsterile fluid was sucked up at detachment. The occurrence of a negative hydrostatic pressure was demonstrated by penetration $(23.8 \mathrm{~mm})$ of a solution of acid fuschine in the vascular tissues when scales were detached from a bulb submerged in the solution. Penetration was only $1.4 \mathrm{~mm}$ when the hydrostatic pressure had been removed by detaching the scale before submergence in the dye-solution. Contamination decreased strongly when the scales were detached from bulbs that were submerged in $0.03 \% \mathrm{NaClO}$. Evidence is presented here that this type of contamination was as expected endogenous, i.e., localized in the interior of the explant. (2) During the rinsing of scales after surfacesterilization, the rinsing water becomes contaminated with microorganisms that have not been killed during surface-sterilization. This caused cross-contamination. This type of additional contamination was controlled by rinsing in $0.03 \% \mathrm{NaClO}$ instead of 'sterile' water. In our conditions, these initiation-related sources of contamination led to ca. $20 \%$ and ca. $25 \%$ contamination, respectively, of otherwise uninfected scales. Bulblet growth increased with $17 \%$ and $22 \%$ by reducing negative-hydrostatic-pressure related contamination and cross contamination, respectively.
\end{abstract}




\section{Introduction}

Several microorganisms have been identified as contaminants in plant tissue culture, in particular fungi, yeast and bacteria. Bacterial contamination is most common (Leifert et al., 1991; Leifert and Cassells, 2001). With respect to the topographical localization, contaminants may inhabit the surface of the tissue (epiphytic) or live within the tissue (endophytic). The former are for the greater part removed by adequate surface-sterilization but for the latter there is no easy treatment. The main obstacle in controling internal contaminants is that within the tissue, antibiotics etc. added via the medium do not reach a concentration sufficiently high to be effective. This is caused by general difficulties in uptake and transport of medium ingredients in tissue-cultured plants (De Klerk, 2010; De Klerk and Askari, 2012). In spite of this, many researchers and companies add antibiotics to the nutrient medium. When the antibiotics are omitted after a number of subcultures, the contaminants always "return". Addition of antibiotics is, however, helpful because they prevent overgrowing of the nutrient medium. Endophytic microorganisms may be beneficial to some extent (Hallmann et al., 1997), but usually they seem to be inhibitory (Long, 1988; Pirttilä et al., 2008).

At the time of collecting explants, contaminants are present at the surface of the tissue and within the tissue. Apart from improper handling by operators, for example, carelessness or inadequate flaming (Kunneman and Faaij-Groenen, 1987), there are during the initiation procedure two possible ways of infection that are as yet not or only little recognized.

(1) When the explant is excised from the stock plant, open vascular tissue is exposed to the nonsterile environment. Since the xylem has a negative hydrostatic pressure brought about by transpiration (Taiz and Zeiger, 2002), neighbouring fluids containing contaminants are sucked up after detachment (Van Meeteren, 1988). (2) Since it is not feasible to sterilize explants individually, they are processed in batches of 5 to 50 or more. Cross-contamination may occur, after the surface-sterilization with concentrated $\mathrm{NaClO}$, during the rinsing of explants with sterile water. Usually, the explants are rinsed three times with sterile water (George, 1993; Pierik, 1997). Rinsing is done rigorously probably because researchers are afraid that $\mathrm{NaClO}$ affects plant tissues also at low concentration. This is, however, unlikely. Some researchers even 
add low levels of $\mathrm{NaClO}$ during tissue culture to avoid flourishing of microorganisms (Teixeira et al., 2006; Yanagawa, 2007; Sawant and Tawar, 2011). Researchers ignore the possibility of cross-contamination during rinsing because there seems to be no feasible alternative procedure and because it is believed that the period during which cross-contamination may occur is too short to cause serious problems.

Organs growing underground like bulbs are notorious for contamination (Ziv and Lilien-Kipnis, 2000). The aims of the present study were to determine whether contaminants are introduced during the initiation step and if so, to reduce this contamination by using a low concentration of $\mathrm{NaClO}$ instead of water.

\section{Materials and Methods \\ Standard tissue culture conditions}

Field-grown bulbs (circumference 18-20 cm) of Lilium cv. Santander were harvested, cold-treated to break dormancy and stored at $-1.0{ }^{\circ} \mathrm{C}$ until use. The procedure was according to (Aguettaz et al., 1990). Scales were surface-sterilized for $30 \mathrm{~min}$ in $1 \%(\mathrm{w} / \mathrm{v}) \mathrm{NaClO}$, rinsed for 1,3 and $10 \mathrm{~min}$ with sterile water and after that stored until use in sterile water (on average for 1-2 h). Two explants of $7 \times 7 \mathrm{~mm}$ were cut from the scales and placed with the abaxial side on $15 \mathrm{ml}$ medium in plastic culture tubes $(3.5 \mathrm{~cm}$ diameter). The medium was composed of macro- and microelements (Murashige and Skoog, 1962), $30 \mathrm{~g} \mathrm{l}^{-1}$ sucrose, $0.4 \mathrm{mg} \mathrm{l}^{-1}$ thiamin, $100 \mathrm{mg} \mathrm{l}^{-1}$ myoinositol, $7 \mathrm{~g} \mathrm{l}^{-1}$ agar (Microagar) and $0.05 \mathrm{mg} \mathrm{l}^{-1} \mathrm{NAA}$ ( $\alpha$-naphthaleneacetic acid). The explants were cultured at $25^{\circ} \mathrm{C}$ and $30 \mu$ mol.m $\mathrm{m}^{-2} \cdot \sec ^{-1}$ (Philips TL 33) for $16 \mathrm{~h}$ per day. Contamination was scored at time intervals of 2-4 days for 6 weeks. After 11 weeks of culture, the regeneration percentage, bulblet number and fresh weight per bulblet were determined.

\section{Minimal concentration of $\mathrm{NaClO}$ for decontamination of fluids}

Twenty nonsurface-sterilized scales were kept for $3 \mathrm{~h}$ in $300 \mathrm{ml}$ water to obtain contaminated water. To determine the minimal effective concentration of $\mathrm{NaClO}$ in fluids, increasing quantities of $\mathrm{NaClO}$ were added to this contaminated water to obtain increasing concentrations $(0,0.01,0.03,0.06,0.1$ and $1.5 \%, \mathrm{w} / \mathrm{v})$ and the solutions 
were stored for $24 \mathrm{~h}$ at room temperature. After that, $2 \mathrm{ml}$ of fluid LB medium (Lysogeny Broth medium, a nutritionally rich medium used for growth of bacteria; Duchefa, Netherlands) was added to $2 \mathrm{ml}$ from each $\mathrm{NaClO}$ concentration and incubated at $37^{\circ} \mathrm{C}$ for $3 \mathrm{~d}$. Then, bacterial growth was evaluated by visual inspection.

\section{Estimation of cross-contamination}

Sixty outer scales and 30 inner scales were sterilized for $30 \mathrm{~min}$ in one beaker with $1 \% \mathrm{NaClO}$ solution plus a few drops Tween 20 . Then the scales were divided into two groups (30 outer scales and 15 inner scales), distributed over two beakers (so per beaker 45 scales), rinsed three times (1, 3 and $10 \mathrm{~min}$; the first group with sterile water and the second group with $0.03 \% \mathrm{NaClO})$, and then stored until use (1-2h) in water or $0.03 \% \mathrm{NaClO}$, respectively. The rinsing fluids were stored at $4{ }^{\circ} \mathrm{C}$ to examine contamination. Explants were prepared and cultured as indicated above. We monitored contamination of the scales during 6 weeks of culture. The percentage contamination due to cross-contamination was calculated with the following formula:

$$
\text { Cross-cont. } \%=\frac{\text { ContWR } \%-\text { ContChlR } \%}{100-\text { ContChlR } \%} * 100
$$

in which "Cross-cont (\%)" is cross-contamination \% and "ContWR (\%)" and "ContChlR (\%)" the contamination percentages after rinsing with water and $0.03 \% \mathrm{NaClO}$, respectively.

\section{Estimation of hydrostatic-pressure related contamination}

Scales were detached from the mother bulb under streaming water or under streaming $0.03 \% \mathrm{NaClO}$ and stored in water or $0.03 \% \mathrm{NaClO}$, respectively. They were surface-sterilized in the usual way ( $30 \mathrm{~min}$ in $1 \% \mathrm{NaClO}$ ), and rinsed three times with $0.03 \% \mathrm{NaClO}$. Explants were prepared and cultured as indicated above. Contamination was monitored for 6 weeks and the hydrostatic-pressure related contamination that occurs when scales are detached from the mother bulb was calculated according the following formula:

$$
\text { ContHP }(\%)=\frac{\text { ContWD }(\%)-\text { ContChlD }(\%)}{100-\text { ContChlD }(\%)} * 100
$$

in which " ContHP (\%)" is hydrostatic-pressure related contamination (\%) and "ContWD (\%)" and "ContChlD(\%)" the contamination percentages after detaching scales from bulbs submerged in water and $0.03 \% \mathrm{NaClO}$, respectively. 


\section{Determination of contamination in the rinsing fluids}

The rinsing fluids (water and $\mathrm{NaClO}$ solutions) were inoculated on $\mathrm{LB}$ solid medium in a 9-cm Petri dish and $30 \mathrm{ml} \mathrm{LB}$ liquid medium in plastic test tubes (Duchefa, Netherlands). On the solid medium, $25 \mu 1$ was inoculated and on the liquid medium $30 \mathrm{ml}$. Bacterial growth was determined after $3 \mathrm{~d}$ in dark at $37{ }^{\circ} \mathrm{C}$.

\section{Determination of transpiration by scales}

Scales were detached from the bulbs, transferred to plastic culture tubes $(3.5 \mathrm{~cm}$ diameter) with $10 \mathrm{ml}$ water solidified with $0.7 \%$ agar and kept standing upright with their basal part on the medium. A layer of $1.5 \mathrm{~mm}$ paraffin oil was carefully added to prevent evaporation from the solidified medium. The weight of container + medium + scale + paraffin oil was determined every $60 \mathrm{~min}$ and the weight loss was taken as transpiration by the scale. There was negligible weight loss when no scales were present (less than $0.1 \mu \mathrm{l}$ per hour) showing that almost all weight loss occurred via the scale.

The surface of scales was measured as follows. The abaxial and adaxial side of scales were traced on paper taking into account the curvature of the scales. Then the drawn surfaces were cut out with scissors and weighed. The surface was calculated using the weight of $1 \mathrm{~cm}^{2}$ paper.

\section{Visualization of stomata in lily bulb scales}

The stomata were visualized by preparing epidermal impressions of the adaxial and abaxial surfaces of lily bulb scales. The scale impressions were made with polyvinylsiloxane based high precision President Light Body impression material (Coltène/Whaledent AG, Altstätten, Switzerland). The lily scales were detached from lily bulbs and pushed onto the semi-soft impression material with the abaxial and adaxial surface. After 5 minutes the impression materials had solidified and scales were removed. Then colourless nail polish was painted on the imprints. Dried nail polish peels were stripped off, placed on a microscope slide and observed with an Axiophot light microscope (Zeiss, Oberkochen, Germany). Images were taken with an AxioCam ERc5S digital camera (Zeiss). 


\section{Determination of water movement into the vascular tubes caused by the negative}

hydrostatic pressure

To show that fluid can penetrate easily far into the scale explants by the negative hydrostatic pressure, the dye acid fuchsine was used as a visual marker. Scales were detached from bulbs that were submerged in $0.5 \%$ acid fuchsine and kept submerged for $5 \mathrm{sec}$. As a control, scales were detached in the normal way and after 2 sec submerged in acid fuchsine for $15 \mathrm{sec}$. Each treatment was represented by 5 scales and each scale was dissected from the bottom upwards until no more color agent was detected by eye and binocular.

\section{Statistics}

In the figures, the means are shown \pm SE. The statistical significances of differences in percentages and means were evaluated by the $\chi^{2}$ and by the Student $t$-test, respectively. For each treatment, at least 50 explants were taken. Each experiment was carried out at least twice.

\section{Results}

\section{Determination of the minimal concentration of $\mathrm{NaClO}$ for decontamination of fluids}

Bacteria did grow in $\mathrm{LB}$ medium to which no or $0.01 \% \mathrm{NaClO}$ had been added (Table 1). The lowest $\mathrm{NaClO}$ concentration that fully inhibited bacterial growth was $0.03 \%$. Thus, a $0.03 \%$ solution of $\mathrm{NaClO}$ is suitable to prevent contamination after the surface-sterilization, provided the tissues are not being damaged.

Table 1. Minimum concentration of $\mathrm{NaClO}$ for disinfection of fluids.

\begin{tabular}{|c|c|c|c|c|c|c|c|}
\hline \multicolumn{9}{|c|}{ NaClO concentration (\%) } \\
\hline \multirow{3}{*}{$\begin{array}{c}\text { LB liquid } \\
\text { medium }\end{array}$} & & 0 & 0.01 & 0.03 & 0.06 & 0.1 & 1.5 \\
\cline { 2 - 9 } & 1 & +++ & ++ & - & - & - & - \\
\cline { 2 - 9 } & 2 & +++ & ++ & - & - & - & - \\
\cline { 2 - 9 } & 3 & +++ & ++ & - & - & - & - \\
\hline
\end{tabular}

To contaminated fluid, a concentrated solution of $\mathrm{NaClO}$ was added. After $2 \mathrm{~d}$ at $25{ }^{\circ} \mathrm{C}$, liquid LB was and after another $3 \mathrm{~d}$ at $37{ }^{\circ} \mathrm{C}$, bacterial incidence was scored. (- not contaminated, ++ moderately contaminated, +++highly contaminated). 


\section{Estimation of cross-contamination caused by rinsing with water}

$\mathrm{NaClO}$ remaining from surface-sterilization was removed by rinsing with water or with diluted $\mathrm{NaClO}(0.03 \%)$. The presence of microorganisms was examined both in the rinsing fluids (Table 2) and in the scale tissues (Fig. 1). The rinsing fluids were examined with solid and liquid LB. No contaminants occurred in $\mathrm{NaClO}$ rinsing solutions but they were present in rinsing water (Table 2). Bacteria were present in the $3^{\text {rd }}$ rinsing water and in the storage water as shown with both solid and liquid LB and in the $2^{\text {nd }}$ rinsing water as shown with liquid LB. The bacterial contaminants in the rinsing and storage water expectedly bring about cross- contamination. Cross-contamination can not occur in $0.03 \% \mathrm{NaClO}$ since at this concentration all contaminants were killed. The $1^{\text {st }}$ rinsing water contained no contamination probably because of a low concentration of $\mathrm{NaClO}$ due to carry-over from the surface-sterilization. Contamination after surface-sterilization can be attributed to incomplete surface-sterilization, endogenous contamination or cross-contamination during rinsing. We assumed that most cross-contamination occurs from outer scale explants (often endogenously contaminated) to inner scale explants (hardly endogenously contaminated). Evidently, there might also be cross-contamination from contaminated to noncontaminated outer scales. In inner scales, the percentage contamination decreased from $27 \%$ after rinsing with water to $3 \%$ after rinsing with $\mathrm{NaClO}$ (Fig. 1).

Table 2. Contamination of rinsing fluids as detected with LB solid (SM) and liquid (LM) medium.

\begin{tabular}{|c|c|c|c|c|c|c|c|c|c|}
\hline & \multicolumn{4}{|c|}{ Water } & \multicolumn{4}{|c|}{$\mathrm{NaClO}$} \\
\hline & & $\begin{array}{l}1^{\text {st }} \text { rinse } \\
(1 \mathrm{~min})\end{array}$ & $\begin{array}{l}2^{\text {nd }} \text { rinse } \\
(3 \mathrm{~min})\end{array}$ & $\begin{array}{l}3^{\text {rd }} \text { rinse } \\
(10 \mathrm{~min})\end{array}$ & $\begin{array}{c}\text { Storage } \\
\text { (120min) }\end{array}$ & $\begin{array}{l}1^{\text {st }} \text { rinse } \\
(1 \mathrm{~min})\end{array}$ & $\begin{array}{l}2^{\text {nd }} \text { rinse } \\
(3 \mathrm{~min})\end{array}$ & $\begin{array}{l}3^{\text {rd }} \text { rinse } \\
(10 \text { min })\end{array}$ & $\begin{array}{c}\text { Storage } \\
\text { (120min) }\end{array}$ \\
\hline \multirow{3}{*}{$\begin{array}{l}\text { Test } \\
\text { SM }\end{array}$} & 1 & - & - & + & ++ & - & - & - & - \\
\hline & 2 & - & - & + & ++ & - & - & - & - \\
\hline & 3 & - & - & + & ++ & - & - & - & - \\
\hline \multirow{2}{*}{$\begin{array}{l}\text { Test } \\
\text { LM }\end{array}$} & 1 & - & + & ++ & +++ & - & - & - & - \\
\hline & 2 & - & + & ++ & +++ & - & - & - & - \\
\hline
\end{tabular}

In rinsing and storage fluids, contamination was examined with solid and liquid LB. The tests were done 3 and 2 times, respectively. Bacterial incidence was scored after $3 \mathrm{~d}$ at 37 ${ }^{\circ} \mathrm{C}$. (- not contaminated, ++ moderately contaminated, +++highly contaminated). 
In this case, most of the contamination in water-rinsed scales was due to crosscontamination during the rinsing. About $25 \%$ of the previously uninfected inner scales were cross-contaminated. Rinsing outer scales with $0.03 \% \mathrm{NaClO}$ reduced the

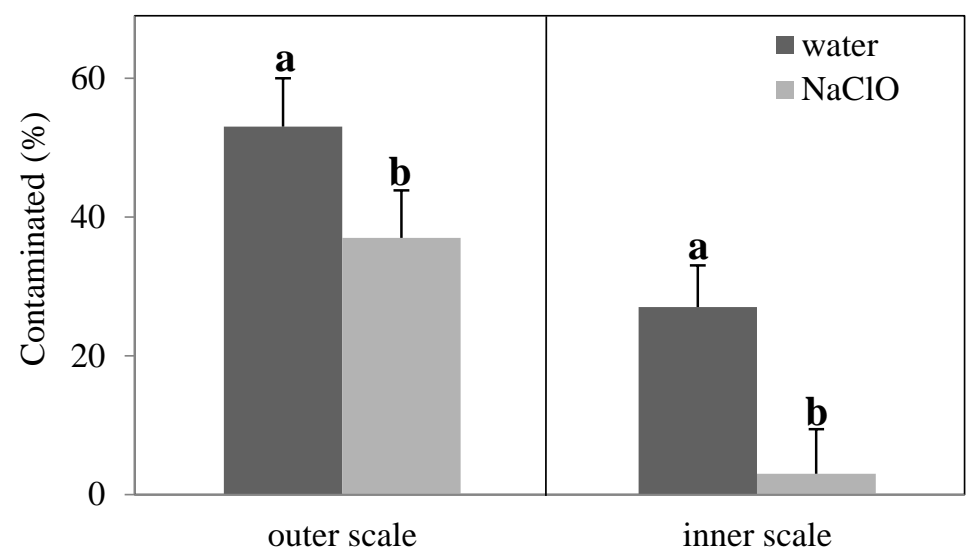

Fig. 1. Contamination of explants cut from inner and outer scales rinsed after the surface-sterilization with $1 \% \mathrm{NaClO}$ with water or with $0.03 \% \mathrm{NaClO}$. Contamination was monitored for 6 weeks.

contamination from $53 \%$ to $37 \%$ (Fig. 1). A similar calculation as done for inner scales showed that in this case cross-contamination also occurred in about $25 \%$ of the otherwise noncontaminated outer scales. Inner scale explants showed lower contamination than outer ones: when rinsed with water $27 \%$ vs. $53 \%$ and when rinsed with $0.03 \% \mathrm{NaClO} 3 \%$ vs. $37 \%$. Contamination in outer scales is high because these scales are often somewhat damaged and because they are much older.

After 11 weeks of culture, FW (fresh weight) of lily bulblets regenerated from scale explants rinsed with sterile water or $\mathrm{NaClO}$ solution was measured. The growth was enhanced significantly by $22 \%$ in $\mathrm{NaClO}$ solution (Fig. 2a). In addition, there were no significant differences between the bulblet numbers (Fig. 2b) and the regeneration percentages (Fig. 2c) for the two rinsing solutions. 

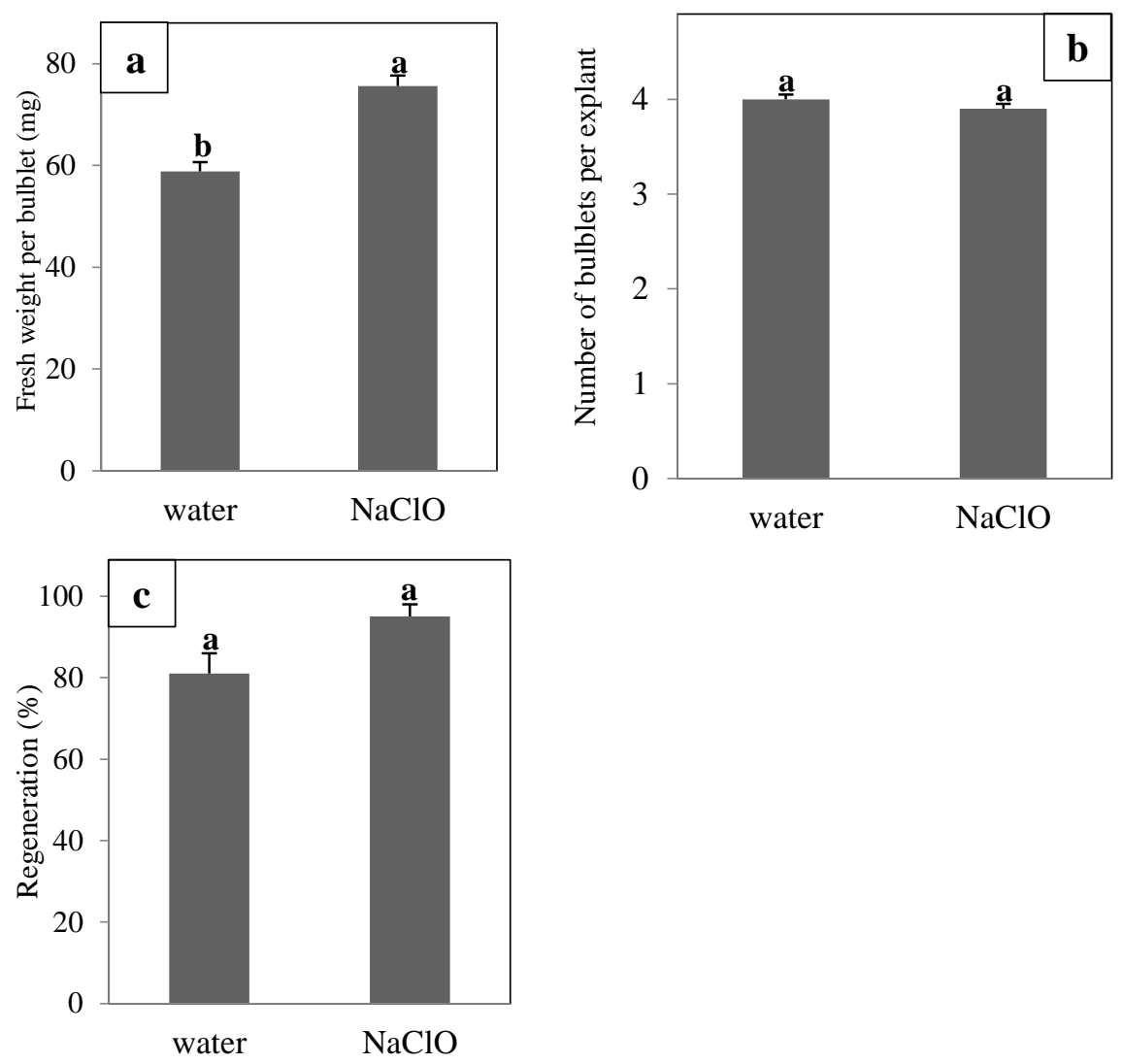

Fig. 2. Performance in vitro of explants cut from inner and outer scales rinsed after the surfacesterilization with sterile water or with $0.03 \% \mathrm{NaClO}$. The various parameters were determined after 11 weeks of tissue culture. Diluted $\mathrm{NaClO}(0.03 \%)$ had a significant effect on bulblet growth (a), but not at the number of regenerated bulblets (b) and not at the percentage of explants regenerating bulblets (c).

\section{Estimation of hydrostatic-pressure related contamination}

The xylem in shoots has a negative hydrostatic-pressure caused by transpiration. To the best of our knowledge, the rate of transpiration by subterranean organs like bulbs, if any, is not known. We determined for lily scales a transpiration rate of $10 \mu \mathrm{l}$ per hour which equals $2.5 \mu \mathrm{l} . \mathrm{cm}^{-2} \cdot \mathrm{h}^{-1}$ (Fig. 3). In cacti, transpiration is $5-15 \mu 1 . \mathrm{cm}^{-2} \cdot \mathrm{h}^{-1}$ 
(Larcher, 1995). As expected, stomata were found (Fig. 4). They occurred on both the adaxial and the abaxial side of the scales.

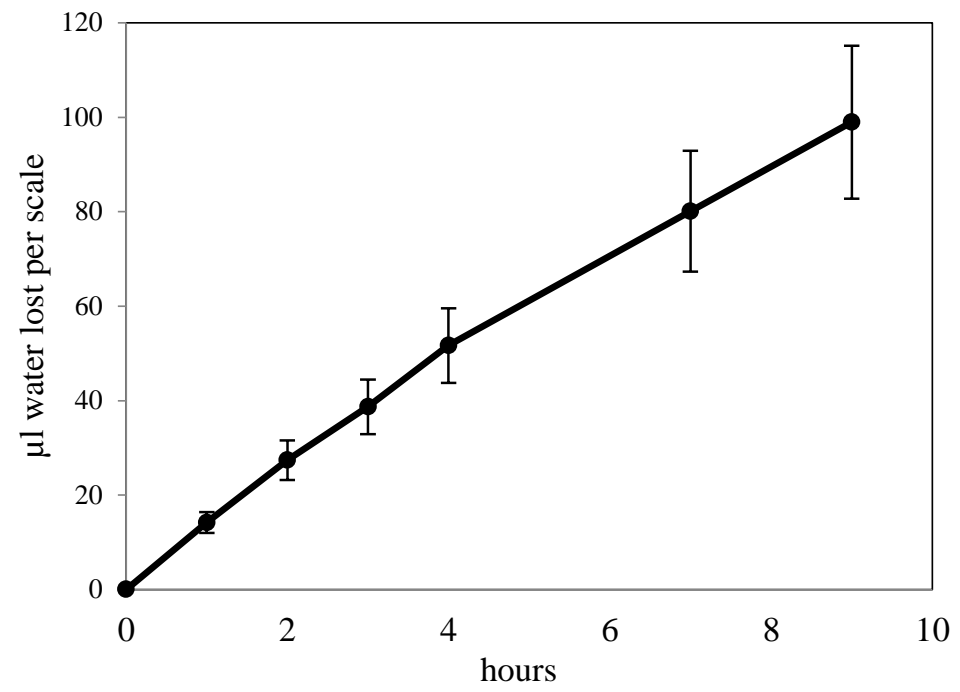

Fig. 3. Transpiration from lily scales at ambient humidity (48\%) and temperature $\left(21^{\circ} \mathrm{C}\right)$.

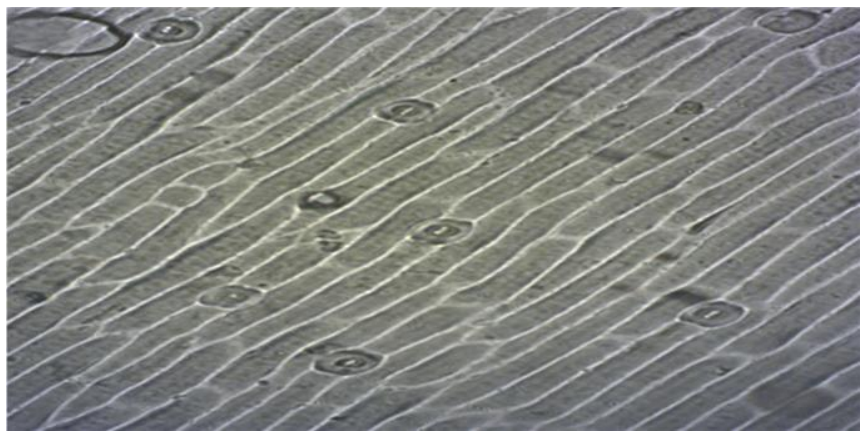

Fig. 4. Stomata located on the adaxial side of a lily bulb scale.

When scales were detached from bulbs submerged in an acid fuchsine solution, the dye penetrated into the bulb scale for $23.8 \mathrm{~mm}$ (Table 3, Fig. 5). In scales first 
detached from the bulbs (so that the negative hydrostatic pressure was removed) and then kept for some seconds in the acid fuchsine solution, penetration was only $1.4 \mathrm{~mm}$.

Table 3. Average distance ( $\mathrm{mm}$ ) of penetration of acid fuchsine in scales.

\begin{tabular}{|l|c|c|}
\hline & Distance (mm) & Penetration (\%) \\
\hline $\begin{array}{l}\text { Scales detached from bulbs submerged } \\
\text { in dye-solution }\end{array}$ & $23.8 \pm 2.8$ & $47.4 \pm 4.6$ \\
\hline $\begin{array}{l}\text { Scales detached from bulbs prior to } \\
\text { submergence in dye-solution }\end{array}$ & $1.4 \pm 0.2$ & $2.8 \pm 0.5$ \\
\hline
\end{tabular}

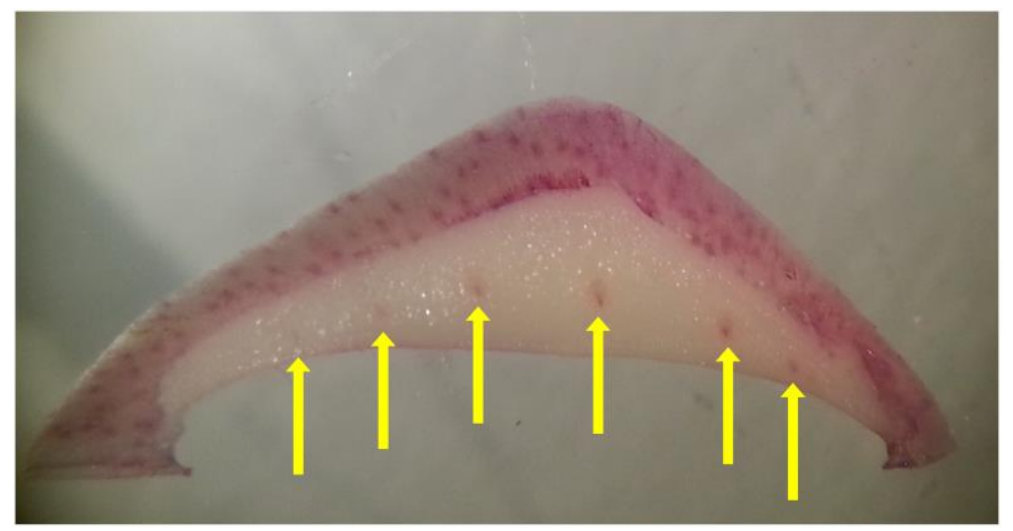

Fig. 5. Acid fuchsine penetrated into scales when the scales had been detached from bulbs submerged in an acid fuchsine solution. This shows the occurrence of a negative hydrostatic pressure in the vascular tissues.

Detaching the scales from the bulbs in diluted $\mathrm{NaClO}$ instead of water reduced contamination from $41 \%$ to $25 \%$ and from 55 to $37 \%$ in two consecutive experiments respectively (Fig. 6). Contamination by sucking up nonsterile water into the vascular tissues occurred in about $20 \%$ of the previously uninfected inner scales. In explants excised from water-collected scales, the period during which contaminants started to grow outside the explant lasted much longer than in NaClO-collected scales. Therefore, we scored visible contamination occurring in the first week and contamination that 

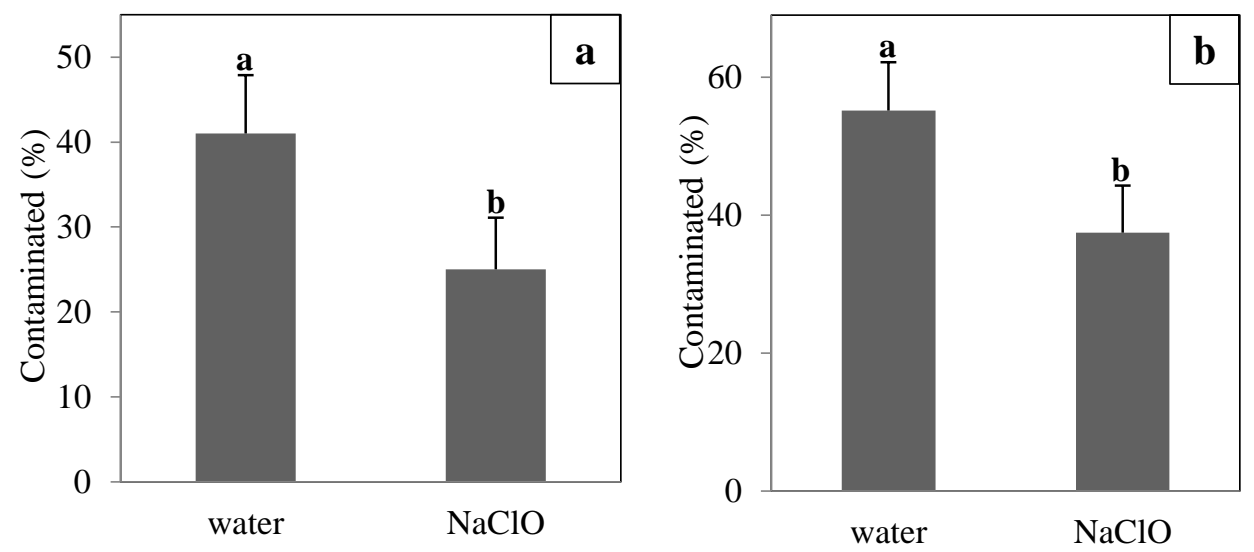

Fig. 6. Contamination of explants cut from inner and outer scales after detaching the scales in streaming water or streaming $0.03 \% \mathrm{NaClO}$. Contamination was monitored for 6 weeks. The results of two experiments are shown. a) $1^{\text {st }}$ experiment; b) $2^{\text {nd }}$ experiment.
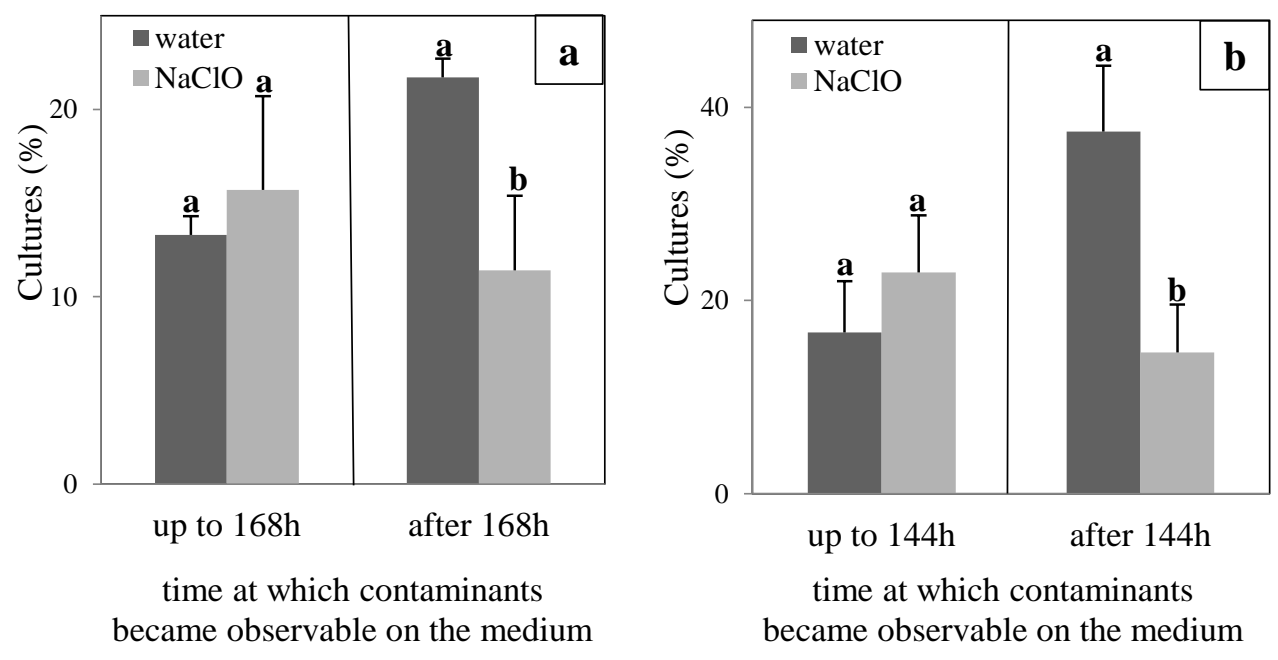

Fig. 7. First appearance of contamination with explants cut from inner and outer scales after detaching the scales in streaming water or streaming $0.03 \% \mathrm{NaClO}$. Contamination was monitored for 6 weeks and the appearance during the first week (up to 168 or 144h) or after that is shown. The results of two experiments are shown. a) $1^{\text {st }}$ experiment; b) $2^{\text {nd }}$ experiment.

appeared after the first week. During the first seven days, the contamination in $\mathrm{NaClO}-$ collected and water-collected scales was the same, but after that the water-collected scales showed higher contamination than the $\mathrm{NaClO}$ ones (Fig. 7). 

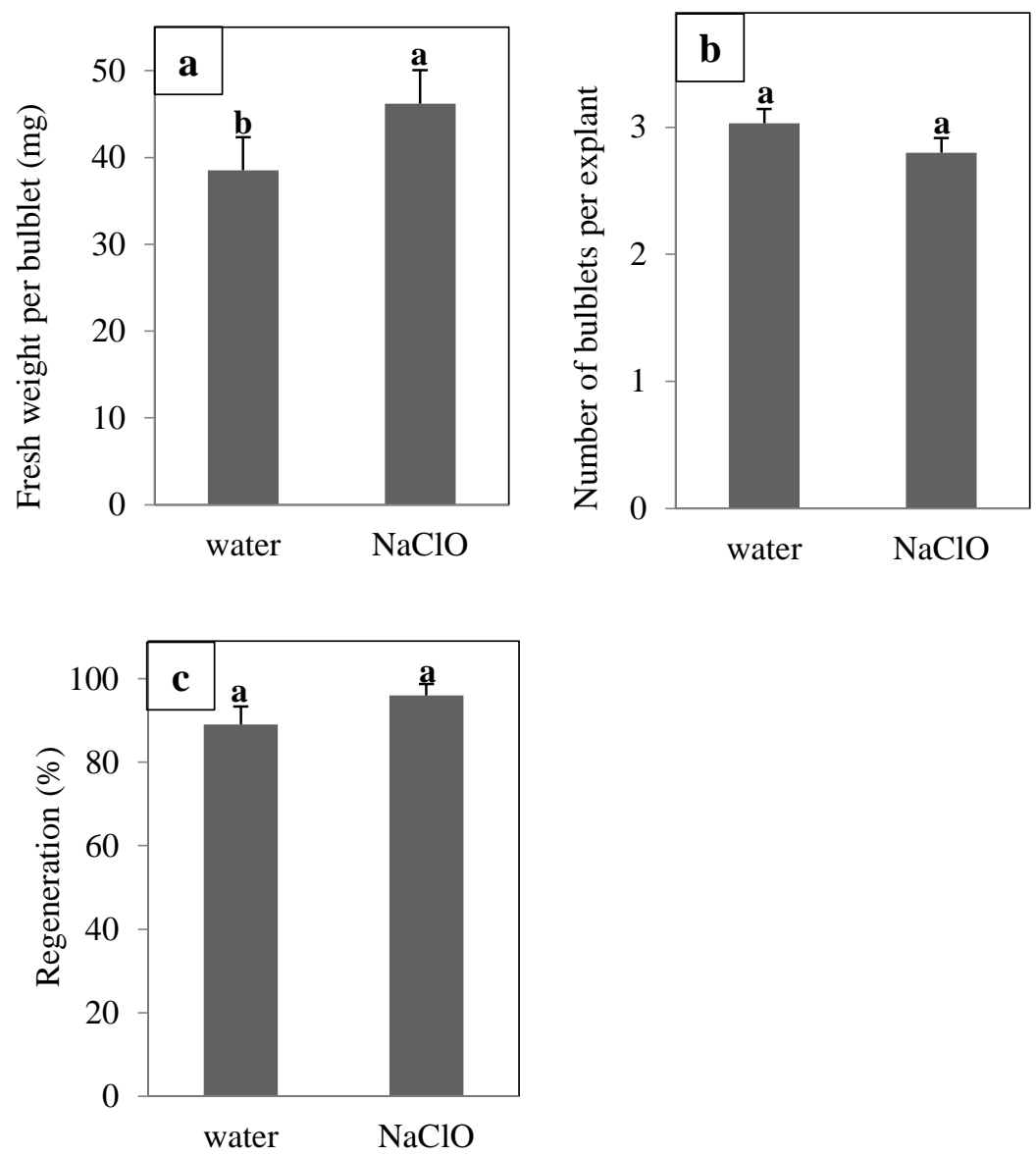

Fig. 8. Performance in vitro of scale-explants after detaching scales in streaming water or streaming $0.03 \% \mathrm{NaClO}$. The various parameters were determined after 11 weeks of tissue culture. a) Fresh weight per bulblets; b) Number of bulblets per explant c) and percentage of explants regenerating bulblets.

We assume that the period before contaminants started to grow outside the explant reflects the topographical localization of the contaminants. Thus, the contaminants that became visible after one week of culture were located more towards the interior of the explants. 
Possibly, the early penetration of $0.03 \% \mathrm{NaClO}$ into the tissue might inhibit regeneration or the growth of the regenerated bulblets. This was not the case (Fig.

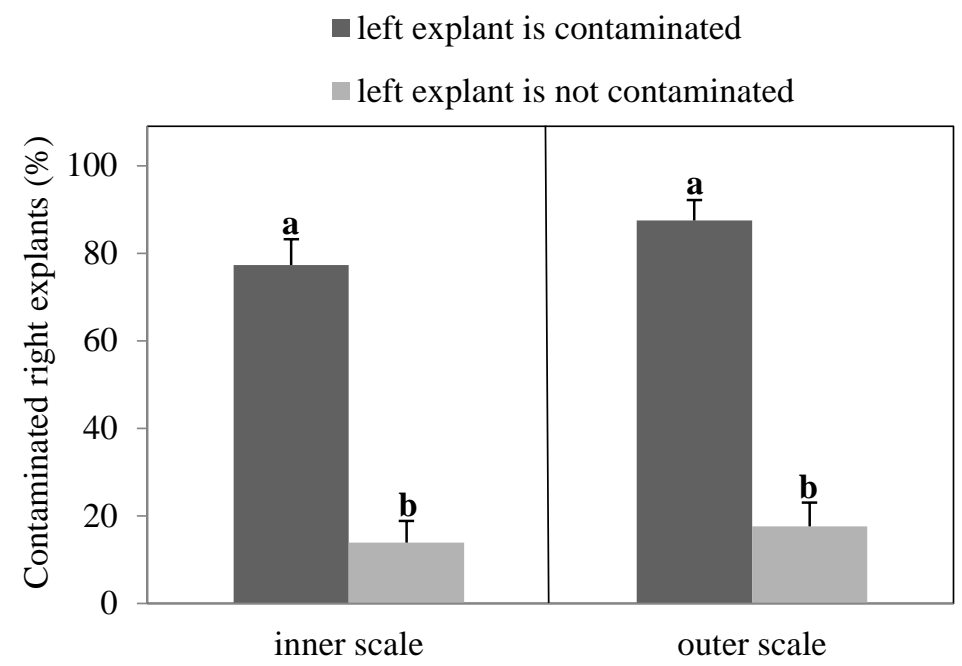

Fig. 9. Correlation of contamination between explants cut from one scale. From scales two explants were cut, one at the right side and one at the left side. Contamination was monitored for 6 weeks. The diagram shows the contamination percentage of the right explant when the left explant was or was not contaminated.

8a,b,c). As a matter of fact, bulblet growth enhanced significantly by the $\mathrm{NaClO}$ treatment with (17\%, Fig. 8 a).

\section{Correlation between right and left explant contamination}

We were interested whether explants excised from the same scale have a similar extent of contamination. To examine this, from each scale two explants were excised, one at the left side and the other at the right side. When in the inner scales the left explant was contaminated, $77 \%$ of the corresponding right explants were contaminated. When the left explant was not contaminated, from the corresponding right explants only $14 \%$ was contaminated (Fig. 9). The difference is highly significant. For the outer scales, these percentages were $88 \%$ and $15 \%$ respectively, also highly significant. 


\section{Discussion}

Contamination is an everlasting problem in plant tissue culture. Apart from inadequate operating during manipulation in the laminar flow cabinet, poor equipment (e.g., damaged filters in the laminar flow cabinet) and contamination by microarthropods (mites and thrips), the source of contamination is the explant that is transferred into tissue culture. In the present paper, we show in lily that explant-related contamination is caused to a substantial extent by faulty procedures during initiation. This may lead to both surface-localized and endogenous contaminants.

Explant-related contaminants may be surface-localized but difficult to kill by disinfectants probably because they are not adequately exposed to the disinfectant solution. Explant-related contaminants may also be internal and because of this not reachable by disinfectants. The latter is caused, among others, by the very slow longdistance translocation of solutes when driven only by diffusion (Taiz and Zeiger, 2002). In this case, only a heat treatment may be successful (Langens-Gerrits et al., 1998). Endophytic bacteria are reported to colonize intercellular spaces and vascular tissues and only a few reports demonstrate intracellular colonization (Hallmann et al., 1997).

In the experiments, we used a low concentration $(0.03 \%)$ of $\mathrm{NaClO}$ for additional disinfection. This concentration was effective (Table 1) and is also reported to be adequate in medical practice (Heling et al., 2001). It should be noted that the target bacteria are moving freely in fluid and are therefore vulnerable. Accordingly, we could use a much lower concentration of $\mathrm{NaClO}$ than the one used for surfacesterilization.

First, we examined cross-contamination during the sterilization/rinsing procedure. When tissues from field-grown plants are surface-sterilized, a batch of a few to tens of explants is processed in one beaker because it is unfeasible to process the explants individually in a large number of beakers. When $\mathrm{NaClO}$ is present (during the surface-sterilization itself), cross-contamination is not possible. However, during the three rinses with sterile water that are commonly used to remove the excess of $\mathrm{NaClO}$ (George, 1993; Pierik, 1997) and the storage up to processing, cross-contamination may occur. When the scales were rinsed with sterile water for the $2^{\text {nd }}$ and $3^{\text {rd }}$ time, the rinsing water became heavily contaminated with bacteria (Table 2). This resulted in 
considerable additional contamination of the explants. A simple way to reduce crosscontamination was rinsing with $0.03 \% \mathrm{NaClO}$ instead of water. After rinsing in a diluted $\mathrm{NaClO}$ solution, lily bulblet growth enhanced significantly by $22 \%$ but regeneration $\%$ and number of bulblets regenerated in vitro had no significant difference between. The low toxicity (or the absence of toxicity) of a low concentration of $\mathrm{NaClO}$ corresponds to studies in which tissue culture was performed in the presence of a low concentration of $\mathrm{NaClO}$ (Teixeira et al., 2006; Yanagawa, 2007; Sawant and Tawar, 2011). Rinsing in diluted $\mathrm{NaClO}$ may also be considered for other crops.

The second target of the present study is the open connection between the vascular tissues and the environment when the scales are detached from the mother bulbs. This allows movement of microorganisms into the vascular tissue. Entering is strongly enhanced by the negative hydrostatic pressure in the tissue which results in sucking up of fluids close to the xylem just after excision. These fluids likely contain microorganisms. The xylem has a negative hydrostatic pressure because of transpiration of water from the leaves. In the case of lily bulbs, it should first be considered whether bulbs do have such negative hydrostatic pressure. Bulbs are underground and therefore may not display transpiration. On the other hand, bulbs are modified leaves (in the case of lily swollen petioles) so they are likely to have stomata. Microscopic inspection demonstrated the presence of stomata at both the abaxial and adaxial side (Fig. 4). Water was transpired at a similar rate as in cacti (Fig. 3). As a result, the xylem in lily scales will suck up liquid and contaminants may penetrate into the interior of the scale via this water flow. Provisional calculations showed that with a transpiration rate of $10 \mu \mathrm{l}$ per scale per hour, water would penetrate in one hour more than $0.5-1 \mathrm{~cm}$ in addition to the intial penetration just after excision. The occurrence of a negative hydriostatic pressure was also shown by the deep penetetration of a dye when scales were detached from a bulb submerged in the dye solution.

As a result, contaminants penetrate so far into the interior of scales that disinfectants cannot reach them later on. It is important to note here that the diameter of xylem vessels is 10 to $100 \mu \mathrm{m}$ and that the diameter of bacteria is a few $\mu \mathrm{m}$. Thus there are no obstacles with respect to sizes. Flagellated bacteria may move actively reaching 
a speed of over $1 \mathrm{~m}$ per hour (Schneider and Doetsch, 1974) and penetrate the tissue in this way.

We used again $0.03 \% \mathrm{NaClO}$ to control these contaminants. Indeed, when the scales were during detachment submerged in $0.03 \% \mathrm{NaClO}$, contamination decreased in outer and inner scale explants by $15-20 \%$ (Fig. 5). Interestingly, in the scales that had been transferred to water and $\mathrm{NaClO}$, the contamination that became visible during the first week was the same but after that, the water-collected scales showed significantly higher additional contamination. Obviously, the more contaminants are located in the interior of the explant, the longer it will take them to reach the nutrient medium. This unexpected finding was reproduced in a second experiment (Fig. 6).

We conclude that after detachment bacteria invade the xylem. When scales are collected in water or in air, these bacteria are transferred to tissue culture. After that, they will gradually exit the tissue and flourish on the nutrient medium. However, after some days or weeks, the wound is repaired and a layer of periderm has been formed. This inhibits uptake of compounds from the medium (Smulders et al., 1990) but also release of microorganisms from the tissue into the medium. So the microorganisms become trapped in the tissue and because of their detrimental effect, growth of the regenerating bulblets may be reduced (Fig. 7). On the other hand, when $\mathrm{NaClO}$ has penetrated the xylem at detachment, it will kill the bacteria. $\mathrm{NaClO}$ may itself have a negative effect on growth but is presumably short-lived within the tissue. Various compounds promote the decomposition of $\mathrm{NaClO}$, among others various metal ions that are administered with MS. Most notably, chemical interactions between chelating agents and $\mathrm{NaClO}$ result in a rapid loss of free available chlorine (Rossi-Fedele et al., 2012) and both plant tissues and MS contain chelating compounds. Thus, within a few days/weeks, $\mathrm{NaClO}$ is probably fully decomposed.

To our knowledge, the problem of exposure of xylem tubes in the cut ends to penetration of contaminants has only been dealt with by (Thakur and Sood, 2006). They report that when sterilizing bamboo, tea and rose shoots with a length of 30-50 $\mathrm{cm}$ instead of a few cm, the contamination percentage drops from 50-60\% to $20-25 \%$. Apparently, in the long shoots the distance is too large for the penetrating microorganism to reach the upper part of the shoot that is transferred to tissue culture. 
In both expriments, $0.03 \% \mathrm{NaClO}$ did not inhibit regeneration. The growth of bulblets showed increases of $17 \%$ and $22 \%$ by reducing negative-hydrostatic-level related contamination and cross contamination, respectively.

In tissue culture of lily, substantial contamination may be caused during the initiation, both by the entrance of microorganisms directly after detachment of the scales (ca. 20\% extra contamination in our conditions) and during the rinsing after surface-sterilization (ca. 25\% extra contamination in our conditions). Both are effectively prevented by a diluted solution of $\mathrm{NaClO}(0.03 \%)$. These effective measures in lily are most probably also suitable for other species. 



\section{Chapter 3}

\section{The influence of scale explants on lily bulblet growth}

in vitro

Naser Askari $^{1,2}$, Richard G.F Visser ${ }^{1}$, and Geert-Jan de Klerk ${ }^{1}$

${ }^{1}$ Wageningen UR Plant Breeding, P. O. Box 16, 6700 AA Wageningen, The Netherlands

${ }^{2}$ Department of Plant Sciences, University of Jiroft, P. O. Box 364 , Jiroft, Iran 


\begin{abstract}
Lily scales cultured in vitro regenerate bulblets that are used as propagules. We examined the influence of scale explants on the growth of regenerating bulblets. A large scale explant $(6 \times 18 \mathrm{~mm})$ improved bulblet growth by $26 \%$ as compared to a small scale explant $(6 \times 6 \mathrm{~mm})$. The beneficial effect of the scale became also clear when bulblets excised from scale explants were transferred to fresh medium for additional growth. When a small piece of the original scale was left attached to these bulblets, growth improved by 33\%. The growth of lily bulblets was highest in explants cut from the middle of a scale (as opposed to the edge) and in explants cut from the basal half (as opposed to the apical half). In the basal scale explants, the number of starch granules was far higher than in apical scale explants. During culture in vitro, the number of vascular bundles increased in basal and apical scale explants from 6 and 3.3 to 8 and 4 bundles, respectively. The scale explants were physiologically very active during the culture in vitro as shown by a several fold increase in weight.
\end{abstract}




\section{Introduction}

Lily is one of the most important ornamental crops worldwide, both as a cut flower and as a flower bulb (Grassotti and Gimelli, 2010; Van Tuyl and Arens, 2010). Lily bulb scales are the common starting material in in vitro and in vivo lily propagation. After planting the new bulblets in soil, they should grow fast and produce plants with high quality. The performance of in vitro bulblets after planting depends among others on endogenous factors, including bulblet size, maturation and dormancy status (Langens-Gerrits et al., 2003a). The size of lily bulblets produced in vitro strongly influences performance after planting. Studies with direct field planting of in vitro bulblets have shown that small bulblets emerge slower and less uniform and have a lower sprouting percentage (Yae et al., 2001). In tulip, large bulblets regenerated in vitro also show better performance compared to small bulblets after transfer to soil (Le Nard et al., 1987; Hulscher et al., 1992). In addition, in vitro lily bulblets in the adult phase sprout with a stem and switch to a reproductive state; on the other hand, bulblets sprout with a rosette in the juvenile phase. Large bulblets are more often in the adult phase as compared to small bulblets (Langens-Gerrits et al., 2003a).

As compared to the growth of bulblets in vivo, the growth of lily bulblets in vitro is less than expected (De Klerk et al., 1992). A major, often overlooked feature of in vitro growth is that some in vitro conditions are far from optimal (e.g., the gaseous composition of the head space) and put plants under heavy stresses. It is generally disregarded that the size of bulblets in vitro is not only related to medium composition, but also to transportation of medium components to the newly regenerated bulblets. In vitro, vascular tissues have the major role in the transport of solutes from the medium to the areas of growth (De Klerk, 2016). Uptake of sucrose mainly occurs through the cut surfaces since the epidermis is relatively impermeable because of its wax layer. Moreover, according to (Langens-Gerrits et al., 2003b), sucrose taken up in the explants is mainly recovered at the basal side of the explants, where regeneration occurs. This indicates that internal transport of sucrose from the apical to the basal side may play a role in bulblet growth in vitro. The metabolism of sucrose is important to the growth and development of geophytes because sucrose metabolism enhances the growth of storage organs, inflorescences and other organs (Matsuo and Mizuno, 1974; 
Wozniewski et al., 1991; Miller, 1992). In L. longiflorum, $85 \%$ of the storage polysaccharides are starch and the remainder consists of glucomannan (Matsuo and Mizuno, 1974). In plant storage organs, starch biosynthesis takes place within the amyloplast (Ji et al., 2003).

In this study we consider the influence of explants on the growth of lily bulblets during in vitro culture. We aim to reveal the mechanism of in vitro bulblet growth in more detail. This should eventually result in procedures that significantly increase the size of lily bulblets and subsequently improve the performance of in vitro bulblets after planting in soil.

\section{Materials and Methods}

\section{Standard tissue culture conditions}

Field-grown bulbs (circumference $18-20 \mathrm{~cm}$ ) of Lilium $c v$. Santander and Stargazer were harvested, cold-treated to break dormancy and stored at $-1.0^{\circ} \mathrm{C}$ until use as described (Aguettaz et al., 1990). Scales were surface-sterilized for $30 \mathrm{~min}$ in 1\% (w/v) $\mathrm{NaClO}$, rinsed for 1, 3, and 10 min with sterile water, then stored in sterile water (on average for 1-2 h) until use. Two explants of $7 \times 7 \mathrm{~mm}$ were cut from the scales and placed with the abaxial side on $15 \mathrm{ml}$ medium in plastic culture tubes $(3.5 \mathrm{~cm}$ diameter). The medium was composed of macro- and microelements (Murashige and Skoog, 1962), $30 \mathrm{~g} \mathrm{l}^{-1}$ sucrose, $0.4 \mathrm{mg} \mathrm{l}^{-1}$ thiamin, $100 \mathrm{mg} \mathrm{l}^{-1}$ myo-inositol, $7 \mathrm{~g} \mathrm{l}^{-1}$ agar (Microagar), and $0.05 \mathrm{mg} \mathrm{l}^{-1} \mathrm{NAA}$ ( $\alpha$-naphthaleneacetic acid). The explants were cultured at $25^{\circ} \mathrm{C}$ and $30 \mu \mathrm{mol} \mathrm{m} \mathrm{mec}^{-1}$ (Philips TL 33) for $16 \mathrm{~h}$ per day.

\section{Different types of explants}

Three different types of explants (scale, leaf and petiole) were excised from Santander in vitro plantlets, and then cultured for 11 weeks on standard medium supplemented with $2 \mathrm{mg} / \mathrm{l} \mathrm{NAA}$ and $2 \mathrm{mg} / \mathrm{l} \mathrm{BA}$ (benzyl adenine) at $25^{\circ} \mathrm{C}$ and light (30 $\mu \mathrm{mol} \mathrm{m} \mathrm{sec}^{-1}$; Philips TL 33) for $16 \mathrm{~h}$ per day. After 11 weeks, the fresh weight (FW) of lily bulblets and the regeneration percentage were scored. Three Santander and Stargazer scale explant sizes $(6 \times 6,6 \times 12$ and $6 \times 18 \mathrm{~mm})$ were cultured on standard 
medium at $25^{\circ} \mathrm{C}$ and $30 \mu \mathrm{mol} \mathrm{m}{ }^{-2} \sec ^{-1}$ (Philips TL 33) for $16 \mathrm{~h}$ per day. After 11 weeks the FW of lily bulblets was measured.

To examine the role of lily scales during culture in vitro, we cultured 11-week old Santander and Stargazer bulblets fully detached from scale explants and bulblets from which a large part but not all of the original scale explant had been cut off, on standard medium at $25^{\circ} \mathrm{C}$ and $30 \mu \mathrm{mol} \mathrm{m} \mathrm{sec}^{-1}$ (Philips TL 33) for $16 \mathrm{~h}$ per day. After 6 weeks, the FW of the bulblets was measured.

Explants excised from different positions of Santander and Stargazer scales (see Fig. 1) were cultured on standard medium and kept at $25^{\circ} \mathrm{C}$ and $30 \mu \mathrm{mol} \mathrm{m} \mathrm{sec}^{-1}$ (Philips TL 33) for $16 \mathrm{~h}$ per day. After 11 weeks the FW of the regenerated bulblets was measured.

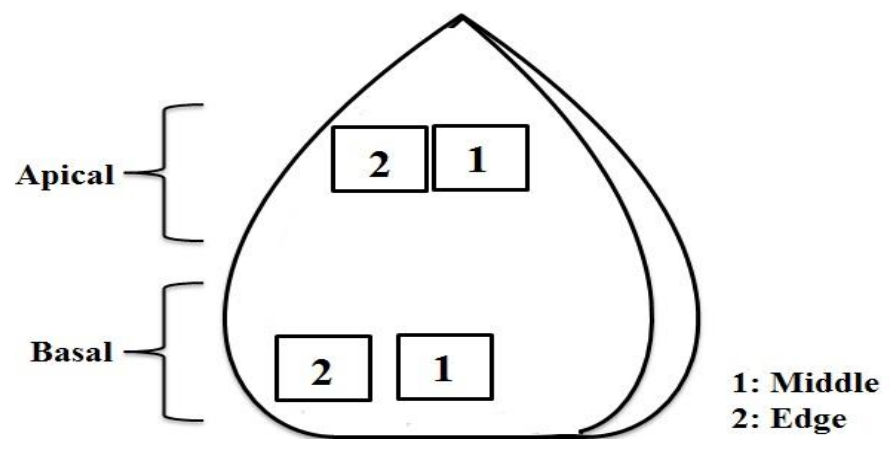

Fig. 1. Schematic drawing of the position of basal, apical, middle and edge explants on a lily bulb scale.

\section{Histological observations}

Scale explants of Santander and Stargazer were fixed in 5\% glutaraldehyde in phosphate buffer, $\mathrm{pH}$ 6.8, and rinsed in the same buffer. They were then dehydrated in an ethanol series and embedded in Spurr's resin. Transversal sections were made on a Sorvall MT 5000 microtome mounted on glass slides, and stained with Toluidin blue to visualize the vascular bundles and with Lugol's IKI solution to visualize starch. The sections were observed with an Axiophot light microscope (Zeiss, Oberkochen, Germany) and images were taken with an AxionCam ERc5S digital camera (Zeiss). The photos were analysed with ImageJ 1.4 software to calculate the starch granule area 
in both scale explants in the freshly cut scale explants and after 12 weeks growth in vitro.

\section{Statistics}

The data were scored 6 and 11 weeks after culturing scale explants in different experiments. The means are the average of 30-100 measurements per treatment. In the figures, the means are shown \pm SE. The means were evaluated with a t-test.

\section{Results}

\section{The growth of lily bulblets regenerated from various types of explants}

The regeneration percentage of scale explants was $88 \%$. In leaf and petiole explants, a much lower regeneration percentage was achieved, viz., 12\% and 18\%, respectively (Fig. 2a). Scale explants produced bigger and heavier bulblets weighing 51 $\mathrm{mg} / \mathrm{bulblet}$ compared to leaf and petiole explants weighing 33 and $38 \mathrm{mg} / \mathrm{bulblet}$, respectively (Fig. 2b).
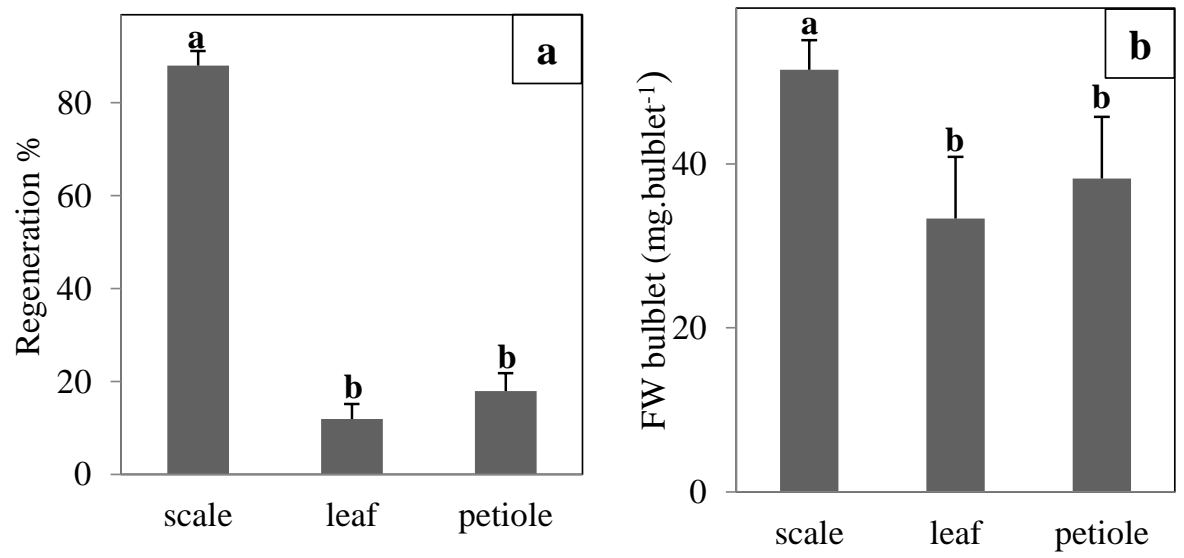

Fig. 2. Regeneration percentage (a); and FW of lily bulblets regenerated on scale, leaf and petiole explants in vitro (b) in Santander.

The FW of bulblets increased with the size of scale explants. The FW of bulblets regenerated on 6x18 mm scale explants was $66 \mathrm{mg} / \mathrm{bulblet}$ and the FWs of bulblets regenerated on $6 \times 6 \mathrm{~mm}$ and $6 \times 12 \mathrm{~mm}$ scale explants were $49 \mathrm{mg} / \mathrm{bulblet}$ and 53 
mg/bulblet, respectively (Fig. 3a). Thus, bigger scale explants improved lily bulblet growth by $26 \%$ compared to smaller scale explants.

To study the positive effect of the scale explants in more detail, we excised 11 week-old lily bulblets from scale explants leaving a small piece of scale attached to the bulblets or removing the original scale explant completely. They were cultured on standard medium for 6 more weeks. The FW of lily bulblets with a small piece of explant was $400 \mathrm{mg} / \mathrm{bulblet}$ and the FW of lily bulblets from which the original scale
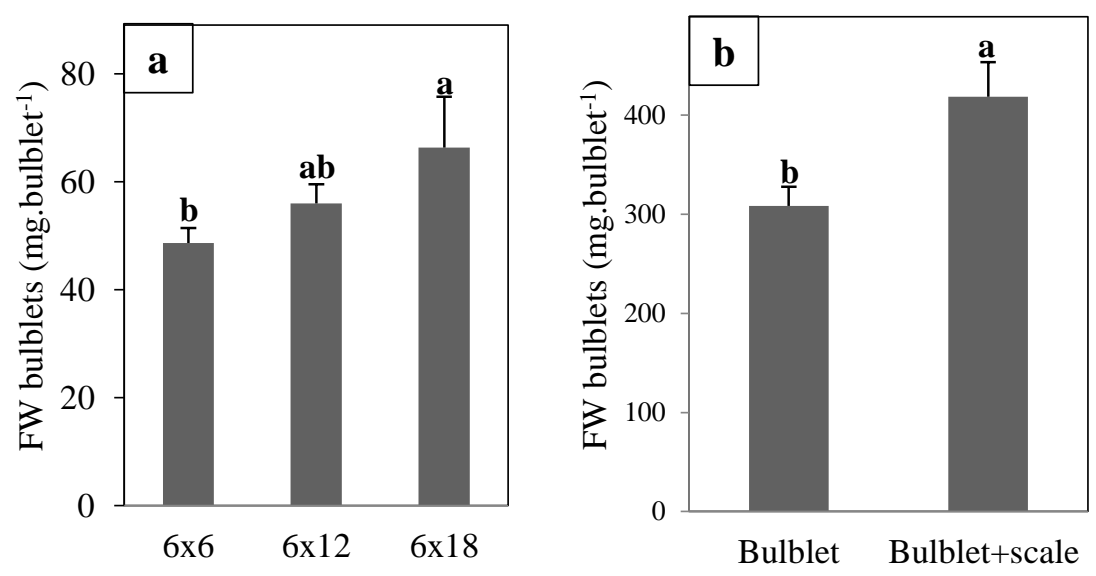

Fig. 3. Effect of the size of the explants on FW of regenerated bulblets (a); Effect of the presence of scale explants on growth of excised bulblets (b) in Santander.

explant had been removed completely was $300 \mathrm{mg} / \mathrm{bulblet}$ (Fig. 3b). The initial average FW of 11-week old bulblets at the beginning of each experiment was 100 $\mathrm{mg} / \mathrm{bulbet}$ for both explant types. In Stargazer, both a large explant and subculturing bulblets leaving a small piece of scale explant attached also improved the growth of bulblets (Data not shown).

We also examined the effect of the original position of the explant on the scale. The various types of explants are shown in Fig. 1. Explants excised from the middle of a scale produced bigger bulblets compared to the explants cut from the edge (ca. 40$50 \%$ ) and explants cut from the basal part of a scale produced bigger bulblets compared to the explants cut from the apical portion (ca. 40-50\%, Fig. 4a and b) in both Santander and Stargazer. 

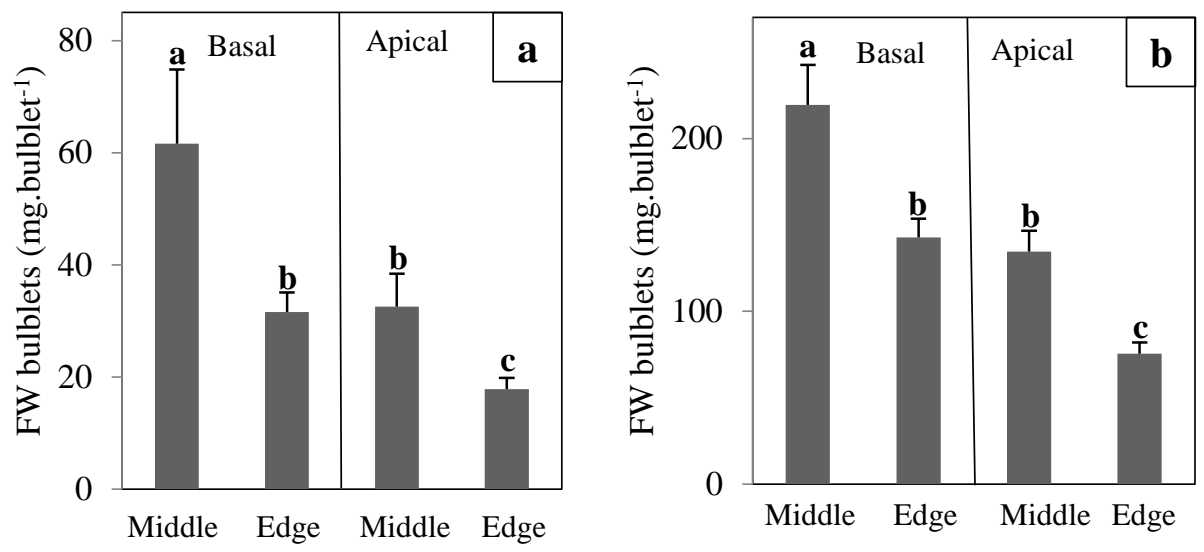

Fig. 4. The effect of scale explant position either basal (middle and edge) or apical (middle and edge) on lily bulblet growth in vitro; Santander (a), Stargazer (b).

\section{Contribution of starch to bulblet growth in relation to scale explants position} (basal and apical)

Increased growth of the bulblets on basal scale explants compared to apical scale explants raised the question how much carbohydrate (mainly starch) reserve is present in these two types of scale explant tissues at the beginning and at the end of the growth period. Since we were especially interested in the distribution of starch in the tissue, we determined starch by visualizing starch grains in a microscopic examination and evaluating starch content by measuring the area covered by starch granules. The surface area covered with starch granules was $44 \%$ and $31 \%$ in basal scale explant and $19 \%$ and $15 \%$ in the apical scale explants at the beginning of the tissue culture period in Stargazer and Santander, respectively (Fig. 5a and c and Fig. 6a and b). The surface area covered with starch granules was 9\% and $8 \%$ in basal scale explants and 5\% and 7\% in the apical scale explants at the end of the tissue culture period in Stargazer and Santander, respectively (Fig. 5b and d and Fig. 6a and b). The surface area covered with starch granules decreased $79 \%$ and $74 \%$ in basal and $74 \%$ and $55 \%$ in apical explants after 12 weeks in Stargazer and Santander, respectively. In general, the 
surface area covered with starch granules in the basal scale explants was $c a .2$ times larger than in the apical scale explants.

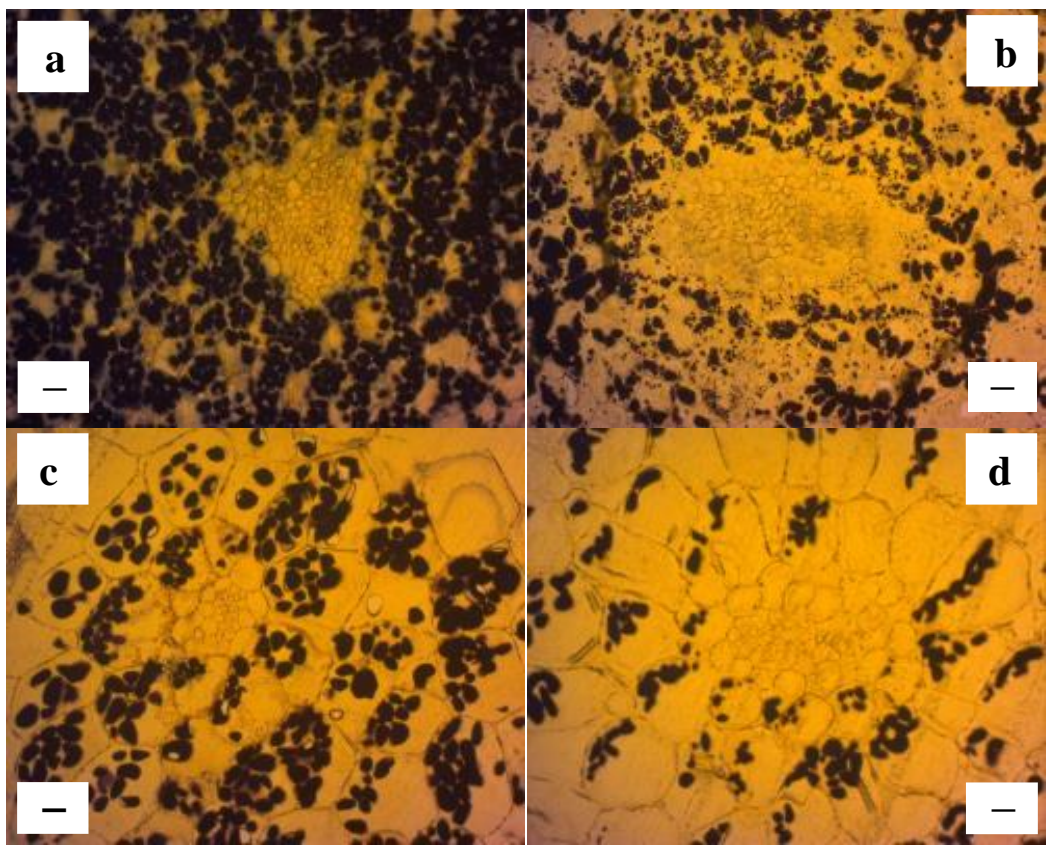

Fig. 5. Distribution of starch in scale explants in relation to their position on bulb scale a) Freshly cut basal explants; b) Basal explants after 12 weeks cultured in vitro; c) Freshly cut apical explants; d) Apical explants after 12 weeks cultured in vitro. Bar $(-)=5 \mu \mathrm{m}$.
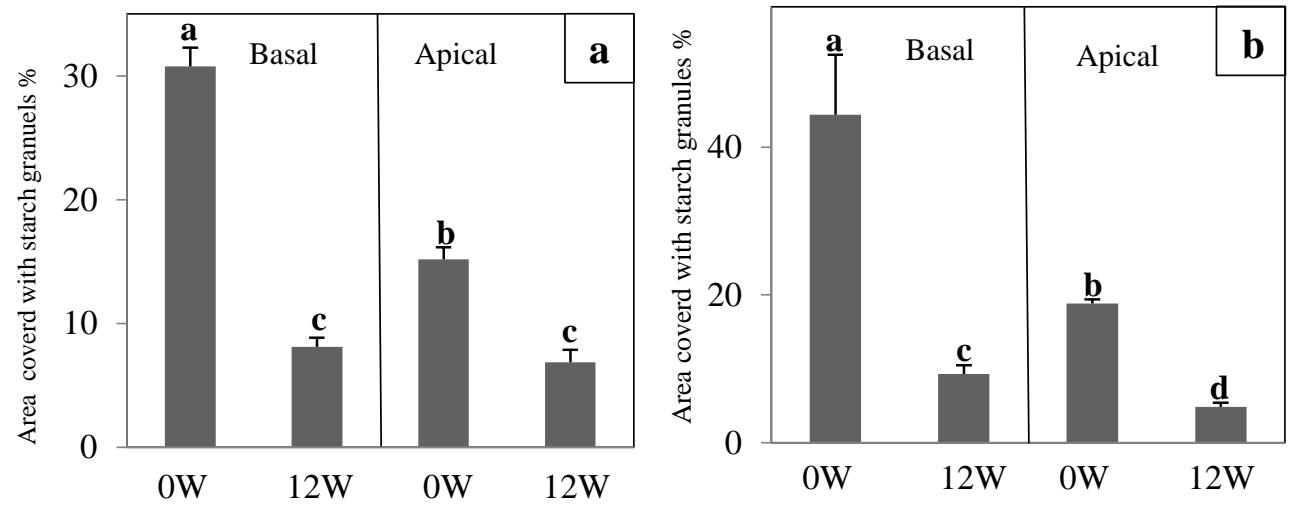

Fig. 6. Surface area covered with starch granules in basal and apical scale explants at the start of culture ( 0 weeks) and after 12 weeks of culture in Santander (a) and Stargazer (b). 


\section{Vascular bundle numbers and size increase during lily bulblets growth in}

\section{both basal and apical scale explants}

In both types of scale explants ( 0 week and 12 weeks old), vascular bundles were histologically analysed. In freshly cut scale explants, the number of vascular bundles in basal scale explants (6 vascular bundles) was higher than apical explants (3.3 vascular bundles). After 12 weeks, the number of vascular bundles increased in basal and apical scale explants to 8 and 4 vascular bundles, respectively. The area of vascular bundles after 12 weeks was two to three times larger than in freshly cut scale explants in both basal and apical scale explants (Fig. 7 and Fig. 8).

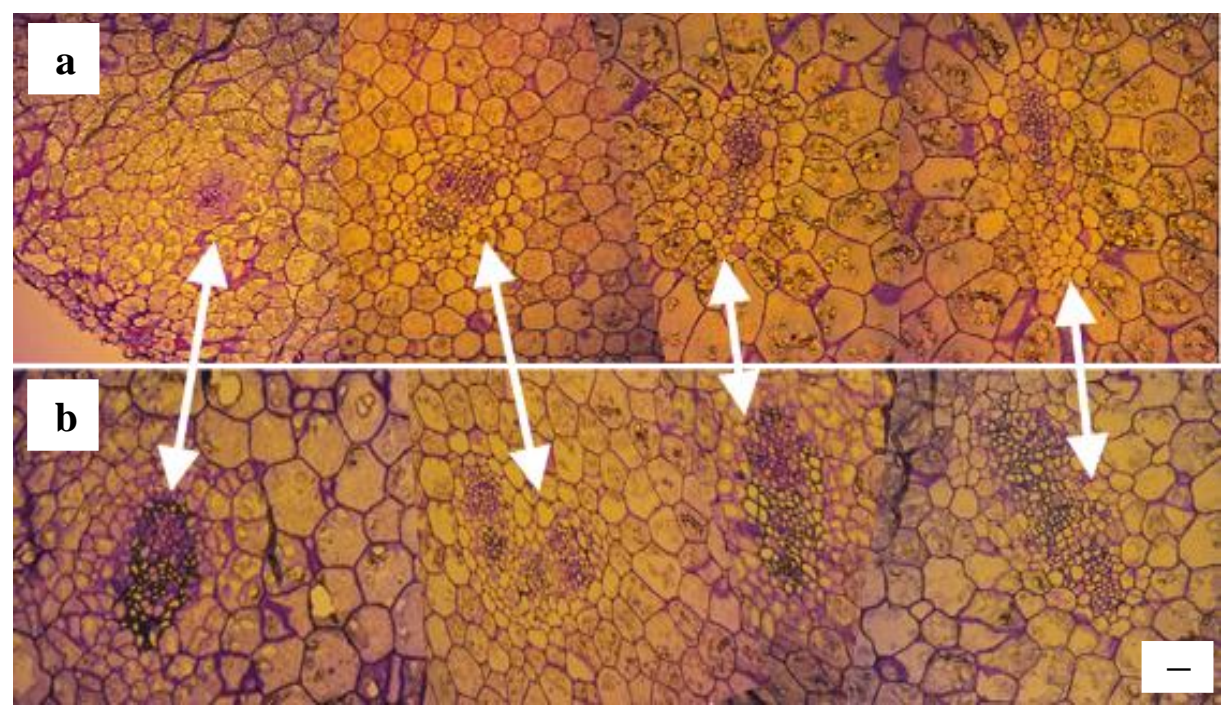

Fig. 7. Increase in the number and the size of vascular bundles in edge basal scale explants; a) vascular tissue in freshly cut edge basal explants of Stargazer; b) the vascular bundles number and size after 12 weeks in the same scale explants; $\operatorname{Bar}(-)=25 \mu \mathrm{m}$ in $\mathrm{a}, \mathrm{b}$. 


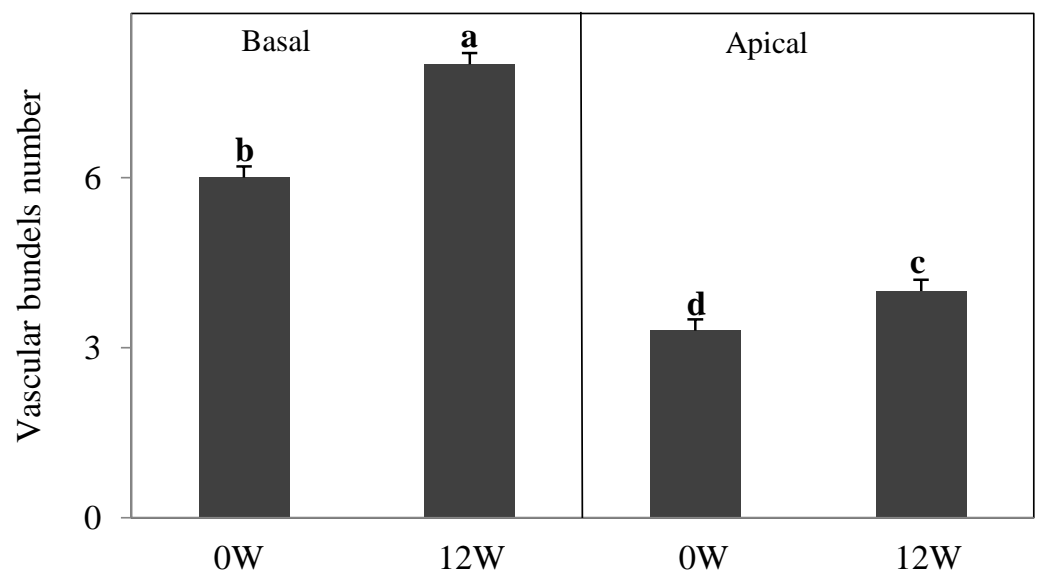

Fig. 8. Vascular bundles number in edge basal and apical lily scale explants at 0 and 12 weeks.

\section{Discussion}

\section{The growth of bulblets on different explant types (scale, leaf and petiole)}

In lily, regeneration occurs from most tissues, like flower organs, stem nodes, leaves, roots and bulb scales (Gupta et al., 1978; Stimart and Ascher, 1981; Van Aartrijk and Blom-Barnhoorn, 1981; Takayama and Misawa, 1983; Niimi, 1984; Nhut et al., 2001a; Nhut et al., 2001b; Bacchetta et al., 2003). Scale explants are superior explants for micropropagation of lily compared to leaf and petiole explants. The regeneration percentage of leaf and petiole explants was very low compared to scale explants and the FW of bulblets regenerated on the scale explants was higher compared to leaf and petiole explants. The reason why scale explants perform better may be that bulb tissue is more resistant to stress so also to stress related to the transfer to in vitro conditions. Moreover, the scale explants contain lots of reserves so that the excised explants depend less on the medium and on transport from the medium.

Previous research showed that large explants regenerated larger bulblets than small explants. A large explant has a large contact area with the medium. Therefore, large explants can take up more nutrients from the medium. The explants act as a sink (growing organ) and as a source (nutrient source for the growing bulblets) simultaneously (Langens-Gerrits et al., 1996b). The bigger explants have more storage materials and vascular bundles to provide the new bulblets with nutrients. Bulblets that 
have regenerated from large explants are often adult and the ones from small explants usually juvenile. These bulblets with a different ontogenetic age sprout with a stem or with a rosette, respectively (Langens-Gerrits et al., 2003a). Adult bulblets grow much faster after planting probably because the stem carries many leaves, much more than present in a rosette (Langens-Gerrits et al., 2003a). In other plants, rose (Marcelis-van Acker and Scholten, 1995) and mung bean (Gulati and Jaiwal, 1992) also bigger organs were produced on bigger explants.

\section{The presence of the scale explants promotes the growth of lily bulblets in vitro}

In lily tissue culture, regenerating bulblets use both carbohydrates broken down from starch in the explants as well as sucrose from the medium to grow (LangensGerrits et al., 2003b). The presence of a small piece of scale explant still attached to the bulblets also improved the growth of excised lily bulblets and reveals a major role of the scale explants possibly as some kind of pump. But the starch in the explant also seems to play a role indicated by the breakdown of the starch reserves during 12 weeks of culture. Measurement of starch degradation after 12 weeks of culture of scale explants showed that $c a .21 \%$ and $26 \%$ of starch granules were still available in basal and ca. 26\% and 45\% in apical scale explants in Stargazer and Santander, respectively. In addition, measurement of starch granules in scale explants cultured on medium without sucrose after 12 weeks showed that most starch granules were degraded during bulblet regeneration on medium without sucrose. The largest sink activity ( $\mu \mathrm{g}$ sucrose taken up from the medium per mg FW) was found in scale explant and it was constant during tissue culture but sink activity decreased in bulblets regenerated in vitro with time (Langens-Gerrits et al., 2003b). These results confirm the major role of the scale explants on the growth of lily bulblets in vitro.

\section{Effect of position of the scale explants on lily bulblets growth in vitro and visualization of starch granules and vascular bundles in basal and apical scale explants}

The position of scale explants influenced the regenerating bulblets growth. As shown in Fig. 4, basal and middle explants regenerated bigger bulblets compared to 
apical and edge explants. In the basal part of lily bulb scale, cells are younger, so the basal scale explants are more vigorous to regenerate bulblets than the apical part. Previous research did find that the lower part of a bulb scale was most suitable for multiple shoot differentiation and rapid growth of bulblets for in vitro propagation of lily (Long et al., 2003). In tulip, basal scale explants produced more callus lumps and shoots compared to apical scale explants (Koster, 1993). The FW of bulblets, bulblet regeneration percentage and the number of bulblets regenerated in vitro was higher on basal scale explants of hyacinth compared to apical scale explants (Pierik and Woets, 1970).

Sucrose taken up in the explants is mainly recovered at the basal side of the explants, where regeneration occurs (Langens-Gerrits et al., 2003b). When lilies are propagated ex vitro by keeping complete scales in a moist environment, starch mobilization proceeds from the apical to the basal region of bulb scales (Miller, 1989). The increased bulb growth on the basal explants reflects the higher contribution of explant reserves during bulblet growth in vitro. The results of starch granules visualization in basal and apical scale explants indicated that in the basal scale explants more starch granules occur compared to the apical scale explants. In the basal explants, the area of degraded starch granules during lily bulblets growth was ca.2 fold higher than in apical scale explants. In field grown lily bulbs, the carbohydrate as well as biomass content of the scales decreased after planting and the degradation of the reserves stored in the outer bulb scale was higher compared to the inner bulb scale (Addai and Scott, 2011). The presence of more starch grains is probably not sufficient to improve bulblet growth when the transport system of nutrients would be the same. We observed that in basal scale explants the number of vascular bundles is almost twice the number than in apical scale explants.

The middle explants in both basal and apical lily scale bulbs include the main vascular bundles and have therefore more and wider vascular bundles. In addition, the explants taken from the middle part are thicker compared to the edge explants. The average FW of middle scale explants and edge explants of the same size $(7 \times 7 \mathrm{~mm})$ was $250 \mathrm{mg} /$ explant and $150 \mathrm{mg} / \mathrm{explant}$, respectively. The middle scale explants have therefore more storage reserves compared to the edge scale explants. Both types of 
explants grow considerably during the tissue culture period. After 11 weeks, the average FWs of middle scale explants and edge scale explants were $1300 \mathrm{mg} / \mathrm{scale}$ and $1400 \mathrm{mg} / \mathrm{scale}$, respectively. This result also shows that bulblets regenerated on edge scale explants used less storage material from the scale explants compared to the middle scale explant because in the beginning even the FW of middle scale explant was higher than edge scale explants but at the end the difference between the FW of edge scale explants and middle scale explants was not statistically significant. This indicates that the vascular bundles play an important role during lily bulblet growth in vitro due to translocation of medium component and transport of scale storage organs to the bulblets regenerated in vitro.

Development of the vascular bundle number and size during bulblet regeneration in vitro occurred in both basal and apical scale explants. In plants, development of new vascular tissues enables regeneration of the plant and its adaptation to interruptions and changes in the environment (Aloni, 1987) so increase in number and the size of vascular bundles during lily bulblets growth in vitro is relevant to the growth of lily scale explants and may be a logic response of scale explants to changes in the growth situations to adapt to the new growth conditions. In tulip, development of scale explant vascular bundles to meristematic centre occurred after 10 days and callus lumps at the upper side of scale explants appearing after 30 days originated from meristematic cells of vascular bundles (Koster, 1993).

\section{Conclusion}

This study shows that characteristics of the scale explants play a major role in the growth of bulblets that regenerate from the scales. Scale explants are the best explants for micropropagation of lily bulblets in vitro. The size of scale explants at the beginning of tissue culture is a useful tool to produce bigger bulblets during lily in vitro micropropagation. It is related to more starch granules that are degraded during the period of bulblet regeneration and more and wider vascular bundles to transfer the nutrients to the bulblets regenerated in vitro. In addition, the significant difference between the growth of lily bulblets on basal and apical scale explants also indicated 
that the amount of starch granules and the intensity of vascular bundles play a major role in lily bulblet growth in vitro. 



\section{Chapter 4}

\section{The effect of abiotic stresses on lily bulblet growth in vitro}

Naser Askari $^{1,2}$, Richard G.F Visser ${ }^{1}$, and Geert-Jan de Klerk ${ }^{1}$

${ }^{1}$ Wageningen UR Plant Breeding, P. O. Box 16, 6700 AA Wageningen, The Netherlands

${ }^{2}$ Department of Plant Sciences, University of Jiroft, P. O. Box 364 , Jiroft, Iran 


\begin{abstract}
We examined effects of different abiotic stresses on the growth of lily plantlets in vitro. Twelve week old lily plantlets responded with an increase in the fresh weight of bulblets by $20 \%$ to hot air treatment (HAT). At a younger age the HAT stress had no significant effect. To assess the most effective temperature to apply HAT stress a range of temperatures $\left(32{ }^{\circ} \mathrm{C}-47^{\circ} \mathrm{C}\right)$ was examined. The most effective temperature to apply HAT was $44^{\circ} \mathrm{C}$ which led to an increase of lily bulblet growth by $30 \%$. The effective duration of HAT and hot water treatment (HWT) was $2 \mathrm{~h}$ and $3 \mathrm{~h}$ respectively. A moderate HAT pre-treatment $\left(38^{\circ} \mathrm{C}\right)$ protected the lily bulblets against severe HAT $\left(47^{\circ} \mathrm{C}\right)$. In non-pretreated bulblets which were exposed for $2 \mathrm{~h}$ to severe HAT stress the survival percentage of plantlets decreased to $10 \%$ and $25 \%$ in cultivars Stargazer and Santander, respectively. In Stargazer at $6 \mathrm{~h}$ drought stress the growth of scale explants decreased by $35 \%$, but the growth of lily bulblets, roots and leaves increased by $40 \%$, $177 \%$ and 34\%. In Santander drought stress decreased the growth of lily bulblets and scale explants and improved the growth of roots and leaves with increase of the duration of drought stress from 0 to $10 \mathrm{~h}$. In Santander, a $10 \mathrm{~h}$ drought stress reduced the growth of bulblets and scale explants by $30 \%$ and increased the growth of roots and leaves by $42 \%$ and $14 \%$. Finally, the application of anaerobiosis as stress led to increase of the growth of lily bulblets (after an $8 \mathrm{~h}$ treatment) by $65 \%$ and $32 \%$ in Santander and Stargazer, respectively.
\end{abstract}




\section{Introduction}

Lily is one of the most valuable ornamental plants. The flowers are popular because of their color and shape. The Netherlands produces $76 \%$ of the lily bulbs worldwide $(\mathrm{Qu}, 2014)$. Lily was one of the first floricultural plants which was propagated in tissue culture. In 1957, the first report on bulblet regeneration of lily from scale explants in vitro was published (Robb, 1957). A scheme for commercial production was published in 1983 (Takayama and Misawa, 1983).

The size of the bulblets produced in vitro has a strong effect on plant performance after planting. Studies with direct field planting of bulblets produced in vitro have shown that small bulblets emerge slower, less uniform and to a smaller percentage (Langens-Gerrits et al., 2000; Lian et al., 2003). It also was observed that bulblets of plantlets growing in soil, show a much faster growth than bulblets growing in vitro (De Klerk et al., 1992).

Plants have developed several mechanisms for protection during adverse periods. One of the main protective mechanisms is dormancy accompanied by storage organ formation. In this way, plants do not grow and do not produce (vulnerable) new tissue during stressful conditions. Regrowth when conditions are suitable is supported by mobilization of nutrients from the storage organ. Plants under stressful conditions tend to increase biomass in subterranean organs to protect against stress (Puijalon et al., 2008). For instance, in bulbous crops moderate heat stress can improve the formation of bulbs and roots of chives (Fölster and Krug, 1977). In Alstroemeria moderate stresses enhance the growth of rhizomes in vitro as a protective reaction (Pumisutapon et al., 2012).

In the present study, the growth of lily bulblets regenerated in vitro was monitored after applying different moderate stresses. We show that moderate abiotic stresses such as heat, drought and anaerobosis improved the growth of lily bulblets in vitro.

\section{Materials and Methods}

Standard tissue culture conditions 
Field-grown bulbs (circumference $18-20 \mathrm{~cm}$ ) of Lilium $c v$. Santander and Stargazer were harvested, cold-treated to break dormancy and stored at $-1.0^{\circ} \mathrm{C}$ until use. The procedure was according to (Aguettaz et al., 1990). Scales were surface-sterilized for $30 \mathrm{~min}$ in $1 \%(\mathrm{w} / \mathrm{v}) \mathrm{NaClO}$, rinsed for 1,3 , and $10 \mathrm{~min}$ with sterile water and after that stored until use in sterile water (on average for 1-2 h). Two explants of $7 \times 7 \mathrm{~mm}$ were cut from the scales and placed with the abaxial side on $15 \mathrm{ml}$ medium in plastic culture tubes $(3.5 \mathrm{~cm}$ diameter). The medium was composed of macro- and microelements (Murashige and Skoog, 1962), $30 \mathrm{~g} \mathrm{l}^{-1}$ sucrose, $0.4 \mathrm{mg} \mathrm{l}^{-1}$ thiamin, 100 $\mathrm{mg} \mathrm{l}^{-1}$ myo-inositol, $7 \mathrm{~g} \mathrm{l}^{-1}$ agar (Microagar), and $0.05 \mathrm{mg} \mathrm{l}^{-1}$ NAA ( $\alpha$ naphthaleneacetic acid). The explants were cultured at $25^{\circ} \mathrm{C}$ and $30 \mu \mathrm{mol} \mathrm{m} \mathrm{sec}^{-1}$ (Philips TL 33) for $16 \mathrm{~h}$ per day. After 12 weeks unless indicated otherwise, different abiotic stresses were administered and the explants were allowed to growth for 6 weeks more.

\section{Heat treatments}

To determine the effect of the temperature during the hot air treatment (HAT), for each treatment 30 explants of 12 week old bulblets were placed in an incubator at different temperatures: $32{ }^{\circ} \mathrm{C}, 35^{\circ} \mathrm{C}, 38^{\circ} \mathrm{C}, 41^{\circ} \mathrm{C}, 44^{\circ} \mathrm{C}$, and $47^{\circ} \mathrm{C}$ for 1 hour after which the explants were cultured for 6 weeks more at a temperature of $25{ }^{\circ} \mathrm{C}$ in a growth chamber. To assess the effect of applying HAT for different times, 30 explants for each treatment were incubated in an incubator at $44^{\circ} \mathrm{C}$ for $1,2,3,4$, and 5 hours after which the explants were incubated in a growth chamber for 6 weeks more. For examination of the effect of bulblet age, 30 containers with explants of 6, 8, 10 and 12 week old bulblets were placed in an incubator (Labcon LTIM 10). The temperature was kept at $38{ }^{\circ} \mathrm{C}$ for 1.5 hour. After that, the explants were cultured in a growth chamber at $25{ }^{\circ} \mathrm{C}$ for 6 weeks.

To find out whether moderate stresses protect the lily bulblets against severe stresses, lily bulblets were pre-treated at $38{ }^{\circ} \mathrm{C}$ for 1 or 2 hours and then after 4 hours treated with severe HAT at $47{ }^{\circ} \mathrm{C}$ for 1 or 2 hours. Next, the explants were kept for 6 weeks in a growth chamber at $25^{\circ} \mathrm{C}$. Finally, survival and growth were determined. 
For hot-water treatment (HWT), 25 explants were placed in a sterile beaker $(200 \mathrm{ml})$ with sterile water $(100 \mathrm{ml})$ and incubated for 1.5 or 3 hours in a water bath (Lauda Bath Circulator C12) at $38{ }^{\circ} \mathrm{C}$ after which the explants were cultured on MS standard medium in small plastic containers with $15 \mathrm{ml}$ medium and kept at $25^{\circ} \mathrm{C}$ for 6 weeks.

\section{Application of other stresses}

The effects of anaerobiosis and drought stress on bulblet growth were investigated. For anaerobiosis the explants were submerged in sterile water (15 explants per treatment) for $0,2,4,8,24$ and 72 hours in the dark at $25^{\circ} \mathrm{C}$ followed by culture on standard MS medium for 6 more weeks at $25^{\circ} \mathrm{C}$. Drought stress was given by keeping the explants on dry filter paper in the laminar air flow cabinet at room temperature for $0,2,6$ and 10 hours after which the explants were cultured for six more weeks on standard medium at $25^{\circ} \mathrm{C}$.

\section{Statistics}

All the data were scored 6 weeks after applying the different abiotic stresses. The fresh weight (FW) of lily bulblets, scale explants, roots and leaves were determined. The means are the average of 15-30 measurements per treatment. In the figures, the means are shown $\pm \mathrm{SE}$. The differences were evaluated with a $t$-test.

\section{Results}

\section{High temperature stress enhances lily bulblet growth in vitro}

To examine the most suitable temperature, containers with lily bulblets of Stargazer regenerated for 12 weeks under standard conditions were transferred to a range of temperatures $\left(25-47^{\circ} \mathrm{C}\right)$. After $1 \mathrm{~h} \mathrm{HAT}$ they were kept for 6 weeks at $25^{\circ} \mathrm{C}$ in a growth chamber. The growth of lily bulblets increased significantly at $44{ }^{\circ} \mathrm{C}$ (with $30 \%$ compared to the control) (Fig. 1). 
Then, the optimal duration of HAT at $44{ }^{\circ} \mathrm{C}$ was determined. As shown in Fig. 2a, the growth of lily bulblets increased (40\%) in 1 and $2 \mathrm{~h} \mathrm{HAT} \mathrm{at} 44{ }^{\circ} \mathrm{C}$, but at the longer durations of 3, 4 and $5 \mathrm{~h} \mathrm{HAT}$, the bulblet growth decreased dramatically.

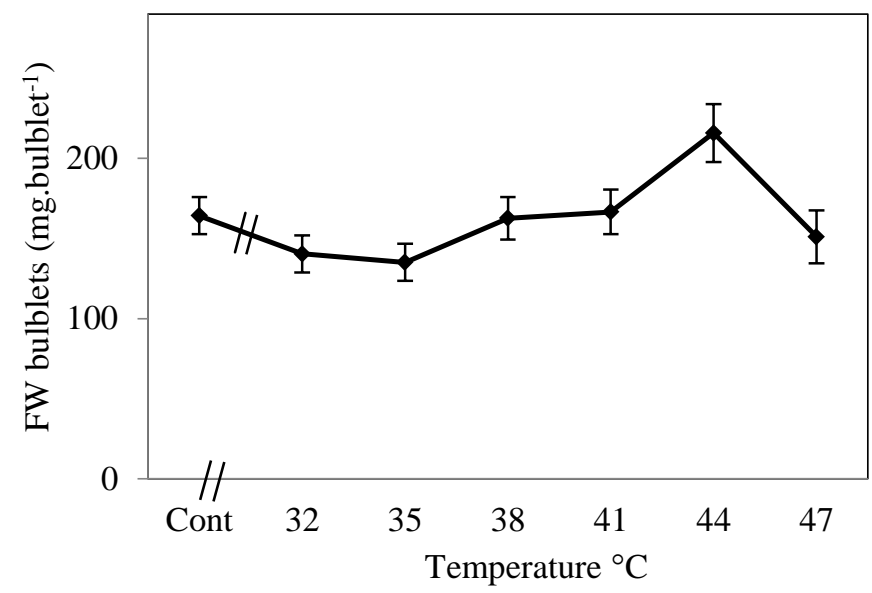

Fig. 1. The effect of $1 \mathrm{~h}$ temperature treatment (HAT) on bulblet growth during the following 6 weeks. The weight that is shown is after the 6 weeks of extra growth. Cont is control (ambient temperature, $21^{\circ} \mathrm{C}$ ).

For the hot water treatment (HWT), two types of explants, bulblets and bulblets still attached to a small piece of scale explant, were submerged in hot $\left(38^{\circ} \mathrm{C}\right)$ water for $0,1.5$ and $3 \mathrm{~h}$, then kept for 6 weeks more at $25^{\circ} \mathrm{C}$ in a growth chamber and then evaluated with respect to growth. The results showed that the lily bulblet growth increased in both explant types and the highest bulblet growth of about $40 \%$ occurred in $3 \mathrm{~h}$ HWT in explants attached to a small piece of scale explant (Fig. 2b). 

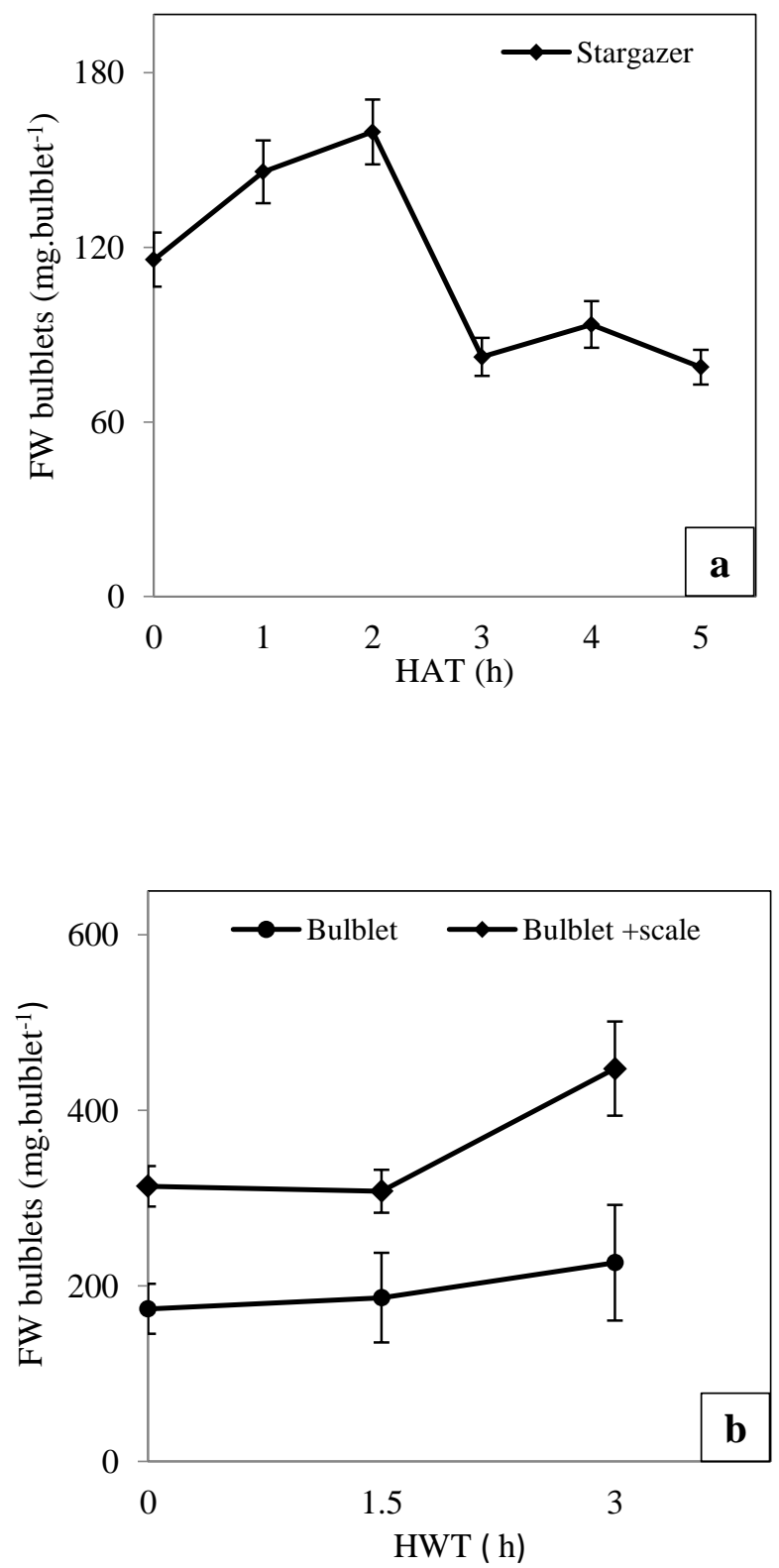

Fig. 2. Effect of duration of HAT (a) and HWT (b) on bulblet growth during the following 6 weeks. The weight that is shown is after the 6 weeks of extra growth. 
To find out whether lily bulblets of different ages respond in the same or in a different way, $1.5 \mathrm{~h} \mathrm{HAT}$ at $38{ }^{\circ} \mathrm{C}$ was applied at $6,8,10$ and 12 weeks after the start of culture of the scale explants on standard medium (Fig. 3). Bulblet growth increased ca. $20 \%$ when the HAT was applied to scale explants at 12 weeks of age compared to the control. At age 6, 8 or 10 weeks, HAT did not show a positive effect on the growth of lily bulblets.

\section{Moderate HAT protects against severe HAT}

Figures 1-3 show that the moderate heat stresses have an effect in the long run (a period of weeks). We examined whether they also had an effect in the short run (a period of hours). A moderate HAT does protect lily from a severe HAT. The results (Fig. 4a and b and Fig. 5) show that fresh weight of lily bulblets in both cultivars decreased significantly when no pre-treatment was applied. In Stargazer, a $1 \mathrm{~h}$ HAT pre-treatment at $38{ }^{\circ} \mathrm{C}$ followed by $1 \mathrm{~h}$ severe $\mathrm{HAT}$ at $47^{\circ} \mathrm{C}$ increased the fresh weight of bulblets compared to a higher duration of severe HAT. Longer severe HAT in Stargazer had a negative effect on the bulblet growth. In Stargazer, the highest fresh weight of bulblets occurred by applying a $2 \mathrm{~h}$ moderate HAT without severe HAT. In Santander, the highest bulblet fresh weight was found by applying $2 \mathrm{~h}$ moderate HAT followed by $2 \mathrm{~h}$ severe HAT. The data showed that severe HAT has a small positive effect on the bulblet growth of Santander bulblets.

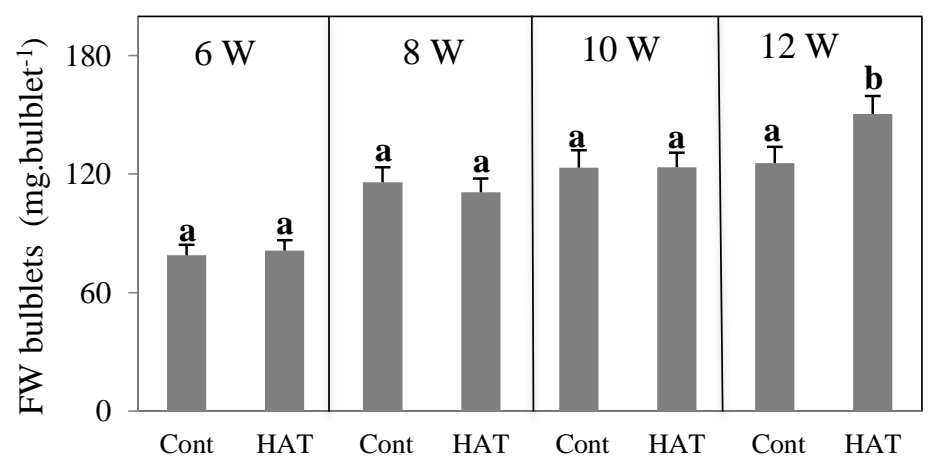

Fig. 3. Effect of $1 \mathrm{~h}$ HAT at cultures of different ages on bulblet growth during the next 6 weeks. The weight that is shown is after the 6 weeks of extra growth. 

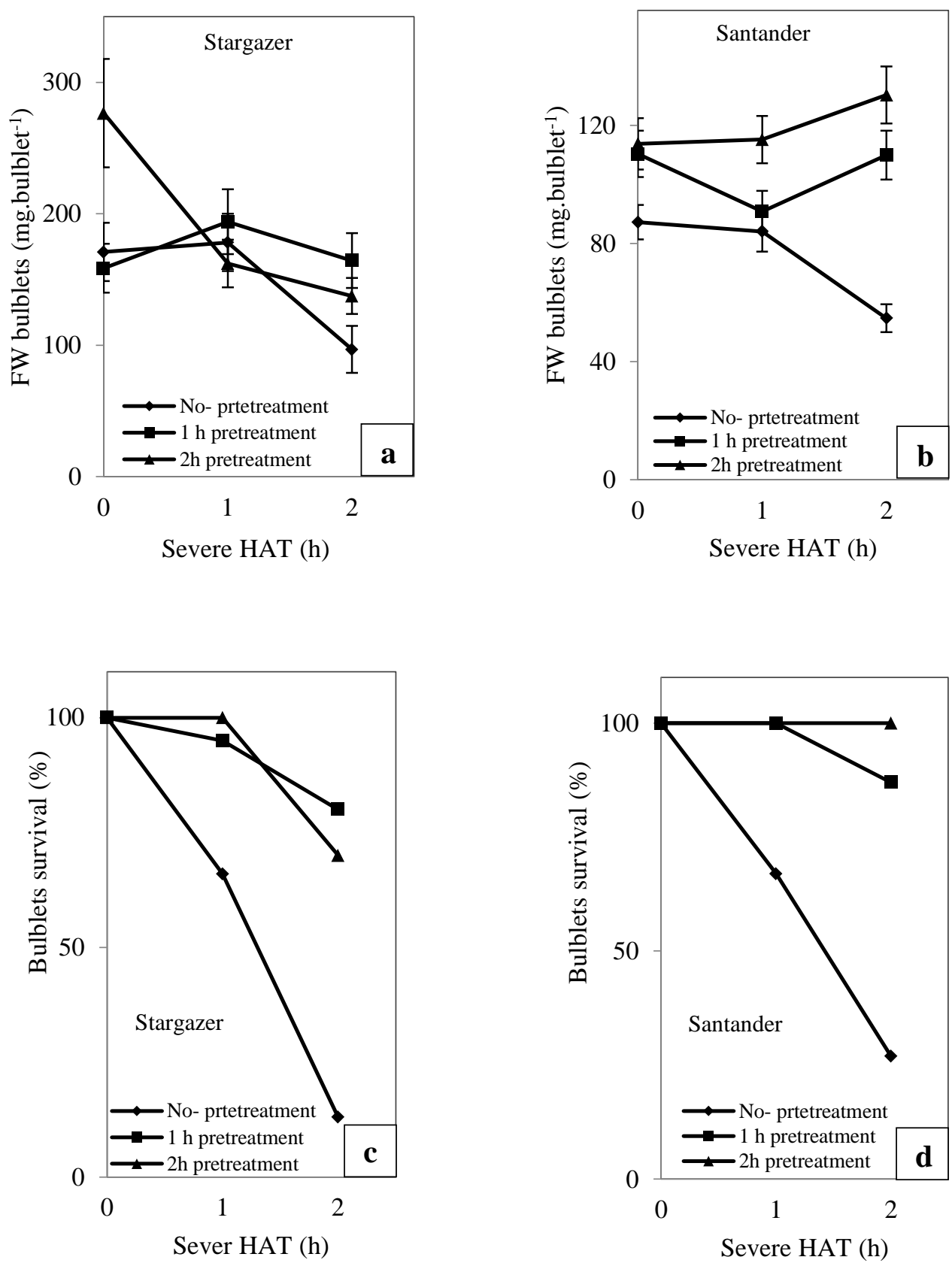

Fig. 4. Effect of $38^{\circ} \mathrm{C}$ HAT pre-treatment followed by $47^{\circ} \mathrm{C}$ severe HAT on bulblet growth during the next 6 weeks of cvs. Stargazer (a) and Santander (b) and bulblet survival percentage in Stargazer(c) and Santander (d). The weight that is shown is after the 6 weeks of extra growth. 
The survival percentage of bulblets after $2 \mathrm{~h}$ severe HAT was reduced to $10 \%$ $25 \%$ when no pre-treatment with moderate HAT was given (Fig. $4 \mathrm{c}$ and d; Fig. 5). The pre-treatments rescued in both cultivars a large percentage of bulblets.

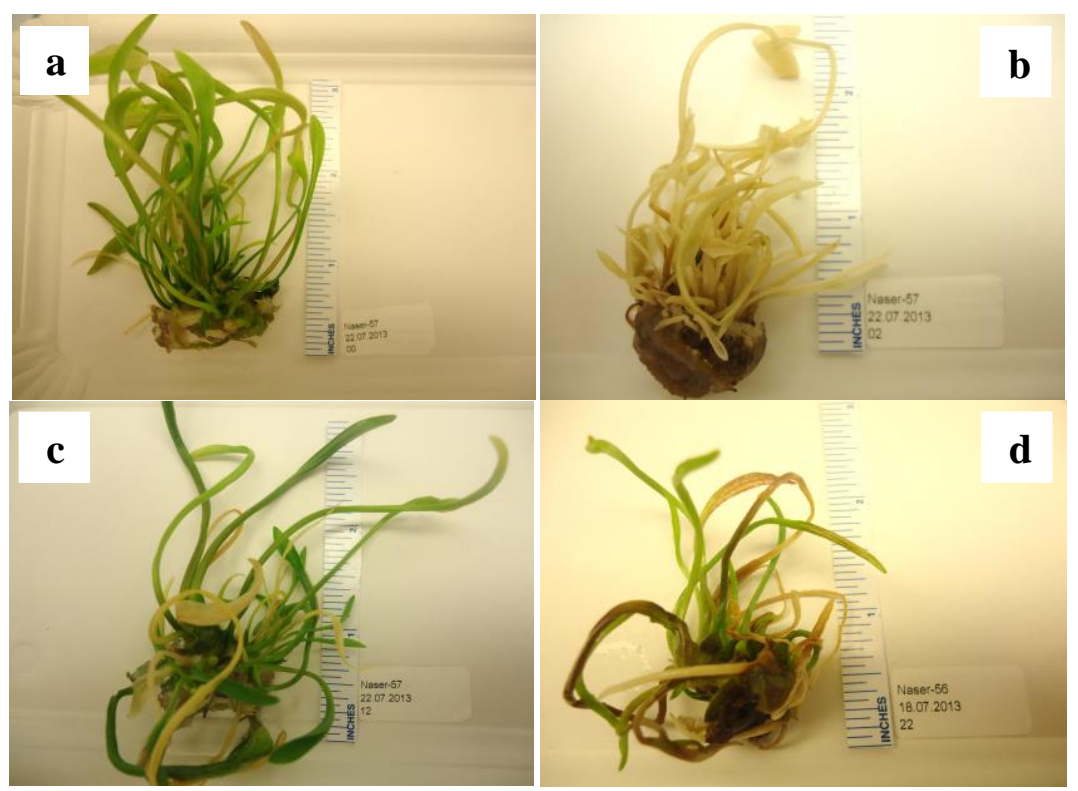

Fig. 5. Effect of moderate stress administered before a severe stress on cv. Santander. a) Control; b) only $2 \mathrm{~h}$ severe stress; c) $1 \mathrm{~h}$ moderate pre-stress $+2 \mathrm{~h}$ severe stress; d ) $2 \mathrm{~h}$ moderate pre-stress $+2 \mathrm{~h}$ severe stress.

\section{Other stresses}

We also examined other stresses. Drought stress was applied for 0, 2, 6 and 10 hours on 12 weeks old bulblets under sterile conditions. The results indicated that the fresh weight of bulblets in Santander reduced when drought stress was applied (Fig. 6). In contrast, the fresh weight of Stargazer increased significantly when drought stress was given. For 2 and $10 \mathrm{~h}$ drought stress there was no significant difference, but the increase at $6 \mathrm{~h}$ drought stress (40\%) was significant. 


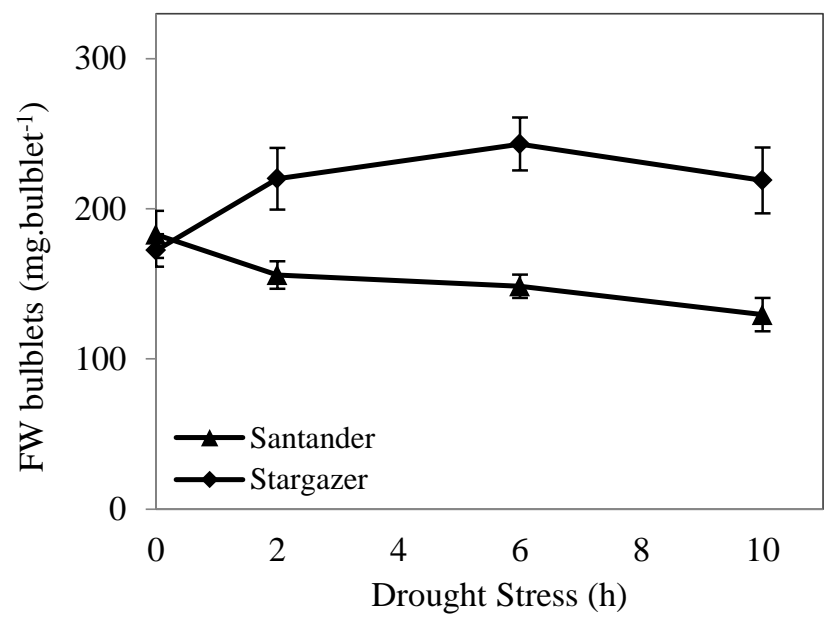

Fig. 6. Effect of drought stress on bulblet growth during 6 weeks after the stress in Stargazer and Santander. The weight that is shown is after the 6 weeks of extra growth.
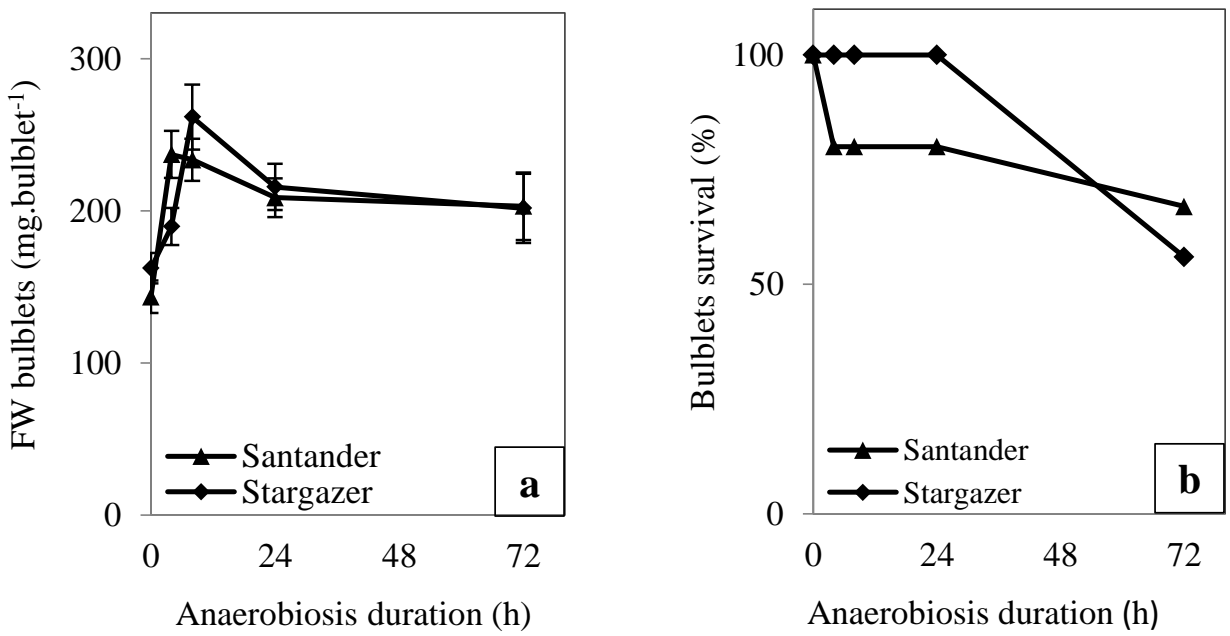

Fig. 7. Effect of anaerobiosis on bulblets growth (a) and bulblets survival (b) during 6 weeks after the stress. The weight that is shown is after the 6 weeks of extra growth.

Different durations of anaerobiosis treatment $(0 \mathrm{~h}, 4 \mathrm{~h}, 8 \mathrm{~h}, 24 \mathrm{~h}$ and $72 \mathrm{~h})$ were applied on the explants and the fresh weight of lily bulblets increased after shorter duration anaerobiosis treatment compared with the control in both cultivars (Fig. 7a). 
The highest amount of fresh weight was measured after $4 \mathrm{~h}$ and $8 \mathrm{~h}$ anaerobiosis treatment with an increase of fresh weight of $65 \%$ and $32 \%$ in $c v s$. Santander and Stargazer respectively. Longer durations of anaerobiosis had a negative effect on fresh weight of both cultivars and reduced the survival percentage in both cultivars too (Fig. $7 b)$.

\section{Discussion}

\section{Improvement of lily bulblet growth}

Plants maturity accelerates under heat stress conditions to overcome unprecedented stress (Nagarajan and Nagarajan, 2009) and in many plants leads to mass allocation of carbohydrates to the storage organs (Chapin et al., 1990) to survive and regrow after stressful conditions. The growth of lily bulblets increased after a moderate stress treatment (HAT, HWT, drought stress and anaerobiosis stress) in vitro. In a previous report (Pumisutapon et al., 2012) the growth of Alstroemeria rhizomes increased after moderate abiotic stress in vitro. On the other hand, the growth of potato tubers and onions reduced after applying heat stress and salt stress respectively (Ewing, 1981) and (Chang and Randle, 2004).

The growth of bulblets increased by almost $40 \%$ in HWT (Fig. 2). The lily bulblets were exposed to both high temperature and anaerobiosis because the bulbs were submerged in hot water for a long time and better heat conduction in water and additional moderate stresses by anaerobiosis may lead to the improved growth (Jackson, 1985) and (Dolferus et al., 2003). Moreover, the small pieces of explant attached to the bulblets increased the bulblet growth under HWT stress compared to bulblets without scale explant. It seems that the scale explant is a favorable nutrient source compared to the medium during growth period after applying HWT.

In moderate HAT, lily bulblets growth increased at $44{ }^{\circ} \mathrm{C}$ and lower temperatures had no impact on the bulblet growth. In addition, longer duration of HAT had a negative effect on lily bulblet growth and development.

Plants under moderate stresses may be primed to respond better or endure longer under future severe stresses. This has been illustrated in Alstroemeria (Pumisutapon et al., 2012) where a moderate HWT stress protected Alstroemeria against severe HWT. 
In lily both cultivars showed a positive effect of pre-treatment HAT compared to nonpretreated bulblets. The moderate HAT stress may activate some thermo-tolerance genes to protect against severe HAT. A heat shock transcription factor gene called LlHsfA2, has been reported to play an important role in heat signalling pathway in lily and it has been demonstrated that overexpression of LlHsfA2 can increase the thermotolerance of transgenic Arabidopsis plants (Xin et al., 2010). This observation is strengthened by the fact that LIHSFAl isolated from lily leaves and overexpressed in transgenic Arabidopsis gave similar results (Gong et al., 2014).

Only Stargazer has shown a positive response to drought stress on bulblet growth. On the other hand, anaerobiosis increased bulblet growth in both cultivars. We assume that increasing the growth of lily bulblets in vitro under different abiotic stresses trace back to the natural response of plants under adverse conditions. Under these stressful conditions plants tend to increase biomass in subterranean organs as a way to protect against future stresses.

\section{Conclusions}

Moderate stress increases the growth of lily bulblets probably due to a protective mechanism against abiotic stress. This method is a useful way to stimulate lily bulblet growth in vitro to achieve bigger bulblets during tissue culture period. The optimal conditions as assessed in two different lily cultivars are anareobiosis and HAT to increase the growth of lily bulblets. Depending on the variety, a pre-treatment with moderate $\mathrm{HAT}$ stress $\left(38^{\circ} \mathrm{C}\right)$ seems to be a valuable way to enhance the response to more severe HAT stress $\left(47^{\circ} \mathrm{C}\right)$. 



\section{Chapter 5}

\section{$\mathrm{CO}_{2}$ starvation in vitro is lethal at heterotrophic conditions}

Naser Askari, ${ }^{1,2}$ Sasan Aliniaeifard ${ }^{3}$, Richard G.F Visser ${ }^{1}$, and Geert-Jan de Klerk ${ }^{1}$

${ }^{1}$ Wageningen UR Plant Breeding, P. O. Box 16, 6700 AA Wageningen, The Netherlands

${ }^{2}$ Department of Plant Sciences, University of Jiroft, P. O. Box 364, Jiroft, Iran

${ }^{3}$ Department of Horticulture, College of Aburaihan, University of Tehran, Pakdasht, Tehran, Iran 


\begin{abstract}
We examined the effect of $\mathrm{CO}_{2}$ starvation on growth in vitro with $3 \%$ sucrose or without sucrose in the nutrient medium. The experiments were carried out with lily bulblets and Arabidopsis seedlings. $\mathrm{CO}_{2}$ removal from the headspace of tissue culture containers by a $20 \% \mathrm{KOH}$ solution reduced the growth of all organs of a regenerating bulblet (bulblets, leaves, roots) and growth of the original scale explant. Reduced growth was observed both in the absence of sucrose in the medium and when $3 \%$ sucrose had been added to the nutrient medium. Growth reduction was higher in the absence of sucrose (depending on the organ 33-79\%) but still considerable with 3\% sucrose in the medium (29-33\%). Similar results for growth reduction were observed in excised 11-week old lily plantlets growing in vitro with or without sucrose under $\mathrm{CO}_{2}$ starvation or 'normal' conditions. $\mathrm{CO}_{2}$ removal from the headspace also decreased growth of Arabidopsis seedlings in vitro on medium with $3 \%$ sucrose or without sucrose. $\mathrm{F}_{\mathrm{v}} / \mathrm{F}_{\mathrm{m}}$ dropped both in lily and in Arabidopsis under $\mathrm{CO}_{2}$ starvation. In lily, $\mathrm{F}_{\mathrm{v}} / \mathrm{F}_{\mathrm{m}}$ decreased from 0.69 to 0.60 and in Arabidopsis from 0.76 to $0.62 . \mathrm{F}_{\mathrm{v}} / \mathrm{F}_{\mathrm{m}}$ of ex vitro growing lily and Arabidopsis was 0.77 and 0.79 , respectively. Occurrence of ROS was examined in Arabidopsis seedlings by staining with nitroblue tetrazolium (NBT). ROS was virtually absent in ex vitro growing seedlings and very abundant in seedlings growing in vitro under $\mathrm{CO}_{2}$ starvation. Seedlings grown under normal tissue culture conditions showed an intermediate level of ROS.
\end{abstract}




\section{Introduction}

The microenvironment in tissue culture containers is very different from the environment in which plants normally grow. Apart from the medium (containing high doses of organic and inorganic nutrients and plant hormones), and the low light intensity, the tissue culture environment is characterized by an unusual atmosphere. The relative humidity is extremely high (continuously very close to $100 \%$ ), and the headspace contains high levels of organic gases such as ethylene and highly fluctuating $\mathrm{CO}_{2}$ and $\mathrm{O}_{2}$ at temporary very low and very high levels (Kozai 1991). The $\mathrm{CO}_{2}$ concentration in an air-tight vessel containing green plantlets is often lower than the $\mathrm{CO}_{2}$ compensation point during most of the photoperiod, viz., less than $100 \mu \mathrm{mol} .1^{-1}$, which is much lower than the normal atmospheric $\mathrm{CO}_{2}$ concentration of $400 \mu \mathrm{l} . \mathrm{1}^{-1}$. Even in loosely capped vessels or vessels capped with gas permeable film, the concentration is often lower than $200 \mu \mathrm{mol} . \mathrm{l}^{-1}$ (Kozai 1991). During the dark period, $\mathrm{CO}_{2}$ increases up to 3000 to $9000 \mu \mathrm{l}^{-1}$ (Fujiwara et al. 1987).

The low $\mathrm{CO}_{2}$ concentration in the vessels and the low light intensity limit photosynthesis. Poor photosynthesis in vitro may also be caused by the high sugar concentration in the medium (Kozai 1991; Desjardins et al. 1995). A reduction of the sucrose concentration enhances net photosynthesis, e.g., in Rosa multiflora (Capellades et al. 1991), and rain tree (Mosaleeyanon et al. 2004). However, addition of sugar is necessary for successful tissue culture: in spite of the increase of photosynthesis, use of medium without sucrose reduces the growth of plantlets dramatically compared to medium with $3 \%$ sucrose. Therefore, medium without sucrose is not useful for the plant tissue culture industry.

A very low $\mathrm{CO}_{2}$ level during exposure to light is deleterious for plants due to the lack of electron acceptors in the photosynthetic electron transport chain (Durchan et al. 2001). In the course of $\mathrm{CO}_{2}$ starvation, all endogenous electron acceptors become reduced and oxygen is the main available electron acceptor. Oxygen can serve as electron acceptor in the Mehler reaction (Mehler 1951; Schreiber and Neubauer 1990). The products of the Mehler reaction such as superoxide, hydroxyl radicals and hydrogen peroxide (ROS) are toxic, and attack vulnerable macromolecules. 
Reactive oxygen species (ROS) are by-products in various metabolic pathways in plants. In stressful conditions, ROS rapidly increase (oxidative burst) and these are toxic for plants (Apel and Hirt 2004; Ramel et al. 2009). ROS is removed by different antioxidative defense components.

In the present study we examined whether the low $\mathrm{CO}_{2}$ in tissue culture is damaging for plant tissue. We first studied plants cultured in tissue culture in an atmosphere from which almost all $\mathrm{CO}_{2}$ was removed by a $20 \% \mathrm{KOH}$ solution. We used Arabidopsis seedlings and lily bulblets regenerating from scale explants as two contrasting tissue culture systems. We observed strongly reduced growth both in lily and Arabidopsis as a result of $\mathrm{CO}_{2}$-poor conditions. We used chlorophyll fluorescence for investigating the damage to the photosynthesis of plants. As a comparison, we also used chlorophyll fluorescence to evaluate any potential damage inflicted during a standard tissue culture cycle. Chlorophyll fluorescence (PSII efficiency) is a simple and widespread method (Baker 2008) to establish photosynthesis performance. The ratio of variable $\left(F_{v}\right)$ to maximal $\left(F_{m}\right)$ chlorophyll fluorescence $\left(F_{v} / F_{m}\right)$ in photosystem II of the photosynthesis apparatus is believed to be an index for maximum photon yield. $F_{v} / F_{m}$ has been used to assess the efficiency of electron transport and/or damage to photosystem II (Maxwell and Johnson 2000; Leipner et al. 2001).

We observed a significant reduction of chlorophyll fluorescence during tissue culture when $\mathrm{CO}_{2}$ was removed indicating severe damage leading to an observed reduced growth. Under normal tissue culture conditions, $\mathrm{F}_{\mathrm{v}} / \mathrm{F}_{\mathrm{m}}$ was also reduced albeit much less.

\section{Materials and Methods}

\section{Lily bulblet regeneration from scale explants}

Field-grown bulbs (circumference18-20 cm) of Lilium cv. Santander were harvested, cold-treated to break dormancy and stored at $-1.0{ }^{\circ} \mathrm{C}$ until use. The procedure for lily was according to (Aguettaz et al. 1990). Scales were surfacesterilized for $30 \mathrm{~min}$ in $1 \%(\mathrm{w} / \mathrm{v}) \mathrm{NaClO}$, rinsed for 1,3 , and $10 \mathrm{~min}$ with sterile water and stored until use in sterile water (on average for 1-2 h). Two explants of $7 \times 7 \mathrm{~mm}$ were cut from the scales and placed with the abaxial side on $30 \mathrm{ml}$ medium in plastic 
culture tubes $(6.5 \mathrm{~cm}$ diameter). The medium (MS) was composed of macro- and microelements (Murashige and Skoog 1962), $30 \mathrm{~g} \mathrm{l}^{-1}$ sucrose or without sucrose, 0.4 $\mathrm{mg} \mathrm{l}^{-1}$ thiamin, $100 \mathrm{mg} \mathrm{l}^{-1}$ myo-inositol, $7 \mathrm{~g}^{-1}$ agar (Microagar), and $0.05 \mathrm{mg} \mathrm{l}^{-1} \mathrm{NAA}$ ( $\alpha$-naphthaleneacetic acid). All chemicals were obtained from Duchefa, Haarlem, the Netherlands. The scale explants were cultured for 12 weeks at $25^{\circ} \mathrm{C}$ and $30 \mu \mathrm{mol} \mathrm{m}$ $\sec ^{-1}$ light for $16 \mathrm{~h}$ per day (Philips TL 33).

\section{Growth of lily plantlets}

11-week old lily plantlets regenerating from scales under standard conditions (with sucrose) were excised from the scales and cultured on medium with MS macroand microelements (Murashige and Skoog 1962), $30 \mathrm{~g} \mathrm{l}^{-1}$ sucrose or without sucrose, $0.4 \mathrm{mg} \mathrm{l}^{-1}$ thiamin, $100 \mathrm{mg} \mathrm{l}^{-1}$ myo-inositol, $7 \mathrm{~g} \mathrm{l}^{-1}$ agar (Microagar), and $0.05 \mathrm{mg} \mathrm{l}^{-1}$ NAA ( $\alpha$-naphthaleneacetic acid). The plantlets were cultured for 6 weeks at $25^{\circ} \mathrm{C}$ and $30 \mu \mathrm{mol} \mathrm{m} \mathrm{sec}^{-1}$ light for $16 \mathrm{~h}$ per day (Philips TL 33).

\section{Arabidopsis seedling growth in medium with $3 \%$ sucrose or without sucrose}

Arabidopsis thaliana (Col-0) seeds were sterilized with $70 \%$ (v/v) ethanol for 1 $\min$ and in $2 \%(\mathrm{w} / \mathrm{v})$ sodium hypochlorite for $15 \mathrm{~min}$. They were subsequently rinsed three times for 10 min with sterilized distilled water. Sterile seeds were transferred to a Petri dish with half-strength Murashige and Skoog (MS) basal salt mixture including vitamins (Murashige and Skoog 1962) supplemented with $30 \mathrm{~g} \mathrm{l}^{-1}$ sucrose and solidified with $7 \mathrm{~g} \mathrm{l}^{-1}$ agar (Microagar). Seeds were stratified in the dark for $3 \mathrm{~d}$ at $4{ }^{\circ} \mathrm{C}$ and after that cultured in a growth chamber with $16 \mathrm{~h}$ light $/ 8 \mathrm{~h}$ dark $\left(30 \mu \mathrm{mol} \mathrm{m}{ }^{-2} \mathrm{~s}^{-1}\right.$, Philips TL33) at $21^{\circ} \mathrm{C}$. After $7 \mathrm{~d}$, the seedlings were transferred to fresh medium with $30 \mathrm{~g} \mathrm{l}^{-1}$ sucrose or without sucrose then incubated for two weeks in a growth chamber with $16 \mathrm{~h}$ light $/ 8 \mathrm{~h}$ dark $\left(30 \mu \mathrm{mol} \mathrm{m}{ }^{-2} \mathrm{~s}^{-1}\right.$, Philips TL33) at $21^{\circ} \mathrm{C}$.

\section{Removal of $\mathrm{CO}_{2}$ from the headspace}

A small vial was placed on the medium next to the explants (Fig. 1 and Fig. 5). This vial contained $3 \mathrm{ml} 20 \% \mathrm{KOH}$ and a piece of filter paper standing vertically to increase the contact surface between the $\mathrm{KOH}$ solution and the atmosphere in the 
headspace. $\mathrm{CO}_{2}$ was removed from the headspace according to the reaction $\mathrm{KOH}+$ $\mathrm{CO}_{2} \rightarrow \mathrm{KHCO}_{3}$. The $\mathrm{KOH}$ solution also reduced the relative humidity (Solomon 1951) and a saturated $\mathrm{KCl}$ solution was used as control for this. Both the $20 \% \mathrm{KOH}$ and saturated $\mathrm{KCl}$ resulted in $c a .85 \% \mathrm{RH}$.

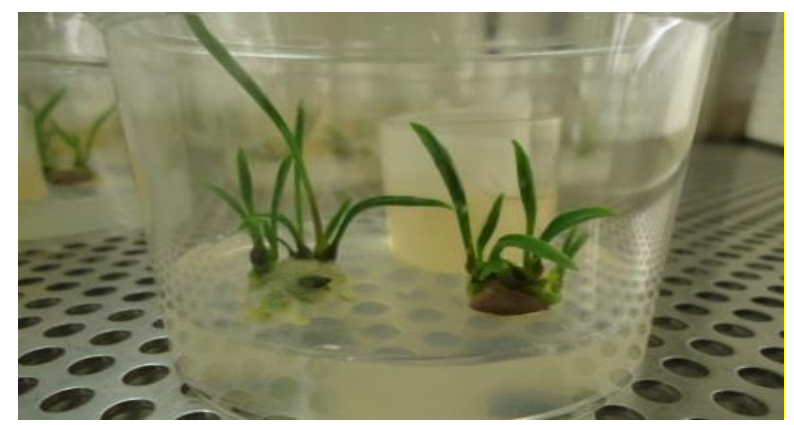

Fig. 1. Container with lily scale explants on a nutrient medium with $3 \%$ sucrose and a vial with $\mathrm{KOH}$-solution to remove $\mathrm{CO}_{2}$.

\section{Measurement of maximum PSII quantum yield $\left(\mathbf{F}_{\mathrm{v}} / \mathbf{F}_{\mathrm{m}}\right)$}

Lily plantlets and Arabidopsis seedlings were cultured ex vitro in 8-cm pots filled with potting soil or in tissue culture containers as described above in control and $\mathrm{CO}_{2}$-poor conditions in medium with $3 \%$ sucrose. After in vitro growth (12 weeks for lily and 3 weeks for Arabidopsis), the leaves were used for measurements in a chlorophyll fluorescence imaging system (FluorCam, Photon System Instruments, Brno, Czech Republic). Intact leaves still attached to the plants in tissue culture containers or in pots were dark-adapted for $20 \mathrm{~min}$. After dark adaptation intact plants (in vitro or ex vitro) were immediately used to measure maximum quantum efficiency of photosystem II $\left(\mathrm{F}_{\mathrm{v}} / \mathrm{F}_{\mathrm{m}}\right)$. In the FluorCam imaging system, an 512 x 512 pixel, CCD camera was used to record fluorescence images. $\mathrm{F}_{\mathrm{v}} / \mathrm{F}_{\mathrm{m}}$ was calculated using a custommade protocol. Images were recorded during short measuring flashes in darkness. These flashes were provided by two panels each containing 345 orange light emitting diodes. At the end of the short flashes a $250 \mathrm{~W}$ halogen lamp produced a one second duration saturating light pulse. The saturating light pulse had an intensity of 2,500 mmol m $\mathrm{m}^{-2}$ that results in a transitory saturation of photochemistry and reduction of 
primary quinone acceptor of photosystem II. After reaching steady state fluorescence, two successive series of fluorescence data were digitized and averaged, one during short measuring flashes in darkness $\left(\mathrm{F}_{0}\right)$, and the other $\left(\mathrm{F}_{\mathrm{m}}\right)$ during the saturating light flash. From these two images, $F_{v}$ was calculated by the expression $F_{v}=F_{m}-F_{0}$. The $F_{v} / F_{m}$ was calculated using the ratio $\left(\mathrm{F}_{\mathrm{m}}-\mathrm{F}_{0}\right) / \mathrm{F}_{\mathrm{m}}$. The average values, and standard deviation of $F_{v} / F_{m}$ per image were calculated by using version 5 of FluorCam software (Genty et al. 1989; Aliniaeifard et al. 2014; Aliniaeifard and Van Meeteren 2014).

\section{Visualization of superoxide radicals}

Superoxide radicals were detected by staining 3-week old Arabidopsis seedlings with nitroblue tetrazolium (NBT) solution according to (Van Den Dries et al. 2013) with minor modifications. Arabidopsis seedlings were cultured ex vitro in 8-cm pots filled with potting soil or in tissue culture containers as described above in control and $\mathrm{CO}_{2}$-poor condition in medium with $3 \%$ sucrose. Seedlings with roots were transferred into a $0.1 \%(w / v)$ NBT solution containing $50 \mathrm{mM}$ phosphate buffer (pH 7.8) and 10 $\mathrm{mM} \mathrm{NaN}_{3}$. The seedlings were vacuum-infiltrated for $5 \mathrm{~min}$ and kept for $45 \mathrm{~min}$ in the dark at room temperature. Stained seedlings were then bleached in acetic acid - ethanol $80 \%(1 / 4)(\mathrm{v} / \mathrm{v})$ at $100{ }^{\circ} \mathrm{C}$ for $30 \mathrm{~min}$. Seedlings were then stored in $50 \%$ ethanol until photographs were taken.

\section{Statistics}

Fresh weight (FW) was scored after 12 weeks (scale explant culture; FW bulblets, FW leaves, FW roots and FW scale explant), after 6 weeks (lily plantlet culture; FW bulblets, FW leaves and FW roots), and after 3 weeks (Arabidopsis seedling culture; FW shoots and FW roots). Thirty explants were used for each observation. In the figures, the means are shown \pm SE. The means were evaluated with a $t$-test.

\section{Results}

Effect of $\mathrm{CO}_{2}$ removal during bulblet regeneration from scale explants 
The presence of sucrose in the nutrient medium increased the growth of explants strongly compared to medium without sucrose. In medium with $3 \%$ sucrose, removal of $\mathrm{CO}_{2}$ caused a significant reduction in lily growth (Fig. 2). Bulblet growth decreased by $33 \%$ compared to the control (Fig. 2a), the leaf fresh weight by $68 \%$ (Fig. 2b) and the root FW by $70 \%$ (Fig. 2c). The FW of scale explants was 1356 and $285 \mathrm{mg} / \mathrm{scale}$ under control and $\mathrm{CO}_{2}$-poor condition respectively. The growth of scale explants decreased by $79 \%$ compared to the control (Fig. 2d). Removal of $\mathrm{CO}_{2}$ significantly reduced growth of lily bulblets grown in the absence of sucrose by $23 \%$ (Fig. 2a), the FW of leaves by $21 \%$ (Fig. 2b), the FW of roots by $34 \%$ (Fig. 2c) and the FW of scale explants by $25 \%$ (Fig. 2d) compared with the control.
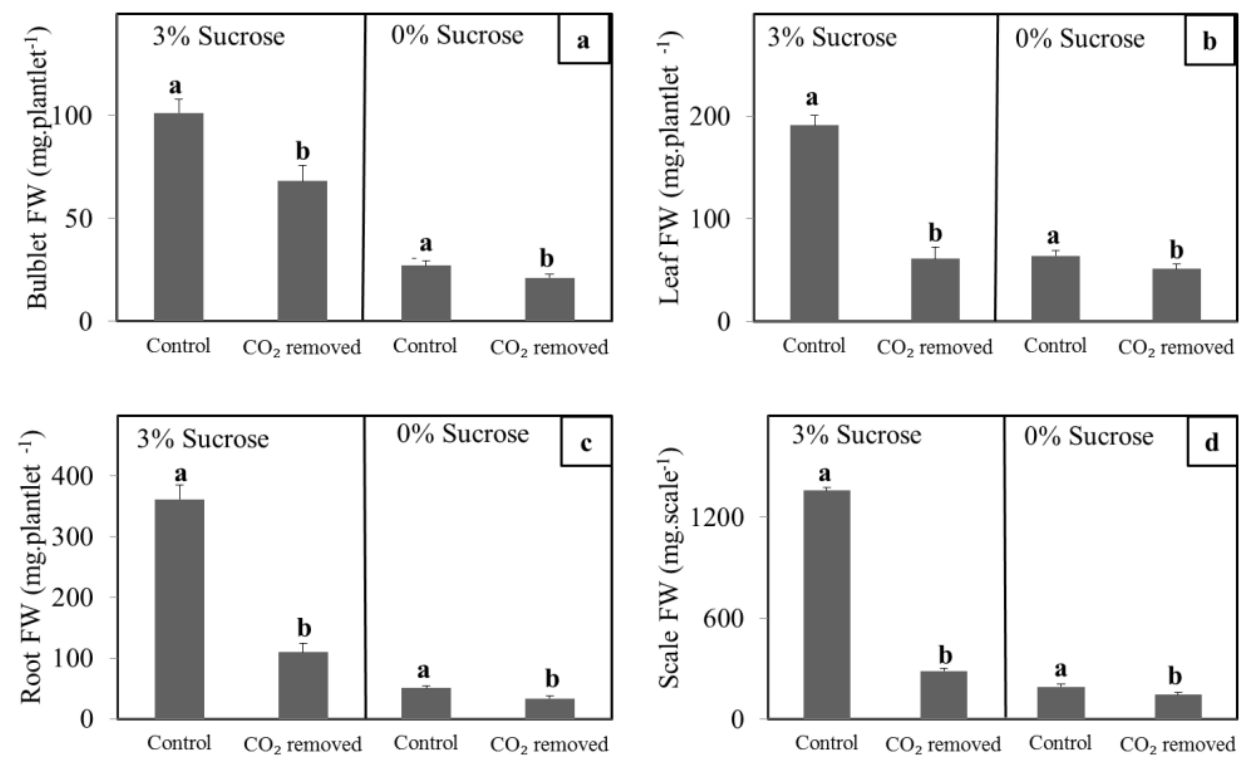

Fig. 2. Effect of $\mathrm{CO}_{2}$ removal from tissue culture containers on lily growth: bulblets (a), leaves (b), roots (c) and scale explants (d) during bulblet regeneration in vitro in medium with $3 \%$ sucrose and without sucrose.

\section{Effect of $\mathrm{CO}_{2}$ removal during culture in vitro of excised 11-week old lily plantlets}

11-Week old plantlets regenerated at standard conditions, were excised from the scales and cultured for another 6 weeks on nutrient medium with $3 \%$ sucrose or without sucrose. There were significant differences between FW of bulblets, leaves and roots between medium with $3 \%$ sucrose and without sucrose. In medium with $3 \%$ 
sucrose, the FW of bulblets was 309 and $219 \mathrm{mg} / \mathrm{bulblet}$ in control and $\mathrm{CO}_{2}$-poor condition respectively, with a start weight of bulblets of $174 \mathrm{mg} / \mathrm{bulblet}$ for both control and $\mathrm{CO}_{2}$-poor treatment. $\mathrm{CO}_{2}$-poor condition caused significant reduction in bulblet growth by $29 \%$ (Fig. 3a), leaves growth by $52 \%$ (Fig. 3b) and root growth by $31 \%$ (Fig. 3c) in medium with 3\% sucrose. $\mathrm{CO}_{2}$-poor treatment reduced profoundly the lily bulblet growth by $162 \%$, leaf growth by $60 \%$ and root growth by $92 \%$ in medium without sucrose.
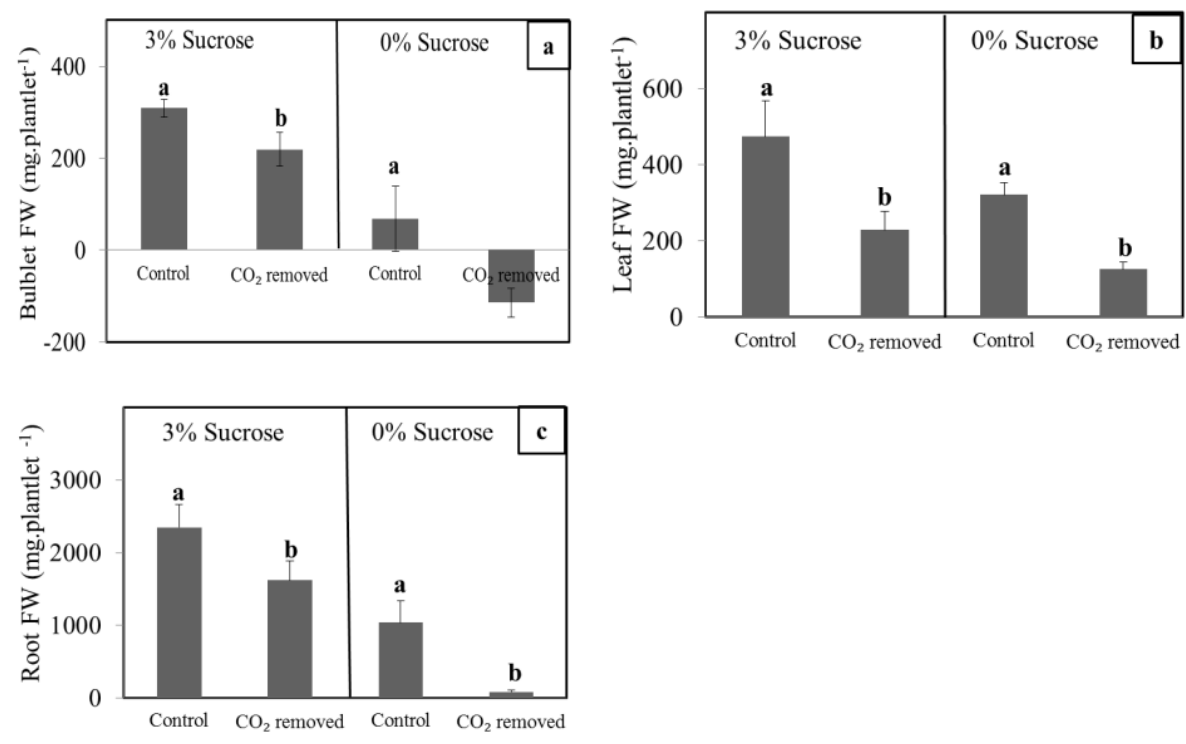

Fig. 3. Effect of $\mathrm{CO}_{2}$ removal from tissue culture containers on 11-week old lily plantlets growth: bulblet (a), leaves (b) and roots (c) in medium with $3 \%$ sucrose and without sucrose.

\section{Effect of $\mathrm{CO}_{2}$ removal during in vitro culture of Arabidopsis seedlings}

Removal of $\mathrm{CO}_{2}$ from the headspace of the tissue culture containers seems related with very general physiological processes. To examine whether effects of $\mathrm{CO}_{2}$ removal from the headspace are general, growth of Arabidopsis seedlings in medium with $3 \%$ sucrose or without sucrose with or without removal of $\mathrm{CO}_{2}$ were examined. In medium with $3 \%$ sucrose, the FW of Arabidopsis shoots was reduced by $50 \%$ (Fig. 4a) and roots by $65 \%$ (Fig. 4b) in $\mathrm{CO}_{2}$-poor conditions. In medium without sucrose, Arabidopsis shoot growth was reduced by $78 \%$ (Fig. 4a) and root growth by $65 \%$ (Fig. 4b) in $\mathrm{CO}_{2}$-poor conditions. With the exception of seedlings grown with sucrose and 

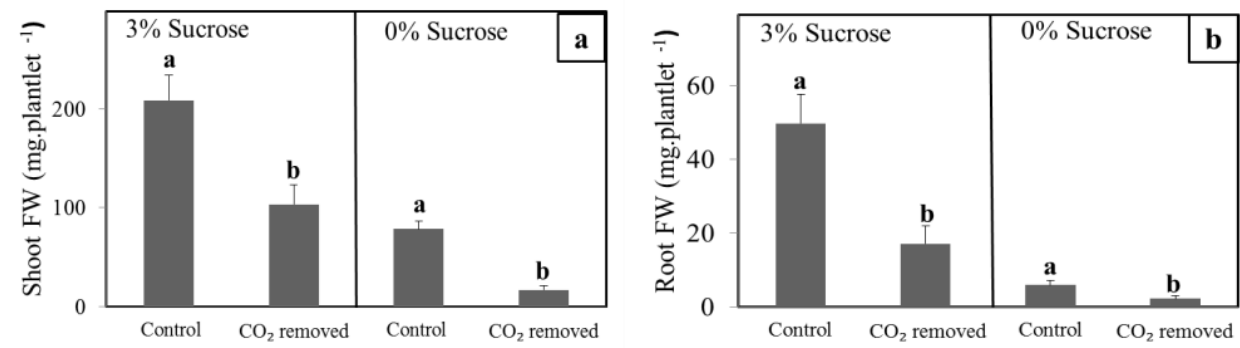

Fig. 4. Effect of $\mathrm{CO}_{2}$ removal on growth of Arabidopsis seedlings in medium with $3 \%$ sucrose and without sucrose.
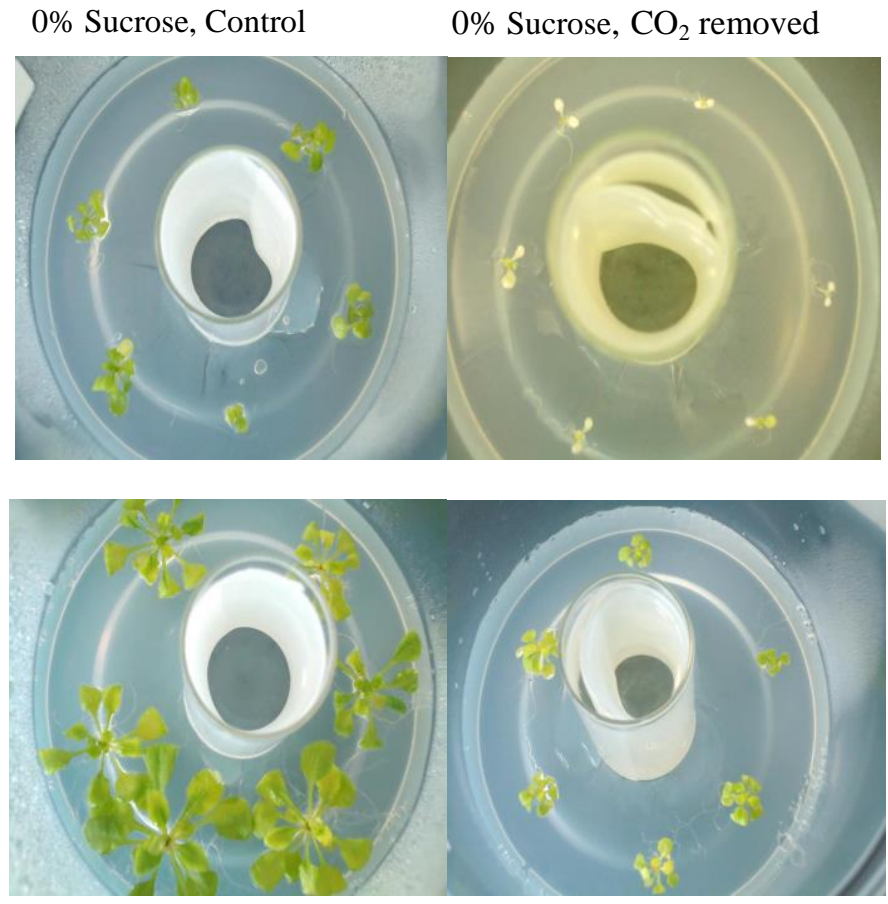

$3 \%$ Sucrose, Control

$3 \%$ Sucrose, $\mathrm{CO}_{2}$ removed

Fig. 5. Arabidopsis seedlings cultured for 7 days on medium without $(0 \%)$ or with sucrose $(3 \%)$. A small vial with $3 \mathrm{ml} 20 \%$ $\mathrm{KOH}$ was added to remove $\mathrm{CO}_{2}$ from the headspace. As a control for the drop of relative humidity $(\mathrm{RH})$ by $20 \% \mathrm{KOH}$ solution, also a small vial with saturated $\mathrm{KCl}$ was added. 
without removal of $\mathrm{CO}_{2}$, the seedlings were in a very poor condition and died soon after the period of observation (Fig. 5). It should also be noted that seedlings bleached in $\mathrm{CO}_{2}$-poor condition.

\section{Effect of $\mathrm{CO}_{2}$ removal on $\mathrm{F}_{\mathrm{v}} / \mathrm{F}_{\mathrm{m}}$ of lily and Arabidopsis and ROS detection}

To investigate the effect of $\mathrm{CO}_{2}$ removal on photosynthetic performance, $\mathrm{F}_{\mathrm{v}} / \mathrm{F}_{\mathrm{m}}$ was measured in lily plantlets and Arabidopsis seedlings grown on medium with 3\% sucrose. In general, higher $\mathrm{F}_{\mathrm{v}} / \mathrm{F}_{\mathrm{m}}$ was observed in Arabidopsis compared to lily (Fig. 6). The results showed that in both plant species, in vitro-generated plants had lower $F_{v} / F_{m}$ compared with the $\mathrm{F}_{\mathrm{v}} / \mathrm{F}_{\mathrm{m}}$ of ex vitro (in soil) plants (Fig. 6). Furthermore, in in vitrogenerated lily and Arabidopsis plants, $\mathrm{F}_{\mathrm{v}} / \mathrm{F}_{\mathrm{m}}$ was significantly decreased in $\mathrm{CO}_{2}$-poor condition in comparison with its value in control ex vitro and in vitro plants (Fig. 6 and Fig. 7 c, f).
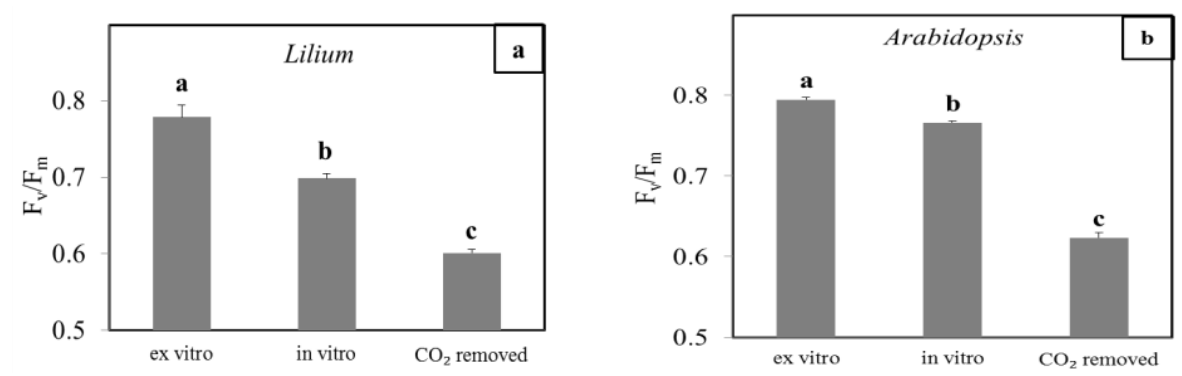

Fig. 6. $\mathrm{F}_{\mathrm{v}} / \mathrm{F}_{\mathrm{m}}$ measurement in lily and Arabidopsis (ex-vitro, in vitro and $\mathrm{CO}_{2}$ removed).

Arabidopsis seedlings grown in vitro on medium with $3 \%$ sucrose with and without $\mathrm{CO}_{2}$ were stained with NBT. When $\mathrm{CO}_{2}$ had been removed, the seedlings became deeply blue showing the abundant formation of ROS (Fig. 8c) whereas the in vitro condition with $\mathrm{CO}_{2}$ shows only little blue staining. Arabidopsis seedlings grown in ex vitro conditions remained colourless (Fig. 8a). 


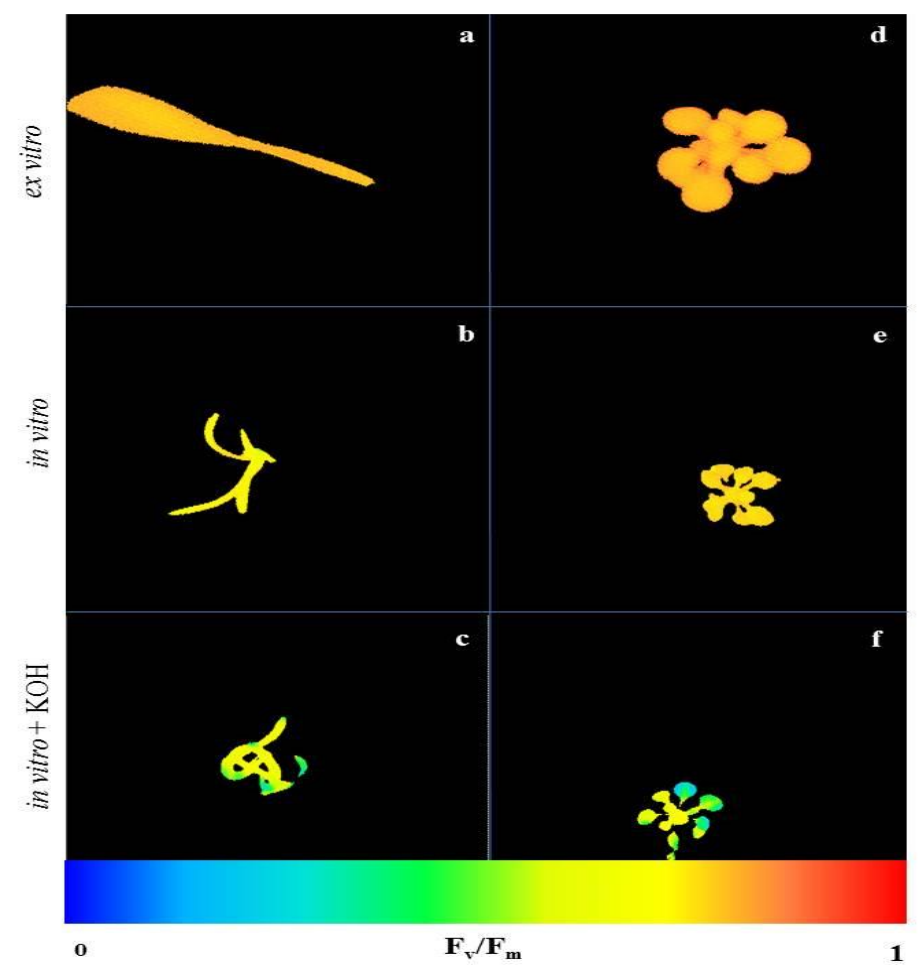

Fig. 7. Image of $\mathrm{F}_{\mathrm{v}} / \mathrm{F}_{\mathrm{m}}$ a) lily grown ex vitro, b) lily grown in vitro, c) lily grown in $\mathrm{CO}_{2}$-poor condition and d) Arabidopsis grown ex vitro, e) Arabidopsis grown in vitro and f) Arabidopsis grown in $\mathrm{CO}_{2}$-poor condition.
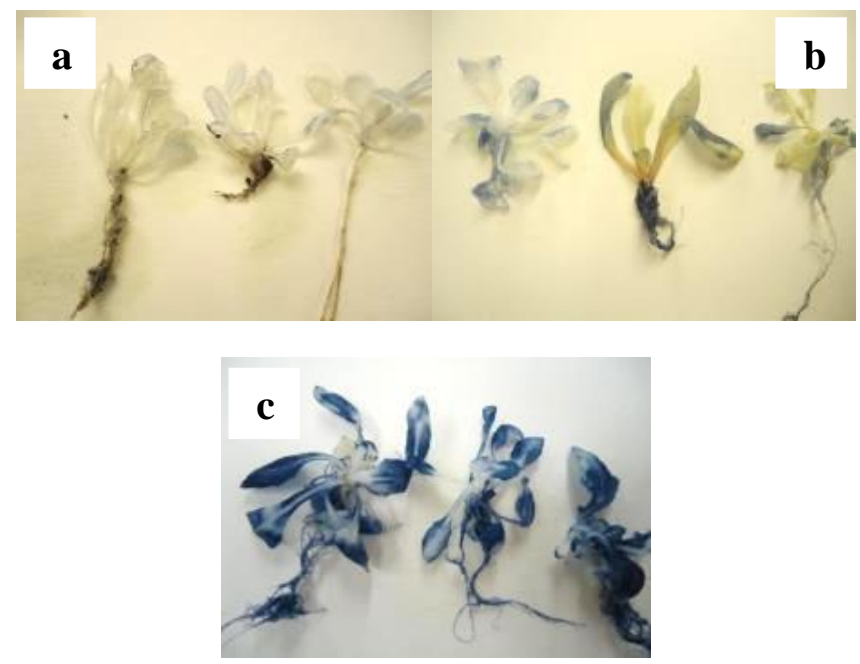

Fig. 8. Arabidopsis seedlings stained with NBT a) Arabidopsis grown ex vitro, b) Arabidopsis grown in control condition and c) Arabidopsis grown in $\mathrm{CO}_{2}$-poor condition. 


\section{Discussion}

In tissue culture, sucrose is applied via the nutrient medium to support growth. Tissue culture is usually carried out in the light and the plant material is chlorophyllous. Under these conditions, photosynthesis is inevitable although at a reduced rate. Indeed at standard tissue culture conditions the characteristic curves for $\mathrm{CO}_{2}$ and $\mathrm{O}_{2}$ during a daily regime of light and dark have been observed: high $\mathrm{CO}_{2}$ / low $\mathrm{O}_{2}$ levels in the dark and low $\mathrm{CO}_{2} /$ high $\mathrm{O}_{2}$ levels during the day (Debergh et al. 1992). The extent to which photosynthesis contributes to growth is not known but seems to be limited during standard tissue culture conditions since growth is very much reduced when no sucrose is added (e.g. see in the present article Fig. 2 and Fig. 4).

We removed most $\mathrm{CO}_{2}$ from the headspace by a $20 \% \mathrm{KOH}$ solution. Just as when omitting sucrose, we observed a very large effect on growth. This is, however, most likely due to a detrimental side-effect of $\mathrm{CO}_{2}$ withdrawal, the abundant formation of ROS (see next section). In this way, the contribution of photosynthesis to growth in vitro cannot be determined. Other ways, in particular feeding ${ }^{14} \mathrm{CO}_{2}$ may be a solution, but this was not investigated in our study.

An important finding in this paper is the huge detrimental effect of low $\mathrm{CO}_{2}$ on the plantlets (Figs. 2, 4 and 5). This can be traced back to the formation of ROS (Fig. 8c). Abundant formation of ROS was measured in Arabidopsis seedlings grown on medium with $3 \%$ sucrose in $\mathrm{CO}_{2}$-poor condition. Chlorophyll remains active in absorbing energy from light also when $\mathrm{CO}_{2}$ is very low. But when $\mathrm{CO}_{2}$ is not available as an electron acceptor in the photosynthetic electron transport chain, other electron acceptors become reduced, in particular oxygen, resulting in toxic, activated oxygen species (Durchan et al. 2001).

A reduced electron transport flux through the photosynthetic electron chain and subsequently ROS formation has also been reported in the presence of high sugar in medium even under normal condition of light (Desjardins et al. 2009). For high sucrose concentration contradictory effects on photosynthesis activity and ROS formation have been reported. Several authors report that high sucrose concentrations in medium is deleterious for photosynthetic activity (Ehness et al. 1997; Serret et al. 1997). However, sucrose has also been reported to stimulate photosynthesis in in vitro plantlets (Tichá et 
al. 1998; Fila et al. 1998). ROS formation is also stimulated (Takahashi and Murata 2008) or decreased (Couée et al. 2006) by sugar.

When $\mathrm{CO}_{2}$ was removed from the headspace by a $20 \% \mathrm{KOH}$ solution, Arabidopsis leaves showed significant bleaching and $\mathrm{F}_{\mathrm{v}} / \mathrm{F}_{\mathrm{m}}$ dropped strongly. In addition, growth declined drastically as well. In lily, bleaching was not so strong (not shown) but $\mathrm{F}_{\mathrm{v}} / \mathrm{F}_{\mathrm{m}}$ dropped even more than in Arabidopsis (Fig. 6). Growth reduction in lily was more severe in leaves than in bulblets. This may be because the leaves are the site with abundant chlorophyll and bulblets contain much less chlorophyll (Fig. 2, compare also Arabidopsis in Fig. 4), so most damage might be done in the leaves.

When there was no $\mathrm{KOH}$ solution in the tissue culture container, we still observed a significant reduction in the $F_{v} / F_{m}$ of the leaves (Fig. 6). This may be related to a very low level of $\mathrm{CO}_{2}$ brought about by photosynthesis (see Introduction). This decrease of the $\mathrm{F}_{\mathrm{v}} / \mathrm{F}_{\mathrm{m}}$ indicates damage to the tissue that may lead to a general reduction in growth. ROS detected in Arabidopsis seedlings in common tissue culture condition compared with ex vitro plantlet showed that the in vitro plantlets in general suffered from in vitro culture condition (Fig. $8 \mathrm{a}$ and b).

A study on gene expression in in vitro and ex vitro tomato leaf tissues showed that stress related genes and ROS scavenging enzymes were up regulated in in vitro tomato plants. Superoxide dismutase (SOD), ascorbate peroxidase (APX) and glutathione reductase (GR) enzymes eliminate toxic superoxide and hydrogen peroxide by conversion to water. The expression of APX and GR were higher in tomato leaf tissues in vitro, compared to ex vitro, which leads to adaptation and acclimatization to in vitro conditions (Dubuc et al. 2009). Up regulation of ROS scavenging enzymes in tomato leaf tissues grown in vitro showed that plants build up mechanisms to overcome stressful in vitro conditions by removing detrimental free radicals. But in severe stressful conditions like the $\mathrm{CO}_{2}$-poor conditions we applied in Arabidopsis the abundant amount of ROS formation (Fig. 8c) severely damaged the growth of Arabidopsis seedlings (Fig. 4a and b) and after a few weeks the plants died.

Monitoring of lipid peroxidation and antioxidant activation during acclimatization processes of gerbera plantlets in vitro indicated that the amount of MDA (malondialdehyde), a marker for lipid peroxidation which is an effect of 
oxidative damage, and hydrogen peroxide $\left(\mathrm{H}_{2} \mathrm{O}_{2}\right)$ were higher at 0 day compared with 25 days after transfer from in vitro to ex vitro conditions. The activity of APX, SOD, GR and CAT (catalase) dropped between 0 to 25 days after transfer of gerbera plantlets from tissue culture containers to soil (Chakrabarty and Datta 2008). As we found ROS in Arabidopsis grown in normal tissue culture conditions (Fig. 8b) and lower $\mathrm{F}_{\mathrm{v}} / \mathrm{F}_{\mathrm{m}}$ in both lily and Arabidopsis grown in vitro compared with ex vitro (Fig. 6), we assume that a reduction in both ROS and antioxidant enzymes activity after the transfer of gerbera plantlets from in vitro to ex vitro conditions mostly traced back to removal of in vitro stressful conditions and an adaptation of gerbera plantlets to ex vitro conditions.

Higher growth of ex vitro plants compared with in vitro plantlets was observed in lily (De Klerk et al. 1992) and tulip (Hulscher et al. 1992). So, the lower growth of in vitro plantlets might be related to the damaging effect of ROS on the growth of in vitro plantlets compared with ex vitro plants.

\section{Conclusion}

In conclusion, photosynthesis is important for the growth of lily and Arabidopsis in vitro. Photosynthesis supplies the plant tissue with sucrose, but it is not known whether this contribution is substantial or marginal. A second major effect of photosynthesis is prevention of the formation of ROS by elicitated chlorophyll. This effect is very substantial. 



\section{Chapter 6}

General Discussion 
Flowering geophytes are among the most preferred ornamental plants because of their aesthetic features, fragrance and suitability to be used as cut flowers, pot plants and garden plants. The Netherlands produces approximately $65 \%$ of world flower bulbs. The Dutch flower bulb sector exports $76 \%$ of bulb flowers in the world market. In the Netherlands, 5\% (23590 ha) of arable land (Buschman, 2004) is covered by bulbous crops for bulb production, mainly tulip (11440 ha), lily (5220), daffodil (1680 ha), hyacinths (1480 ha), gladiolus (1110 ha), crocus (470 ha) and iris (250 ha) (Rabobank, 2015).

Just as most floricultural crops, geophytes are propagated vegetatively. This is conventionally done in the field but as propagation is not fast, many years in the field are required. Such long periods in the field necessitates extensive chemical protection. From an environmental point of view, the production of flower bulbs on arable lands is quite challenging as surface and underground water have been contaminated by the use of pesticides and fertilizers (Jansma et al., 2000). This is accepted less and less by society. Moreover, a large percentage of the plants still harbours pathogenic microorganisms. An illustration of the emerging problems with environmental pollution is conventional propagation of tulip. Conventional propagation of tulip is the Achilles heel of this symbol of The Netherlands due to the low rate of in vitro shoot and bulblet formation and slow growth of the in vitro bulblets (Van Rossum, 1997).

Production of pathogen-free starting materials, rapid introduction of cultivars bred for resistance, and reduction of the period of growth in the field, make tissue culture the desirable alternative tool for propagation of ornamental geophytes instead of conventional propagation methods. Because of their robustness, storage organs (bulbs, tubers) are the ideal propagules for geophytes. Thus, for micropropagation of geophytes, in vitro storage organ formation is one of the focal points of research.

Production of high quality in vitro bulblets (bigger and uniform size) has a direct influence on the performance in the field and leads to a reduction of the field growth period in the flower bulb production processes. With $88 \%$ of world tulip bulbs, and $77 \%$ of world lily bulbs being produced in the Netherlands (Buschman, 2004), a study on the improvement of geophytes tissue culture is extremely important from an economical and environmental point of view for The Netherland. We have selected lily 
as the second economically most valuable ornamental geophyte as experimental model for elucidation and improvement of bulblet growth in vitro.

\section{Lily breeding and tissue culture}

Lily breeding is a lengthy process and introduction of a newly bred lily cultivar on the market takes up to 15 years. First, selection of the best clone takes several years: from seed to flowering plant takes about three years so that the first selection for flower properties is only possible several years after the initial crosses have been made. Then, several years are needed to evaluate quantitative properties like yield or resistance to diseases. After selection of the best clones, production of a sufficient number of bulbs takes again several years due to the low speed of the available vegetative propagation methods (natural propagation and scaling). Micropropagation considerably shortens this propagation period and is nowadays used in most breeding programs. Starting with one bulb, it is possible to produce a large number of genetically identical bulblets in vitro in a relatively short time. Because of the high propagation rates in vitro, newly bred cultivars can be introduced on the market nowadays within 7-8 years and tissue culture thus plays an essential role in the rapid expansion of the lily assortment (Langens-Gerrits, 2003).

The main constraints in conventional propagation of lilies include the insufficient availability of healthy, disease-free planting material, and slow multiplication rates. One of the best and most prolific vegetative propagation methods for lilies in vitro is scale culture (Varshney et al., 2001; Bahr and Compton, 2004). On the bulb scale explants, bulblets regenerate and after 8-10 weeks these bulblets can be used for further propagation. Individual scales of bulblets, or parts thereof, are used as explant for the next propagation cycle and a cycle can be repeated every 8-10 weeks. Using tissue culture, from one large bulb, about one million small bulblets can be obtained in 2 years (Langens-Gerrits, 2003). From a commercial point of view, micropropagation is a fast and disease-free propagation method for lily. Bulblets and other storage organs produced in vitro have properties that make them preferable propagules. They can be easily handled, transported and stored and they do not require an extensive acclimatization procedure after transfer to soil (Thakur et al., 2006). 
The size of the bulblets produced in vitro has a strong effect on performance after planting. Studies with direct planting of bulblets produced in vitro have shown that small bulblets emerge slower, less uniform and to a smaller percentage (Lian et al., 2003). When bulblets are sufficiently large (>300 mg), they increasingly sprout with a stem instead of a rosette (Langens-Gerrits et al., 2003a). Performance after planting depends on the physiology of the bulblets at the time of planting. Obviously, these physiological characteristics have been formed during the culture in vitro. Three main factors are relevant: bulblet weight, ontogenetic age (maturation) and dormancy status. It is desirable to produce large bulblets in vitro as they show a larger increase of fresh weight per bulblet after planting than small ones (Langens-Gerrits et al., 1996a).

The aim of this thesis was to improve the growth of lily bulblets as a model bulbous crop by studying the basic and applied aspects of the following main topics:

- The increase of bulblet growth under a more stringent aseptic condition (Chapter 2),

- The effect of several scale-explant related factors (Chapter 3),

- The increase of bulblet growth by moderate abiotic stresses (Chapter 4) and

- The decrease of bulblet growth by incomplete photosynthesis (Chapter 5).

\section{Approaches to enhance lily bulblet growth in vitro}

Many plant organs can be used as explants in micropropagation of ornamental geophytes. Aerial segments of plants (leaf, pedicle, sepal, petal, ovary, embryo anther) and undergrounds organs (tuber, bulb, rhizome, corm and tuberous root) were used as explant in tissue culture of geophytes (Kim and De Hertogh, 1997). The most commonly used explant for micropropagation of geophytes are bulb scales (Mirici et al., 2005). The greatest problem in tissue culture of underground organs like bulb scales is the high percentage of contamination, which can result in a significant loss of cultures during the in vitro period (Kim and De Hertogh, 1997). Apart from inadequate operating during manipulation in the laminar flow cabinet, poor equipment (e.g., damaged filters in the laminar flow cabinet) and contamination by micro-arthropods (mites and thrips), the biggest source of contamination is the explant itself that is transferred into tissue culture. A wide range of microorganisms (filamentous fungi, 
yeasts, bacteria, viruses and viroids) has been detected as contaminants in plant tissue culture (Altan et al., 2010). Underground organs attached to soil may carry higher numbers of inner and outer microorganisms compared with aerial organs. This leads often to a defective sterilization process in the in vitro initiation procedure of bulbous crops. All kinds of contaminants, have been causing considerable economical losses in commercial tissue culture laboratories (George, 1993; Reed et al., 1998; Leifert, 2000). Scientists tried to tackle this problem in different ways. The effect of fungicides, antibiotics, pre-treatment with hot water, and sugar-free media were examined (Shields et al., 1984; Langens-Gerrits et al., 1998; Kubota and Tadokoro, 1999). Increase in the growth of explants has been also reported due to side effects of decontamination agents in tissue culture. For instance, application of low concentrations of benomyl (a systemic fungicide which is taken up and translocated by plant cells and organs) as a decontamination agent in medium enhanced the growth of roots and shoots in tissue culture of Asparagus officinalis (Yang, 1976).

In Chapter 2 we used $\mathrm{NaClO}$ at a very low concentration (0.03\%) for additional disinfection. This concentration was effective and is also reported to be adequate in medical practice (Heling et al., 2001). First, we examined cross-contamination during the sterilization/rinsing procedure. When the scales are rinsed with sterile water for the 2nd and 3rd time, the rinsing water may become heavily contaminated with bacteria when infected scales are still present. This resulted in considerable additional contamination of the explants. We used a simple way (rinsing with $0.03 \% \mathrm{NaClO}$ instead of water) to reduce this cross-contamination. Bulblet growth increased with $22 \%$ by reducing cross-contamination. The second cause for development of contamination in lily scale explants is the open connection between the vascular tissues and the environment when the scales are detached from the mother bulbs. This allows movement of microorganisms into the vascular tissue. Entering is strongly enhanced by the negative hydrostatic pressure in the tissue, which results in sucking up of fluids into the xylem just after excision. These fluids often contain microorganisms. We used again $0.03 \% \mathrm{NaClO}$ to control these contaminants (Chapter 2). Bulblet growth increased with $17 \%$ by reducing this type of contamination. These effective measures in lily are most probably also valid for other species. 
Storage organ formation is a process controlled by interacting environmental, developmental and genetic factors. Studies on different stages of storage organ formation, induction, initiation and growth of storage organs (De Hertogh and Le Nard, 1993; Sarkar, 2008), can be considered on the morphological, physiological, biochemical and molecular level (Podwyszynska, 2012). Bulb scales are the main explants used in tissue culture of bulbous crops (Mirici et al., 2005). Many valuable bulbous crops like lily (Varshney et al., 2000; Skorić et al., 2014), amaryllis (Ilczuk et al., 2005), hyacinths (Yi et al., 2002) and daffodils (Santos and Salema, 2000) are propagated via bulb scale explants in vitro. The size of lily bulblets produced in vitro strongly affects performance after planting. Studies with direct field planting of in vitro bulblets have shown that small bulblets emerge slower and less uniform and have a lower sprouting percentage (Lian et al., 2003). After transfer to soil large tulip bulblets regenerated in vitro also show better performance compared to small bulblets (Le Nard et al., 1987; Hulscher et al., 1992). In vitro lily bulblets in the adult phase sprout with a stem and switch to a reproductive state; on the other hand in the juvenile phase, bulblets sprout with a rosette. Large bulblets are more often in the adult phase compared to small bulblets (Langens-Gerrits et al., 2003a).

In Chapter 3, we examined lily bulblet growth and regeneration percentage in different lily explants including, petiole, leaves and scale explants. Scale explants gave a higher bulblet regeneration percentage and the growth of lily bulblets regenerated on scale explants was higher than on the other explants. The reason why scale explants perform better may be that bulb tissue is more resistant to stress so also to stress related to the transfer to in vitro conditions. Moreover, the scale explants contain lots of reserves so that the excised explants depend less on the medium and on transport of solutes from the medium. The bigger scale explants produced bigger lily bulblets in vitro most probably due to a higher amount of starch granules and a higher vascular bundle intensity.

In this chapter we also showed that the presence of a small piece of scale explant attached to the bulblets improved the growth of excised lily bulblets and reveals a major role for the scale explants possibly as some kind of "pumping" unit. But the starch in the explant also seems to play a role even though the starch reserves are not 
exhausted after 11 weeks of culture. The growth of lily bulblets regenerated on basal scale explants was higher compared with apical scale explants. Staining of starch granules in the same area around vascular bundles of basal and apical scale explants at two stages, freshly cut scale explants and after 12 weeks cultured on medium showed that the basal scale explants are covered with more starch granules. In addition, the number and development of vascular bundles during tissue culture period in complete basal scale explant $(7 \times 7 \mathrm{~mm})$ was more than apical scale explant in freshly cut scale explants and after 12 weeks cultured on medium. More starch granules and more vascular bundles in basal scale explants probably traced back to higher cellular density due to the smaller size of the cells in the younger part of bulb scales. These results indicated that starch content and vascular bundles are important for an efficient growth of lily bulblets in vitro. Thus, keeping a piece of scale explant after bulblet regeneration in vitro during sub culturing, using bigger scale explants and using basal and middle parts of bulb scale as scale explant resulted in the production of bigger bulblets. These results may be also applied to in vitro micropropagation of other bulbous crops.

Stress conditions (drought, salinity, heat, anaerobiosis) reduce growth, development and productivity in plants. Plants have developed different mechanism to overcome stressful conditions. Tolerance mechanisms are activated by different abiotic stresses and result in the accumulation of different protective low molecular weight compounds (Bohnert et al., 1995) viz., proline, glycine, betaine, polyamine or trehalose, and protective protein, viz., heat shock proteins (HSPs; chaperone-function, (Wang et al., 2003). Plants in stressful conditions tend to allocate a high proportion of biomass to below ground biomass (roots and storage organs) compared to above ground (Fritz et al., 2004). Dormancy accompanied by storage organ formation is also one of the main protective mechanisms in plants. In this way, plants do not grow and do not produce (vulnerable) new tissue during stressful conditions. Regrowth when conditions are suitable is supported by mobilization of nutrients from the storage organ. Plants under stressful conditions tend to increase biomass in subterranean organs to protect against stress (Puijalon et al., 2008). For instance, in bulbous crops moderate heat stress can improve the formation of bulbs and roots of chives (Fölster and Krug, 1977). In 
Alstroemeria moderate stresses enhance the growth of rhizomes in vitro as a protective reaction (Pumisutapon et al., 2012).

In Chapter 4, we examined several moderate abiotic stresses (HAT, Hot Air Treatment; HWT, Hot Water Treatment; drought stress and anaerobiosis stress) on lily bulblets growth. The growth of lily bulblets increased after a moderate stress in vitro. Moderate HAT and HWT and anaerobiosis increased the growth of lily bulblets. Depending on the cultivar, drought stress also increased the bulblet growth. We examined the effect of HWT on two explant types (bulblets and bulblets attached to a small piece of scale explant) and found that the presence of a piece of scale explant increased the effect of the HWT. We assume that the scale explant has a role in the positive effect of abiotic stresses by accelerating mobilization of the reserves. We also found that moderate abiotic stresses can protect lily against further severe abiotic stresses in vitro. Thus, the moderate abiotic stresses are a promising tool to promote the growth of lily bulblets and may be used for other storage organs.

Photosynthesis is the most characteristic physiological process in all green plants. Different components, including photosynthetic pigments, photosystems, the electron transport system and $\mathrm{CO}_{2}$ reduction pathway are involved in photosynthesis. In general, any damage at any level caused by stresses may reduce the overall photosynthetic capacity of green plants (Ashraf and Harris, 2013). In ex vitro conditions, a lot of research has been conducted and described to determine the influence of stresses like drought (Medrano et al., 2002; Dias and Brüggemann, 2010), salt (Aragão et al., 2005; Abdel-Latif, 2008), and high temperature stresses (Wang et al., 2010) on photosynthesis.

In general, in vitro conditions are not the most favourable situation for plants to grow in. Composition of the medium, limited gas exchange, high humidity, low light, mechanical injuries and wounding are unfavourable elements that plants have to acclimatize to in order to survive and grow. Inhibition of photosynthesis by high sugar concentrations in vitro has been reported in several plants. In strawberry, high concentrations of sucrose (3\% and 5\%) in the medium caused a notable reduction in photosynthetic activity compared with $0 \%$ and $1 \%$ sucrose in the medium (Hdider and Desjardins, 1994). Further studies showed that sucrose inactivated Rubisco and 
increased sugar phosphates, which interacted and inhibited the carboxylation sites (Hdider and Desjardins, 1995). Addition of sucrose in medium also reduced the expression of photosynthetic genes (Jones et al., 1996). Feedback inhibition of photosynthesis induced by the presence of sugar increased the oxidative stress both in chloroplasts and mitochondria. ROS production above a putative threshold caused damage in the presence of high sugar concentrations in vitro (Desjardins et al., 2009).

In Chapter 5, we applied a severe $\mathrm{CO}_{2}$-poor condition by removal of $\mathrm{CO}_{2}$ from the headspace of tissue culture containers by a small vial filled with a $20 \% \mathrm{KOH}$ solution. The removal of $\mathrm{CO}_{2}$ was done to investigate the deleterious effect of continuous severe $\mathrm{CO}_{2}$-poor conditions during lily and Arabidopsis growth in vitro. Just as when omitting sucrose, we observed a very large effect on growth. This is, however, most likely due to a detrimental side effect of $\mathrm{CO}_{2}$ withdrawal, that is the abundant formation of ROS. When $\mathrm{CO}_{2}$ is not available as an electron acceptor in the photosynthetic electron transport chain, other electron acceptors become reduced, in particular oxygen, resulting in toxic, activated oxygen species. Abundant formation of ROS was measured in Arabidopsis seedlings grown on medium with 3\% sucrose in $\mathrm{CO}_{2}$-poor condition. Low $\mathrm{F}_{\mathrm{v}} / \mathrm{F}_{\mathrm{m}}$ and ROS in normally in vitro grown Arabidopsis and lily compared with ex vitro grown plants indicated that in vitro is a stressful condition for these plants.

\section{Conclusions and future prospects}

In all geophytes, also in the economically prominent ornamental geophytes like tulip, lily, hyacinths, iris and narcissuses, the formation of storage organs in vitro is a slow and problematic process. Although micropropagation protocols have been developed for all major geophytes, most are not sufficiently workable in commercial laboratories and a major reason for this is inadequate bulb formation. So research is needed to study and improve in vitro storage organ formation. Especially, since the Netherlands is the leader of bulbous crops production in the world, improvement of in vitro propagation of geophytes has a direct economic and environmental effect at the national level. 
In general, studies on geophytes are difficult, time-consuming and risky due to the lack of physiological, biochemical and molecular knowledge and to the long growth period. In vitro storage organ formation is hard due to the long-term storage organ formation in tissue culture, in the case of lily 3-4 months and for tulip 6-8 months, while many of the physiological, biochemical and molecular mechanisms, which are relevant for in vitro growth, are fully unknown. We developed new and valuable knowledge with respect to different aspects of lily bulblet growth in vitro, but there is still much need to further investigate the in vitro storage organ formation.

We introduced two novel and simple ways to reduce contamination in bulbous crops. We added a diluted $\mathrm{NaClO}$ solution as rinsing fluid to avoid cross contamination. We identified negative-hydrostatic-pressure related contamination and reduced it with a diluted $\mathrm{NaClO}$ solution. For further investigations, we propose to use other decontaminating components like antibiotics and fungicides specifically to reduce negative hydrostatic pressure related contamination. Penetration of antibiotics or fungicides assisted by the negative hydrostatic pressure into scale explants may reduce genuine endogenous contamination that has entered the bulbs during culture in the field.

We also performed a detailed study about the effect of scale explants on lily bulblets regeneration in vitro. We found that scale explants, even after regeneration period, are a valuable tool to improve lily bulblet growth. Starch and vascular bundles also seem to play a major role in regeneration and growth of lily bulblets in vitro. We propose to investigate mobilization and degradation of scale explant storage reserves during tissue culture in more detail using labelling with ${ }^{3} \mathrm{H}$-sucrose and ${ }^{14} \mathrm{C}$-sucrose. In addition, a study of detailed anatomical changes like vascular bundles development during bulblet regeneration and growth in vitro is needed. Scale explants increase fresh weight and even synthesise new starch granules in newly formed tissue like callus, but in bulb scales the fresh weight decreased during scaling. Studies on different morphological and physiological growth patterns between scale explants during bulblet regeneration in vitro and scaling (vegetative propagation) may give results to reveal more information about mechanisms of storage organ formation.

We also report the positive effect of abiotic stresses on lily bulblet growth in vitro. We propose to examine combined abiotic stress on lily bulblets growth. 
Applying abiotic stresses examined in this study to more cultivars of lily and to other geophytes and testing the field performance of treated plants may lead to the identification of specific abiotic stresses to apply in commercial laboratories.

We examined the effect of $\mathrm{CO}_{2}$-poor conditions on lily and Arabidopsis growth in vitro. Investigation of $\mathrm{CO}_{2}$-poor conditions as a severe stressful condition in vitro at the molecular level, especially in Arabidopsis as a model crop, can be a valuable asset to identify genes involved in coping with in vitro stresses. Studies on pulse ventilation during the in vitro period, to balance gas exchange, could be a useful way to reduce this kind of stress and lead to increase in the growth of plantlets in vitro. In addition, study on ROS formation during in vitro periods and during acclimatization and after acclimatization at the molecular and biochemical level, to detect changes in enzyme activities and gene expression could be very revealing. ROS might be removed by adding selected antioxidants.

All these observations are of use and instrumental to improve tissue culture in plants. The different steps in micropropagation of both woody and bulbous crops are depicted in Table 1. Adopting the results described in this thesis in the different steps during this process will have a positive impact on the speed by which cultures can be established.

Table 1. Different steps in micropropagation of herbaceous and woody plants (left) and of bulbous crops like lily (right) (adapted from De Klerk, 2012).

\begin{tabular}{ll}
\hline Herbaceous and woody plants & Bulbous crops \\
\hline Stage 0: preparation of mother plants & Stage 0: preparation of mother plants \\
Stage 1: initiation & Stage 1: initiation \\
Stage 2: multiplication & Stage 2: multiplication \\
Stage 3a: elongation & Stage 3a: bulbing / bulb growth \\
Stage 3b: rooting & Stage 3b: dormancy breaking \\
Stage 4: planting and acclimatization & Stage 4: planting \\
\hline
\end{tabular}

These quantitative improvements of bulblet growth are listed in Table 2. The improvement of growth is shown between brackets as a percentage of the control. It should be noted that not only treatments that directly influence bulblet growth are essential, but also the treatment during the initiation, viz., a stringent control of 
contamination. The latter obviously results in a decreased level of microorganisms in the tissues so in more "healthy" cultures.

Table 2. Table summarizing the approaches developed in this thesis to improve lily bulblet growth in vitro. The growth increase compared to the non-treated control is in brackets.

- During sterilization ${ }^{1}$

- Reduction of cross contamination (22\%)

- Reduction of hydrostatic pressure related contamination (17\%)

- At the transfer to tissue culture

- Selection origin of scale explant

- Basal and middle scale explants (40-50\%)

- Size of scale explant

- Large explant (25\%)

- During bulblet growth

○ Original scale left attached (30\%)

- Mild stress (20-65\%)

${ }^{1}$ Increase in addition to the positive effect of a reduced contamination rate

Finally the presented results in this thesis are a further stepping stone towards improving the knowledge about the various steps in tissue culture as well as a way forward to increase the speed by which new cultivars of sufficient high quality can become available to the market. 


\section{References}


Abdel-Latif, A. (2008). Phosphoenolpyruvate carboxylase activity of wheat and maize seedlings subjected to salt stress. Australian Journal Basic Applied Science 2, 37 41.

Addai, I., and Scott, P. (2011). Plant carbohydrate partitioning and metabolism of lily (Lilium longiflorum L.) during bulb production. Ghana Journal of Horticulture 9, $13-23$.

Aguettaz P., Paffen A., Delvallée I., Van Der Linde P., and De Klerk G.J. (1990). The development of dormancy in bulblets of Lilium speciosum generated in vitro. Plant Cell, Tissue and Organ Culture 22, 167-172.

Aksenova, N.P., Konstantinova, T.N., Sergeeva, L.I., Macháčková, I., and Golyanovskaya, S.A. (1994). Morphogenesis of potato plants in vitro. I. Effect of light quality and hormones. Journal of Plant Growth Regulation 13, 143-146.

Aliniaeifard S., and Van Meeteren U. (2014). Natural variation in stomatal response to closing stimuli among Arabidopsis thaliana accessions after exposure to low VPD as a tool to recognize the mechanism of disturbed stomatal functioning. Journal of Experimental Botany 65, 6529-6542.

Aliniaeifard S., Malcolm Matamoros P., and Van Meeteren U. (2014). Stomatal malfunctioning under low vapour pressure deficit (VPD) conditions: Induced by morphological and anatomical or by signalling alterations? Physiologia Plantarum 152, 688-699.

Aloni, R. (1987). Differentiation of vascular tissues. Annual Review of Plant Physiology 38, 179-204.

Altan, F., Bürün, B., and Sahin, N. (2010). Fungal contaminants observed during micropropagation of Lilium candidum L. and the effect of chemotherapeutic substances applied after sterilization. African Journal of Biotechnology 9, 991-995.

Apel K., and Hirt H. (2004). Reactive oxygen species: metabolism, oxidative stress, and signal transduction. Annual Review of Plant Biology 55, 373-399.

Aragão, M.E.F.d., Guedes, M.M., Otoch, M.d.L.O., Guedes, M.I.F., Melo, D.F.d., and Lima, M.d.G.S. (2005). Differential responses of ribulose-1, 5-bisphosphate carboxylase/oxygenase activities of two Vigna unguiculata cultivars to salt stress. Brazilian Journal of Plant Physiology 17, 207-212.

Ashraf, M., and Harris, P. (2013). Photosynthesis under stressful environments: an overview. Photosynthetica 51, 163-190. 
Bacchetta, L., Remotti, P.C., Bernardini, C., and Saccardo, F. (2003). Adventitious shoot regeneration from leaf explants and stem nodes of Lilium. Plant Cell, Tissue and Organ Culture 74, 37-44.

Bach, A., and Świderski, A. (2000). The effect of light quality on organogenesis of Hyacinthus orientalis L. in vitro. Acta Biologica Cracoviensia. Series Botanica 42, 115-120.

Bahr, L.R., and Compton, M.E. (2004). Competence for in vitro bulblet regeneration among eight Lilium genotypes. HortScience 39, 127-129.

Baker N.R (2008). Chlorophyll fluorescence: a probe of photosynthesis in vivo. Annual Review of Plant Biology 59, 89-113.

Beattie, D., and White, J. (1993). Lilium-hybrids and species. The Physiology of Flower Bulbs. A. De Hertogh and M. Le Nard (eds) Elsevier Science Publishers, Amsterdam, The Netherlands, 423-454.

Bohnert, H.J., Nelson, D.E., and Jensen, R.G. (1995). Adaptations to environmental stresses. The Plant Cell 7, 1099-1111.

Bonnier, F., and Van Tuyl, J. (1997). Long term in vitro storage of lily: effects of temperature and concentration of nutrients and sucrose. Plant Cell, Tissue and Organ Culture 49, 81-87.

Buschman, J. (2004). Globalisation-flower-flower bulbs-bulb flowers. Acta Horticulturae 673, 27-33.

Capellades M., Lemeur R., and Debergh P. (1991). Effects of sucrose on starch accumulation and rate of photosynthesis in Rosa cultured in vitro. Plant Cell, Tissue and Organ Culture 25, 21-26.

Chakrabarty D., and Datta S.K. (2008). Micropropagation of gerbera: lipid peroxidation and antioxidant enzyme activities during acclimatization process. Acta Physiologiae Plantarum 30, 325-331.

Chang, P.T., and Randle, W.M. (2004). Sodium chloride in nutrient solutions can affect onion growth and flavor development. HortScience 39, 1416-1420.

Chapin, F.S., Schulze, E.D., and Mooney, H.A. (1990). The ecology and economics of storage in plants. Annual Review of Ecology and Systematics 21, 423-447.

Chopra, J., Kaur, N., and Gupta, A.K. (2007). Sustained activities of carbon metabolizing enzymes determine seed size in Vigna radiata (mungbean). Current Science-Bangalore 92, 1420-1424. 
Couée I., Sulmon C., Gouesbet G., and El Amrani A. (2006). Involvement of soluble sugars in reactive oxygen species balance and responses to oxidative stress in plants. Journal of Experimental Botany 57, 449-459.

De Hertogh, A., and Le Nard, M. (1993). The physiology of flower bulbs: A comprehensive treatise on the physiology and utilization of ornamental flowering bulbous and tuberous plants. Amsterdam, The Netherlands, Elsevier, 811pp.

De Jong, P. (1974). Some notes on the evolution of lilies. The Lily Yearbook of the North American Lily Society.

De Klerk G.J., and Askari N. (2012). A century of plant tissue culture. Basal features ignored for too long. Prophyta Annual, 46-49.

De Klerk, G.J. (2009). A cold treatment promotes both sprouting and sink strength of lily bulblets. Propagation of Ornamental Plants 9, 102-106.

De Klerk, G.J. (2010). Why plants grow in tissue culture. Questions, answers and exciting prospects. Prophyta Annual, 42-44.

De Klerk, G.J. (2016). Micropropagation of lily : history, obstacles and advancements on the horizon. The Lily Yearbook of the North American Lily Society (in press).

De Klerk, G.J., Kim, K., Schadewijk, M.v., and Gerrits, M. (1992). Growth of bulblets of Lilium speciosum in vitro and in soil. Acta Horticulture 325, 513-520.

Debergh P.C., Demeester J., Deriek J., Gillis S., and Vanhuylenbroeck J. (1992). Ecological and physiological-aspects of tissue-cultured plants. Acta Botanica Neerlandica 41, 417-423.

Desjardins Y., Hdider C., and De Riek J. (1995). Carbon nutrition in vitro regulation and manipulation of carbon assimilation in micropropagated systems. In: Automation and Environmental Control in PlantTissue Culture. Springer, pp. 441-471.

Desjardins, Y., Dubuc, J., and Badr, A. (2009). In vitro culture of plants: a stressful activity. Acta Horticulturae 812, 29-50.

Dias, M., and Brüggemann, W. (2010). Limitations of photosynthesis in Phaseolus vulgaris under drought stress: gas exchange, chlorophyll fluorescence and Calvin cycle enzymes. Photosynthetica 48, 96-102.

Dolferus, R., Klok, E.J., Delessert, C., Wilson, S., Ismond, K.P., Good, A.G., Peacock, W.J., and Dennis, E.S. (2003). Enhancing the Anaerobic Response. Annals of Botany 91, 111-117. 
Dubuc J., Desjardins Y., and Romano A. (2009). Stress gene expression modulation in in vitro tomato plantlets. Acta Horticulturae 812, 507-513.

Durchan M., Vácha F., and Krieger-Liszkay A. (2001). Effects of severe $\mathrm{CO}_{2}$ starvation on the photosynthetic electron transport chain in tobacco plants. Photosynthesis Research 68, 203-213.

Ehness R., Ecker M., Godt D.E., and Roitsch T. (1997). Glucose and stress independently regulate source and sink metabolism and defense mechanisms via signal transduction pathways involving protein phosphorylation. The Plant Cell 9,1825-1841.

Ewing, E.E. (1981). Heat stress and the tuberization stimulus. American Potato Journal 58, 31-49.

Fila G., Ghashghaie J., Hoarau J., and Cornic G. (1998). Photosynthesis, leaf conductance and water relations of in vitro cultured grapevine rootstock in relation to acclimatisation. Physiologia Plantarum 102, 411-418.

Fölster, E., and Krug, H. (1977). Influence of the environment on growth and development of chives (Allium schoenoprasum L.). II. Breaking of the rest period and forcing. Scientia Horticulturae 7, 213-224.

Fritz, K.M., Evans, M.A., and Feminella, J.W. (2004). Factors affecting biomass allocation in the riverine macrophyte Justicia americana. Aquatic Botany 78, 279288.

Fujiwara, K., Kozai, T., and Watanabe, I. (1987). Measurements of carbon dioxide gas concentration in closed vessels containing tissue cultured plantlets and estimates of net photosynthetic rates of the plantlets. Journal of Agricultural Meteorology. 43, 21-30.

Genty B., Briantais J.M., and Baker N.R. (1989). The relationship between the quantum yield of photosynthetic electron transport and quenching of chlorophyll fluorescence. Biochimica et Biophysica Acta 990, 87-92.

George, E.F. (1993). Plant propagation by tissue culture. Part 1: The Technology. Edington, Exegetics, 574pp.

George, E.F., Hall, M.A., and De Klerk, G.J. (2008). Plant Propagation by Tissue Culture: Volume 1. The Background. Springer, 520pp.

Gong, B., Yi, J., Wu, J., Sui, J., Khan, M., Wu, Z., Zhong, X., Seng, S., He, J., and Yi, M. (2014). LlHSFA1, a novel heat stress transcription factor in lily (Lilium 
longiflorum), can interact with LlHSFA2 and enhance the thermotolerance of transgenic Arabidopsis thaliana. Plant Cell Reports 33, 1519-1533.

Grassotti, A., and Gimelli, F. (2010). Bulb and cut flower production in the genus Lilium: current status and the future. Acta Horticulturae 900, 21-35.

Gulati, A., and Jaiwal, P.K. (1992). In vitro induction of multiple shoots and plant regeneration from shoot tips of mung bean (Vigna radiata L. Wilczek). Plant Cell, Tissue and Organ Culture 29, 199-205.

Gupta, P., Sharma, A., and Chaturvedi, H. (1978). Multiplication of Lillium longiflorum Thunb. by aseptic culture of bulb scales and their segments. Indian Journal of Experimental Biology 16, 940-942.

Hallmann, J., Quadt-Hallmann, A., Mahaffee, W., and Kloepper, J. (1997). Bacterial endophytes in agricultural crops. Canadian Journal of Microbiology 43, 895-914.

Han, B.H., Yae, B.W., Yu, H.J., and Peak, K.Y. (2005). Improvement of in vitro micropropagation of Lilium oriental hybrid 'Casa blanca'by the formation of shoots with abnormally swollen basal plates. Scientia Horticulturae 103, 351-359.

Hdider, C., and Desjardins, Y. (1994). Effects of sucrose on photosynthesis and phosphoenolpyruvate carboxylase activity of in vitro cultured strawberry plantlets. Plant Cell, Tissue and Organ Culture 36, 27-33.

Hdider, C., and Desjardins, Y. (1995). Reduction of ribulose-1, 5-bisphosphate carboxylase/oxygenase efficiency by the presence of sucrose during the tissue culture of strawberry plantlets. In Vitro Cellular \& Developmental Biology-Plant 31, 165-170.

Heling, I., Rotstein, I., Dinur, T., Szwec-Levine, Y., and Steinberg, D. (2001). Bactericidal and cytotoxic effects of sodium hypochlorite and sodium dichloroisocyanurate solutions in vitro. Journal of Endodontics 27, 278-280.

Hulscher, M., Krijgsheld, H., and Van der Linde, P. (1992). Propagation of shoots and bulb growth of tulip in vitro. Acta Horticulturae 325, 441-446.

Ilczuk, A., Winkelmann, T., Richartz, S., Witomska, M., and Serek, M. (2005). In vitro propagation of Hippeastrum $\times$ chmielii $\mathrm{Chm}$. influence of flurprimidol and the culture in solid or liquid medium and in temporary immersion systems. Plant Cell, Tissue and Organ Culture 83, 339-346.

Ishimori, T., Niimi, Y., and Han, D. S. (2007). Benzyladenine and low temperature promote phase transition from juvenile to vegetative adult in bulblets of Lilium $\times$ 
formolongi 'White Aga'cultured in vitro. Plant Cell,Tissue and Organ Culture 88, 313-318.

Jackson, M.B. (1985). Ethylene and responses of plants to soil waterlogging and submergence. Annual Review of Plant Physiology 36, 145-174.

Jaleel, C.A., Kishorekumar, A., Manivannan, P., Sankar, B., Gomathinayagam, M., Gopi, R., Somasundaram, R., and Panneerselvam, R. (2007). Alterations in carbohydrate metabolism and enhancement in tuber production in white yam (Dioscorea rotundata Poir.) under triadimefon and hexaconazole applications. Plant Growth Regulation 53, 7-16.

Jansma, J.E., Snoek, B.J., and Wondergem, M. (2000). Sustainable flower bulb production: prototyping integrated flower bulb production systems on sandy soils in The Netherlands. Acta Horticulturae 570, 191-204.

Jásik, J., and De Klerk, G.J. (2006). Effect of methyl jasmonate on morphology and dormancy development in lily bulblets regenerated in vitro. Journal of Plant Growth Regulation 25, 45-51.

Ji, Q., Vincken, J.P., Suurs, L.C., and Visser, R.G. (2003). Microbial starch-binding domains as a tool for targeting proteins to granules during starch biosynthesis. Plant Molecular Biology 51, 789-801.

Jones, P., Lloyd, J., and Raines, C. (1996). Glucose feeding of intact wheat plants represses the expression of a number of Calvin cycle genes. Plant, Cell \& Environment 19, 231-236.

Kato, T., Shinmura, D., and Taniguchi, A. (2007). Activities of enzymes for sucrosestarch conversion in developing endosperm of rice and their association with grain filling in extra-heavy panicle types. Plant Production Science 10, 442-450.

Keller, E. (1993). Sucrose, cytokinin, and ethylene influence formation of in vitro bulblets in onion and leek. Genetic Resources and Crop Evolution 40, 113-120.

Kim, K. W., and De Hertogh, A. (1997). Tissue culture of ornamental flowering bulbs (Geophytes). Horticultural Reviews 18, 87-169.

Kim, K.S., Davelaar, E., and De Klerk, G.J. (1994). Abscisic acid controls dormancy development and bulb formation in lily plantlets regenerated in vitro. Physiologia Plantarum 90, 59-64.

Knypl, J. (1980). Stimulation of bulb growth in onion (Allium cepa L.) by N, N-diethyl-N(2-hydroxyethyl) glycine. Biologia Plantarum 22, 226-230. 
Koster, J. (1993). In vitro propagation of tulip : formation and bulbing of shoots on bulb scale explants from Tulipa gesneriana $\mathrm{L}(\mathrm{PhD}$ Thesis: Leiden University).

Kozai T .(1991). Photoautotrophic micropropagation. In Vitro Cellular \& Developmental Biology - Plant 27, 47-51.

Kubota, C., and Tadokoro, N. (1999). Control of microbial contamination for large-scale photoautotrophic micropropagation. In Vitro Cellular \& Developmental BiologyPlant 35, 296-298.

Kuijpers, A.M., and Langens-Gerrits, M.M. (1996). Propagation of tulip in vitro. Acta Horticultrae 430, 321-324.

Kumar, S., Kanwar, J., and Sharma, D. (2006). In vitro propagation of Lilium. Advances in Horticultural Science 2, 181-188.

Kumar, S., Kashyap, M., and Sharma, D. (2005). In vitro regeneration and bulblet growth from lily bulb scale explants as affected by retardants, sucrose and irradiance. Biologia Plantarum 49, 629-632.

Kunneman, B., and Faaij-Groenen, G. (1987). Elimination of bacterial contaminants: a matter of detection and transplanting procedures. Acta Horticulturae 225, 183-188.

Langens-Gerrits, M.M. (2003). Phase change, bulb growth and dormancy development in lily (PhD Thesis: Radboud University Nijmegen).

Langens-Gerrits, M.M, Albers, M., and De Klerk, G.J. (1998). Hot-water treatment before tissue culture reduces initial contamination in Lilium and Acer. Plant Cell, Tissue and Organ Culture 52, 75-77.

Langens-Gerrits, M.M, and De Klerk, G.J. (1999). Micropropagation of flower bulbs. In: Plant Cell Culture Protocols, Springer, pp. 141-147.

Langens-Gerrits, M.M, De Klerk, G.J., and Croes, A. (2000). How to produce lily bulblets in vitro that perform optimally after planting. Acta Horticulture 530, 289296.

Langens-Gerrits, M.M, De Klerk, G.J., and Croes, A. (2003a). Phase change in lily bulblets regenerated in vitro. Physiologia Plantarum 119, 590-597.

Langens-Gerrits, M.M, Hol, T., Croes, T., Miller, W.B., Hardin, B., and De Klerk, G.J. (1996a). Dormancy breaking in lily bulblets regenerated in vitro: effects on growth after planting. Acta Horticulturae 430, 429-436.

Langens-Gerrits, M.M, Kuijpers, A.M., De Klerk, G.J., and Croes, A. (2003b). Contribution of explant carbohydrate reserves and sucrose in the medium to bulb 
growth of lily regenerated on scale segments in vitro. Physiologia Plantarum 117, 245-255.

Langens-Gerrits, M.M, Lilien-Kipnis, H., Croes, T., Miller, W.B., Kollöffel, C., and De Klerk, G.J. (1996b). Bulb growth in lily regenerated in vitro. Acta Horticulturae 430, 267-274.

Larcher, W. (1995). Physiological Plant Ecology. Berlin, Springer, 528pp.

Le Guen-Le Saos, F., Hourmant, A., Esnault, F., and Chauvin, J. (2002). In vitro bulb development in shallot (Allium cepa L. Aggregatum Group): effects of anti-gibberellins, sucrose and light. Annals of Botany 89, 419-425.

Le Nard, M., Ducommun, C., Weber, G., Dorion, N., Bigot, C., Casenave, M., and Leboeuf, J. (1987). Observations sur la multiplication in vitro de la tulipe (Tulipa gesneriaha L.) à partir de hampes florales prélevées chez des bulbes en cours de conservation. Agronomie 7, 321-329.

Leifert, C. (2000). Quality assurance systems for plant cell and tissue culture; the problem of latent persistence of bacterial pathogens and Agrobacterium-based transformation vector systems. Acta Horticulturae 530, 87-92.

Leifert, C., and Cassells, A.C. (2001). Microbial hazards in plant tissue and cell cultures. In Vitro Cellular \& Developmental Biology-Plant 37, 133-138.

Leifert, C., Ritchie, J.Y., and Waites, W.M. (1991). Contaminants of plant-tissue and cell cultures. World Journal of Microbiology and Biotechnology 7, 452-469.

Leipner J., Oxborough K., and Baker N.R. (2001). Primary sites of ozone-induced perturbations of photosynthesis in leaves: identification and characterization in Phaseolus vulgaris using high resolution chlorophyll fluorescence imaging. Journal of Experimental Botany 52, 1689-1696.

Leshem, B., Lilien-Kipnis, H., and Steinitz, B. (1982). The effect of light and of explant orientation on the regeneration and subsequent growth of bulblets on Lilium longiflorum Thunb, bulb-scale sections cultured in vitro. Scientia Horticulturae 17, 129-136.

Li, Y., Gu, Y., Qin, H., and Zhang, Y. (2010). Two pairs of sucrose transporters in Ipomoea batatas L. Lam are predominantly expressed in sink leaves and source leaves respectively. Plant science 179, 250-256.

Lian, M.L., Chakrabarty, D., and Paek, K.Y. (2003). Growth of Lilium Oriental Hybrid 'Casa blanca' bulblet using bioreactor culture. Scientia Horticulturae 97, 41-48. 
Long, C., Cheng, Z., Wang, L., and Zuo, T. (2003). Position effect on the propagation in vitro of different explants from Lilium davidii var. unicolor. Acta Botanica Yunnanica 26, 221-225.

Long, R.D., Curtin, T.F. and Cassells, A.C. (1988). An investigation of the effects of bacterial contaminants on potato nodal cultures. Acta Horticulturae 225, 83-92.

Marcelis-van Acker, C., and Scholten, H. (1995). Development of axillary buds of rose in vitro. Scientia Horticulturae 63, 47-55.

Matsuo, E., and Arisumi, K. (1978). Studies on the leaf development of the scale bulblet in the Easter lily (Lilium longiflorum Thunb.). 2. Relationship between the size of the parent bulb or the parent scale and the type of leaf development (plant type). Gakujutsu Hokoku Bulletin, 1-8.

Matsuo, T., and Mizuno, T. (1974). Changes in the amounts of two kinds of reserve glucose-containing polysaccharides during germination of the Easter lity bulb. Plant and Cell Physiology 15, 555-558.

Maxwell K, and Johnson G.N. (2000). Chlorophyll fluorescence a practical guide. Journal of Experimental Botany 51, 659-668.

Medrano, H., Escalona, J.M., Bota, J., Gulías, J., and Flexas, J. (2002). Regulation of photosynthesis of $\mathrm{C} 3$ plants in response to progressive drought: stomatal conductance as a reference parameter. Annals of Botany 89, 895-905.

Mehler A.H (1951). Studies on reactions of illuminated chloroplasts: I. Mechanism of the reduction of oxygen and other hill reagents. Archives of Biochemistry and Biophysics 33, 65-77.

Miller, W.B. (1989). Localization of reserve mobilization during scalet formation on Easter lily scales. Acta Horticulturae 266, 95-100.

Miller, W.B. (1992). A review of carbohydrate metabolism in geophytes. Acta Horticulturae 325, 239-246.

Mirici, S., Parmaksız, İ., Özcan, S., Sancak, C., Uranbey, S., Sarıhan, E.O., Gümüşcü, A., Gürbüz, B., and Arslan, N. (2005). Efficient in vitro bulblet regeneration from immature embryos of endangered Sternbergia fischeriana. Plant Cell,Tissue and Organ Culture 80, 239-246.

Mohapatra, P., Sarkar, R., and Kuanar, S. (2009). Starch synthesizing enzymes and sink strength of grains of contrasting rice cultivars. Plant Science 176, 256-263. 
Mosaleeyanon, K., Cha-um, S., and Kirdmanee, C. (2004). Enhanced growth and photosynthesis of rain tree (Samanea saman Merr.) plantlets in vitro under a $\mathrm{CO}_{2}$ enriched condition with decreased sucrose concentrations in the medium. Scientia Horticulturae 103, 51-63.

Murashige, T., and Skoog, F. (1962). A revised medium for rapid growth and bio assays with tobacco tissue cultures. Physiologia Plantarum 15, 473-497.

Nagarajan, S., and Nagarajan, S. (2009). Abiotic tolerance and crop improvement. In: Abiotic Stress Adaptation in Plants. Springer, The Ntherlands, pp1-11.

Nhut, D.T., Le, B.V., Da Silva, J.A.T., and Aswath, C.R. (2001a). Thin cell layer culture system in Lilium: Regeneration and transformation perspectives. In Vitro Cellular \& Developmental Biology - Plant 37, 516-523.

Nhut, D.T., Van Le, B., Tanaka, M., and Van, K.T.T. (2001b). Shoot induction and plant regeneration from receptacle tissues of Lilium longiflorum. Scientia Horticulturae 87, 131-138.

Niimi, Y. (1984). Bulblet-productivity of explants from scales, leaves, stems and teplas of Lilium rubellum Baker. Scientia Horticulturae 22, 391-394.

Niimi, Y. (1995). In vitro propagation and post-in vitro establishment of bulblets of Lilium japonicum Thunb. Journal of the Japanese Society for Horticultural Science 63, 843-852.

Pierik, R.L.M. (1997). In vitro culture of higher plants 4th edition. Dordrecht, Kluwer Academic Publishers, 348 pp.

Pierik, R.L.M., and Woets, J. (1970). Regeneration of Isolated Bulb Scale Segments of Hyacinth. Acta Horticulturae 23, 423-428.

Pirttilä, A.M., Podolich, O., Koskimäki, J.J., Hohtola, E., and Hohtola, A. (2008). Role of origin and endophyte infection in browning of bud-derived tissue cultures of Scots pine (Pinus sylvestris L.). Plant Cell, Tissue and Organ Culture 95, 47-55.

Podwyszynska, M. (2012). The Mechanisms of in Vitro Storage Organ Formation in Ornamental Geophytes. Floriculture and Ornamental Biotechnology 6, 9-23.

Puijalon, S., Piola, F., and Bornette, G. (2008). Abiotic stresses increase plant regeneration ability. Evolutionary Ecology 22, 493-506.

Pumisutapon, P., Visser, R.G., and De Klerk, G.J. (2012). Moderate abiotic stresses increase rhizome growth and outgrowth of axillary buds in Alstroemeria cultured in vitro. Plant Cell, Tissue and Organ Culture 110, 395-400. 
Qu, L.W., Yin, D.S., Su, S.J., Pan, B.T., Zhao, X.H., Yang, J.M., Pei, X.H. and Fu, B. (2014). Production of Lily (Lilium) Bulbs And Cut Flowers In Liaoning Province of Northeast China. Acta Horticulturae 1027, 105-112.

Rabobank. (2015). Rabobank Cijfers \& Trends. https://www.rabobankcijfersentrends.nl.

Ramel, F., Sulmon, C., Bogard, M., Couée, I., and Gouesbet, G. (2009). Differential patterns of reactive oxygen species and antioxidative mechanisms during atrazine injury and sucrose-induced tolerance in Arabidopsis thaliana plantlets. BMC Plant Biology 9, 28-47.

Ravnikar, M., Žel, J., Plaper, I., and Špacapan, A. (1993). Jasmonic acid stimulates shoot and bulb formation of garlic in vitro. Journal of Plant Growth Regulation 12, 73-77.

Reed, B.M., Mentzer, J., Tanprasert, P., and Yu, X. (1998). Internal bacterial contamination of micropropogated hazelnut: identification and antibiotic treatment. Plant Cell, Tissue and Organ Culture 52, 67-70.

Rice, R., Alderson, P., and Wright, N. (1983). Induction of bulbing of tulip shoots in vitro. Scientia Horticulturae 20, 377-390.

Robb, S.M. (1957). The culture of excised tissue form bulb scales of Lilium speciosumThun. Journal of Experimental Botany 8, 348-352.

Rossi-Fedele, G., Doğramacı, E.J., Guastalli, A.R., Steier, L., and De Figueiredo, J.A.P. (2012). Antagonistic interactions between sodium hypochlorite, chlorhexidine, EDTA, and citric acid. Journal of Endodontics 38, 426-431.

Saniewski, M., and Puchalski, J. (1987). The effect of methyl jasmonate and abscisic acid on differentiation of benzyladenine-induced bulblets in Muscari bulbs. Biologia Plantarum 29, 63-65.

Santos, I., and Salema, R. (2000). Promotion by Jasmonic acid of bulb formation in shoot cultures of Narcissus triandrus L. Plant Growth Regulation 30, 133-138.

Sarkar, D. (2008). The signal transduction pathways controlling in planta tuberization in potato: an emerging synthesis. Plant Cell Reports 27, 1-8.

Sawant, R.A., and Tawar, P.N. (2011). Use of sodium hypochlorite as media sterilant in sugarcane micropropagation at commercial scale. Sugar Tech 13, 27-35.

Schneider, W., and Doetsch, R. (1974). Velocity measurements of motile bacteria by use of a videotape recording technique. Applied Microbiology 27, 283-284. 
Schreiber U., and Neubauer C .(1990). O $\mathrm{O}_{2}$-dependent electron flow, membrane energization and the mechanism of non-photochemical quenching of chlorophyll fluorescence. Photosynthesis Research 25, 279-293.

Serret M.D., Trillas M.I., Matas J., and Araus J.L. (1997). The effect of different closure types, light, and sucrose concentrations on carbon isotope composition and growth of Gardenia jasminoides plantlets during micropropagation and subsequent acclimation ex vitro. Plant Cell, Tissue and Organ Culture 47, 217-230.

Shields, R., Robinson, S.J., and Anslow, P.A. (1984). Use of fungicides in plant tissue culture. Plant Cell Reports 3, 33-36.

Skorić, M., Živković, S., Savić, J., Šiler, B., Sabovljević, A., Todorović, S., and Grubišić, D. (2014). Efficient one-step tissue culture protocol for propagation of endemic plant, Lilium martagon var. cattaniae vis. African Journal of Biotechnology 11, 1862-1867.

Smulders, M.J., Visser, E.J., Van der Krieken, W.M., Croes, A.F., and Wullems, G.J. (1990). Effects of the developmental state of the tissue on the competence for flower bud regeneration in pedicel explants of tobacco. Plant Physiology 92, 582586.

Solomon M. (1951). Control of humidity with potassium hydroxide, sulphuric acid, or other solutions. Bulletin of Entomological Research 42, 543-554.

Staikidou, I., Watson, S., Harvey, B.M., and Selby, C. (2005). Narcissus bulblet formation in vitro: effects of carbohydrate type and osmolarity of the culture medium. Plant Cell, Tissue and Organ Culture 80, 313-320.

Stimart, D., and Ascher, P. (1981). Foliar emergence from bulblets of Lilium longiflorum Thunb. as related to in vitro generation temperatures (Ornamentals). Journal American Society for Horticultural Science 106, 446-450.

Taiz, L., and Zeiger, E. (2002). Plant Physiology. 3rd edition. New York, Sinauer, 690pp.

Takahashi S, and Murata N. (2008). How do environmental stresses accelerate photoinhibition?. Trends in Plant Science 13, 178-182

Takayama, S., Amo, T., and Fukano, M. (1991). Rapid clonal propagation of Hyacinthus orientalis bulbs by shake culture. Scientia Horticulturae 45, 315-321.

Takayama, S., and Misawa, M. (1982). Regulation of organ formation by cytokinin and auxin in Lilium bulbscales grown in vitro. Plant and Cell Physiology 23, 67-74. 
Takayama, S., and Misawa, M. (1983). A scheme for mass propagation of Lilium in vitro. Scientia Horticulturae 18, 353-362.

Tanaka, A., Hoshi, Y., Kondo, K., and Taniguchi, K. (1991). Induction and rapid propagation of shoot primordia from shoot apices of Lilium japonicum. Plant Tissue Culture Letters 8, 206-208.

Teixeira, S., Ribeiro, J., and Teixeira, M. (2006). Influence of $\mathrm{NaClO}$ on nutrient medium sterilization and on pineapple (Ananas comosus cv Smooth cayenne) behavior. Plant Cell, Tissue and Organ Culture 86, 375-378.

Thakur, R., and Sood, A. (2006). An efficient method for explant sterilization for reduced contamination. Plant Cell, Tissue and Organ Culture 84, 369-371.

Thakur, R., Sood, A., Nagar, P.K., Pandey, S., Sobti, R.C., and Ahuja, P.S. (2006). Regulation of growth of Lilium plantlets in liquid medium by application of paclobutrazol or ancymidol, for its amenability in a bioreactor system: growth parameters. Plant Cell Reports 25, 382-391.

Tichá I., Čáp F., Pacovská D., Hofman P., Haisel D., Čapková V and Schäfer C. (1998). Culture on sugar medium enhances photosynthetic capacity and high light resistance of plantlets grown in vitro. Physiologia Plantarum 102,155-162.

Van Aartrijk, J., and Blom-Barnhoorn, G. (1981). Growth regulator requirements for adventitious regeneration from Lilium bulb-scale tissue in vitro, in relation to duration of bulb storage and cultivar. Scientia Horticulturae 14, 261-268.

Van Aartrijk, J., and Van der Linde, P. (1986). In vitro propagation of flower-bulb crops. In: Tissue culture as a plant production system for horticultural crops, Springer, pp. 317-331.

Van Bel, A. (1993). Strategies of phloem loading. Annual Review of Plant Biology 44, 253-281.

Van Den Dries N., Giannì S., Czerednik A., Krens F., De Klerk G.J. (2013). Flooding of the apoplast is a key factor in the development of hyperhydricity. Journal of Experimental Botany 64, 5221-5230.

Van der Linde, P., and Schipper, J. (1992). Micropropagation of iris with special reference to Iris $x$ hollandica Tub. Biotechnology in Agriculture and Forestry 20, 173-197.

Van Meeteren, U. (1988). Water relations and early leaf wilting of cut chrysanthemums. Acta Horticulturae 261, 129-136. 
Van Rossum, M.W.P.C. (1997). Role of physiological factors in tulip bulb scale micropropagation. (PhD Thesis: Wageningen University).

Van Tuyl, J.M., and Arens, P. (2010). Lilium: breeding history of the modern cultivar assortment. Acta Horticulturae 900, 223-230.

Varshney, A., Dhawan, V., and Srivastava, P. (2000). A protocol for in vitro mass propagation of Asiatic hybrids of lily through liquid stationary culture. In Vitro Cellular \& Developmental Biology-Plant 36, 383-391.

Varshney, A., Lakshmikumaran, M., Srivastava, P., and Dhawan, V. (2001). Establishment of genetic fidelity of in vitro-raised Lilium bulblets through RAPD markers. In Vitro Cellular \& Developmental Biology-Plant 37, 227-231.

Viola, R., Pelloux, J., Van Der Ploeg, A., Gillespie, T., Marquis, N., Roberts, A.G., and Hancock, R.D. (2007). Symplastic connection is required for bud outgrowth following dormancy in potato (Solanum tuberosum L.) tubers. Plant, Cell \& Environment 30, 973-983.

Vreugdenhil, D., and Sergeeva, L.I. (1999). Gibberellins and tuberization in potato. Potato Research 42, 471-481.

Vreugdenhil, D., Bindels, P., Reinhoud, P., Klocek, J., and Hendriks, T. (1994). Use of the growth retardant tetcyclacis for potato tuber formation in vitro. Plant Growth Regulation 14, 257-265.

Wang, L.J., Fan, L., Loescher, W., Duan, W., Liu, G.J., Cheng, J.S., Luo, H.B., and Li, S. H. (2010). Salicylic acid alleviates decreases in photosynthesis under heat stress and accelerates recovery in grapevine leaves. BMC Plant Biology 10, 1-10.

Wang, Q.M., Zhang, L.M., Guan, Y.A., and Wang, Z.L. (2006). Endogenous hormone concentration in developing tuberous roots of different sweet potato genotypes. Agricultural Sciences in China 5, 919-927.

Wang, W., Vinocur, B., and Altman, A. (2003). Plant responses to drought, salinity and extreme temperatures: towards genetic engineering for stress tolerance. Planta 218, $1-14$.

Wozniewski, T., Blaschek, W., and Franz, G. (1991). In vitro propagation of Lilium testaceum and structural investigation of the storage $\beta$-1, 4-glucomannan. Plant Cell Reports 10, 457-460. 
Xin, H., Zhang, H., Chen, L., Li, X., Lian, Q., Yuan, X., Hu, X., Cao, L., He, X., and Yi, M. (2010). Cloning and characterization of HsfA2 from Lily (Lilium longiflorum). Plant Cell Reports 29, 875-885.

Xu, X., van Lammeren, A.A., Vermeer, E., and Vreugdenhil, D. (1998). The role of gibberellin, abscisic acid, and sucrose in the regulation of potato tuber formation in vitro. Plant Physiology 117, 575-584.

Yae, B., Han, B., and Goo, D. (2001). Dormancy breaking and in vivo growth of in vitro bulblets in Lilium Oriental Hybrid Casa Blanca. Journal Korean Society for Horticultural Science 42, 99-102.

Yamagishi, M. (1998). Effects of culture temperature on the enlargement, sugar uptake, starch accumulation, and respiration of in vitro bulblets of Lilium japonicum Thunb. Scientia Horticulturae 73, 239-247.

Yanagawa, T., Tanaka, R. and Funai, R. (2007). Simple micropropagation of ornamentals By direct application of chlorine disinfectants without equipment. Acta Horticulturae 764, 289-298.

Yang, H. (1976). Effect of benomyl (a systemic fungicide) on Asparagus officinalis L. shoot and root development in culture media. HortScience 5, 473-474.

Yi, Y.B., Lee, K.S., and Chung, C.H. (2002). Protein variation and efficient in vitro culture of scale segments from Hyacinthus orientalis L. cv. Carnegie. Scientia Horticulturae 92, 367-374.

Zhang, Y., Zhang, Q., and Xue, X. (2010). The effects of the photoperiods on the bulblet formation and sugar metabolism change of wild Lilium lancifoiium in vitro. Acta Horticulturae Sinica 201, 957-962.

Zimmermann, M.H., and Ziegler, H. (1975). List of sugars and sugar alcohols in sievetube exudates. Encyclopedia of Plant Physiology. Springer, New York, pp 480503.

Ziv, M., and Lilien-Kipnis, H. (2000). Bud regeneration from inflorescence explants for rapid propagation of geophytes in vitro. Plant Cell Reports 19, 845-850. 
Summary 
Many geophytes have a high ornamental value. They are preferably propagated by micropropagation because in this way large quantities of uniform, disease-free starting material are produced in a short period of time. In comparison with shoots, bulblets have several clear advantages as starting material. Therefore, in vitro bulblet formation is an important target for improvement of tissue culture of geophytes. The research described in this thesis was carried out with the lily cultivars 'Santander' and 'Stargazer'.

Commercially, lily is the second geophyte in the global flower industry. The size of lily bulblets regenerated in vitro has a direct effect on the performance in the field. After planting, large bulblets sprout with a stem and gain twice as much weight compared with small bulblets that sprout with a rosette. In the present study we studied basic and applied aspects of the following topics: (1) new methods for sterilization during initiation, (2) the effect of scale-related factors on bulblet growth, (3) growth enhancement by moderate abiotic stresses, and (4) the effect of $\mathrm{CO}_{2}$ removal from headspace of tissue culture containers on lily bulblet growth and as a control Arabidopsis thaliana seedling growth.

Contamination is an everlasting problem in tissue culture laboratories. Lily bulbs are underground organs and contain therefore more contaminants as compared with aerial organs. During initiation, operators cause additional contamination in two ways that have as yet not been recognized adequately. (1) Rinsing explants with sterile water after surface-sterilization is the generally advised method to remove the residues of decontaminants. However, when scales are heavily contaminated, the surfacesterilization does not kill microorganisms in all scales. Surface-sterilization is usually done with batches of 10 to 30 scales and the contaminated scales may crosscontaminate uninfected scales during rinsing in water. We have tested the rinsing water and found heavy bacterial contamination in the $2^{\text {th }}$ and especially the $3^{\text {rd }}$ rinse. The contaminated rinsing water resulted in a high incidence of cross-contamination. Cross contamination was reduced almost fully by rinsing in diluted $\mathrm{NaClO}$ solution $(0.03 \%)$ instead of sterile water. There was no negative effect of diluted $\mathrm{NaClO}$ on growth. (2) A second way of introducing contamination by the operator is the entering of microorganisms during detachment from mother bulbs via the vascular bundles caused 
by negative hydrostatic pressure within the bulb tissue. By detaching scales from bulbs submerged in $0.03 \% \mathrm{NaClO}$, hydrostatic-pressure related contamination was strongly reduced. The growth of bulblets increased by $22 \%$ and $17 \%$ when cross contamination and negative-hydrostatic pressure related contamination were prevented.

Storage organ formation is controlled by interacting environmental, biochemical and genetic factors. We studied various aspects of the effect of the scale explant. We found that large explants produced larger bulblets than small explants. When bulblets were excised and cultured in vitro, growth was improved by $33 \%$ when a small piece of the original scale explant was left attached to the bulblet. The position in the scale from where the explant was excised affected the growth of the regenerating bulblets. Basal-scale explants improved bulblet growth by 40-50\% compared with apical-scale explants. This might be related to the physiological state of the tissues: there was more starch and there were more vascular bundles present in basal scale explants. Furthermore, excision of an explant from the middle of the scale improved bulblet growth by 40-50\% compared with explants excised from the edge of the scale. In general, the middle scale explants were heavier and contained wider vascular bundles.

Plants in stressful conditions tend to allocate a higher proportion of biomass to below-ground biomass (roots and storage organs) as compared to above ground biomass. We investigated the effect of moderate abiotic stresses on lily bulblets grown in vitro. In general, lily bulblets showed an increased growth after moderate stresses. Hot air increased growth by $30 \%$, hot water by $40 \%$. We also examined the effect of drought and anaerobiosis. Drought stress increased growth of bulblets by $40 \%$ in the cultivar 'Stargazer', but significantly decreased bulblet growth in cv 'Santander'. Anaerobiosis increased growth in 'Stargazer' and 'Santander' by $32 \%$ and $65 \%$, respectively. We also showed that a moderate stresses treatment protects lily bulblets against future severe abiotic stresses.

In general, the in vitro situation is not favorable for plants. Composition of the headspace (high humidity, strongly fluctuating $\mathrm{CO}_{2}$ - and $\mathrm{O}_{2}$-levels and accumulation of gases like ethylene), low light, and wounding are unfavorable conditions that plants have to deal with. We examined the effect of $\mathrm{CO}_{2}$ starvation on growth in vitro with and without addition of $3 \%$ sucrose to the medium. $\mathrm{A} \mathrm{CO}_{2}$-poor headspace reduced the 
growth of bulblets, leaves, roots and scale explants strongly, also in the presence of 3\% sucrose. $\mathrm{CO}_{2}$ removal from the headspace decreased growth of Arabidopsis seedlings by $50 \%$ on medium with $3 \%$ sucrose. It seems unlikely that the growth reduction on medium with $3 \%$ sucrose is caused solely by the lack of sucrose production in photosynthesis when $\mathrm{CO}_{2}$ is removed. Indeed, we found evidence that the low $\mathrm{CO}_{2}$ resulted in heavy stress that in turn may reduce growth. $\mathrm{F}_{\mathrm{v}} / \mathrm{F}_{\mathrm{m}}$ in lily and Arabidopsis dropped when $\mathrm{CO}_{2}$ was removed. Occurrence of reactive oxygen radicals (ROS) was examined in Arabidopsis seedlings by staining with nitroblue tetrazolium (NBT). ROS was virtually absent in ex vitro growing seedlings and very abundant in seedlings grown under $\mathrm{CO}_{2}$ starvation. Seedlings grown under normal tissue culture conditions showed an intermediate presence of ROS. We hypothesize that low levels of $\mathrm{CO}_{2}$ may results in ROS in in vitro seedlings which reduces growth. 
Acknowledgments 
It is not easy to write adequate acknowledgments for all the people who supported and helped me during my 6-year stay at Wageningen University.

The shiniest star in my scientific life is Dr. Geert-Jan De Klerk who opened the international windows for me. Dear Geert-Jan, I will always be thankful for all your scientific and life advises from our first meeting at Schiphol airport on March 16, 2010 till this very day. Studying at an international and high quality University that Wageningen University is and gaining international experiences is the biggest present that I have received during all my life. You gave me this opportunity with accepting me as your $\mathrm{PhD}$ student and you made it much easier for me with your well placed advises and support. I have learned a lot from all your experiences with bulbous crops tissue culture and you always did your utmost for me even with your recent difficult health condition. I will never forget your kind help and support.

I extend my utmost gratitude to my promotor Prof. Dr. Richard G.F Visser for quick corrections and comments and his constructive advises and valuable input on the thesis during the different stages of my $\mathrm{PhD}$ journey.

I want to thank the Dutch Horticultural Board for financial support to the project, and Vletter and De Haan (Rijnsburg, Netherlands) for supplying lily bulbs for my thesis experiments.

My special thanks go to Dr. Paul Arens, Dr. Jaap Van Tuyl, Dr. Frans Krens, Dr. Yuling Bai, Dr. Luisa Trindade, Dr. Elma Salentijn, Dr. Rene Smulders, Dr. Anne-Marie Wolters, Dr. Clemens van de Wiel, Dr. Guusje Bonnema, Dr. Christian Bachem, Dr. Henk Schouten, Dr. Johan Baars, Dr. Olga Scholten, Dr. Rients Niks, Dr. Jan Schaart, Dr. Chris Maliepaard, Dr. Jose Abelenda Vila, Dr. Oene Dolstra, Dr. Anton Sonnenberg, Dr. Michela Appiano, Dr. Niels van Den Dries and Dr. Anne Kortstee for their advises, collaborations and enjoyable conversations and scientific discussions.

My deepest gratitude to Isolde Pereira, Annemarie Dechesne, Iris Tinnenbroek-Capel, Marjan Bergervoet, Bernadette van Kronenburg, Helen Furrer-Verhorst, Alex van Sifhout, Patrick Hendrickx, Johan Bucher, Gerard Bijsterbosch, Jos Brinkhuis, Aranka van der Burgh and Marcel Visser for their help and support during all my hours of lab work. 
My special thanks to the Plant Breeding secretaries Annie Marchal, Janneke van Deursen, Nicole Trefflich and Letty Dijker for warm and kind support for administrative works. You are the best secretariat that I have ever seen.

I would like to thank my paranymphs Behzad Rashidi and Manos Domazakis for their intensive work to manage my thesis ceremony.

I appreciate the contributions of students who were working under my supervision, Ni Pan, Neshe Yousef, Niels van der Rest, Qiqi Li, Marie Febvre, Dewi Pramanik, Saiful Islam and Anika Heimink and visitor researcher Dr. Youguo Wang on different chapters of this thesis.

My special thanks go to my officemates Dr. Christos Kissoudis, Cynara Romero, Dr. Sara Bergonzi, Gurnoor Sing, Dr. Grace Rodriguez Ferreira, Mehdi Massoumi and Laura Rojas Martinez for their help and support during my $\mathrm{PhD}$.

I also appreciate the help and support of current PBR- PhD students, Behzad Rashidi, Ehsan Motazedi, Manos Domazakis, Nurashikin Bint Kemat, Nurfatihah Bint Hassan Nudin, Huayi Li, Kaile Sun, Yiqian Fu, Ernest Aliche, Thijs van Dijk, Piter Dinh, Xiao Lin and former PBR- PhD students and guest researchers, Dr. Paweena Pumisutapon, Dr. Arwa Shahin, Dr. Heba Shahin, Dr. Mirjana Vukosavljev, Dr. Luigi Faino, Dr. Yousef Sen, Dr. Stefano Pavan, Dr.Sergio Gianni, Dr. Lotfali Naseri, and Dr. Esmaeil Ghasemi.

I also appreciate help and advices of former Iranian PhD students and post-docs at Wageningen University, Dr. Rahim Mehrabi, Dr. Alireza Seifi, Dr. Reza Aghnoum, Dr. Benyamin Houshyani, Dr. Afshin Mehraban, Dr. Farhad Nazarian, Dr. Hedayat Bagheri and Dr. Hossein Jafari.

And special thanks to all members of FC Persia (football team) at Wageningen university, Dr. Mohamad Majdi, Dr. Mohamad Chizari, Dr. Mahmood Tabib Ghafari, Dr. Saeid Karimi, Dr. Sasan Aliniaeifard, Dr. Mansoor Karimi, Dr. Amir Mirzadi, Dr. Saeid Khalaj, Dr. Saeid Hamzeh Dr. Omidali Esmaeilipour, Abouzar Sheykhalian, Ehsan Kamali, Arash Rahimi, Arman Beyraghdar, Jalal Samia, Saadat Sarikhani, Ali Pourkhalooei and Siavash Sheikhi Zadeh. They not only became good soccer friends but also study friends. And all true friends in my life, who are glad with my successes and deeply upset with my misfortunes. 
I finally would like to thank my former employer, Shahid Bahonar Unversity of Kerman and my current employer, University of Jiroft to have given me this excellent opportunity for a $\mathrm{PhD}$ in the Netherlands.

At the end, I deeply appreciate the mental and emotional support of my family members during the last 6 years. My dear Mom and Dad, I am lucky to have you both. My brothers, Hamid, Masoud, Abasalt and Malek, and my sister Masoumeh, and brother- in- law, Meghdad and sister- in- law Nasim, my niece and nephew, Nazanin and Amir. I am very glad to join you again after these long years.

\section{Naser Askari}

Wageningen, 5 July 2016

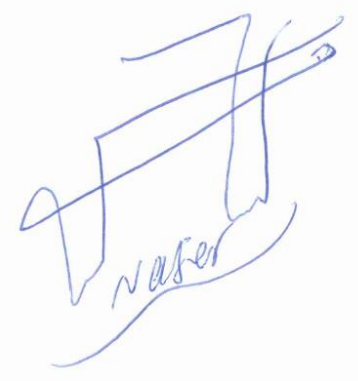


About the author 


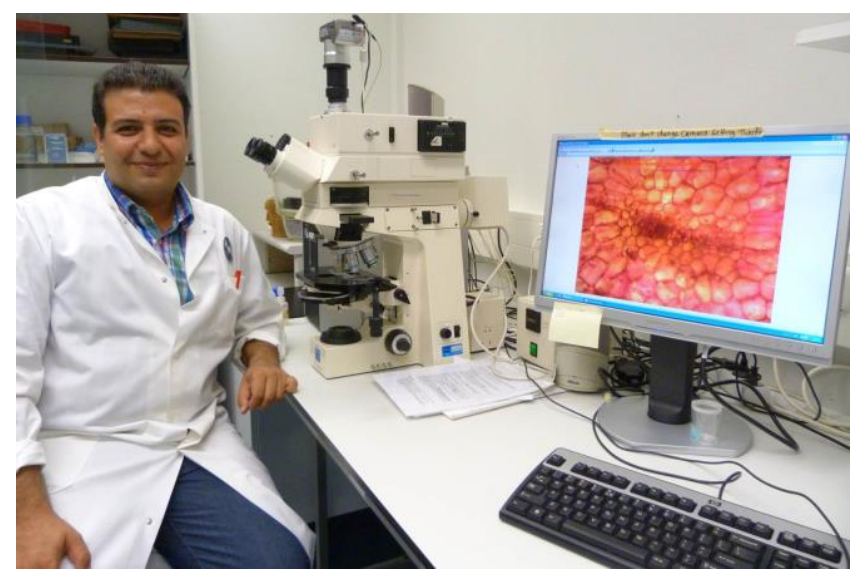

Naser Askari was born in Rabor, a beautiful mountain city in the south of Iran on March 6, 1977. In 1998, he received an associate degree in plant production from Shahid Bahonar University of Kerman. Subsequently, he finalized in 2000 a BSc in the horticultural crops production department at Tehran University (Aboureyhan Campus). On June 24, 2004 he defended his MSc thesis entitled "Improvement of micropropagation of Gerbera jamesonii" in the horticultural department of Guilan University. Since September 2004, he has been working as lecturer and researcher at Shahid Bahonar University of Kerman.

On March 18, 2010, Naser Askari started a PhD research under supervision of Prof. Dr. Richard G.F Visser and Dr. Geert-Jan De Klerk at the Plant Breeding department of Wageningen University. Naser Askari will continue his research and teaching career as assistant professor in ornamental plants physiology, micropropagation and biotechnology at University of Jiroft in Iran. 
Publications 
Askari, N., Wang, Y., \& de Klerk, G. J. (2014). In tissue culture of lilium explants may become heavily contaminated by the standard initiation procedure. Propagation of ornamental plants, 14(2), 49-56.

De Klerk, G.J., Van Der Rest, N and Askari, N (2014). Initiation of Tissue Culture: Standard procedure contaminates lily. Prophyta Annual, 30-33.

De Klerk, G. J., \& Askari, N. (2012). A Century of Plant Tissue Culture; Basal features ignored for too long. Prophyta Annual, 46-49.

Dastan, D., Pezhmanmehr, M., Askari, N., Ebrahimi, S. N., \& Hadian, J. (2010). Essential Oil Compositions of the Leaves of Azadirachta indica A. Juss from Iran. Journal of Essential Oil Bearing Plants, 13(3), 357-361.

Tatari, M., Askari, N., \& Nosrati, Z. (2010). Optimization of in vitro Culture for Gerbera cv. Tropic Blend. Seed and Plant Production Journal, 25(4), 389-401.

Abdi, G., and Askari, N. (2009). Enhancement of IBA, urea-phosphate, paclobutrazol and their combinations on rooting of royal Poinciana (Delonix regia) stem cuttings. American-Eurasian Journal of Agricultural and Environmental Science, 6(2), 132-136.

Askari, N., \& Fotouhi Ghazvini, R. (2007). Shoot regeneration of Gerbera jamesonii cultivars from young capitulum. Acta Horticulturae 812, 197-200.

Askari, N., Fotouhi, G. R., \& Moeini, A. (2006). In vitro plantlet production from young capitulum of two gerbera cultivars (gerbera jamesonii hook.). Iranian Journal of Horticultural Science and Technology, 6(4):203-214. 
EPS Certificate 


\section{Experimental Plant Sciences}

\section{Issued to: \\ Naser Askari Rabori}

Date:

5 July 2016

Group:

\section{Plant Breeding}

University:

Wageningen University \& Research Centre

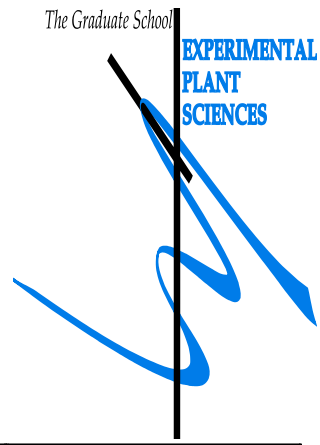

1) Start-up phase

date

- First presentation of your project

Elucidation and improvement of bulb induction and bulb growth in tissue culture of lily and other bulbous crops

- Writing or rewriting a project proposal

Elucidation and improvement of bulb induction and bulbgrowth in tissue culture of lily and other bulbous crops

Writing a review or book chapter

MSc courses

Plant Biotechnology (GEN 20806)

Nov-Dec, 2012

Gene Technology (MOBB 20306)

Sep-Nov, 2015

Genomics (ABG 30306)

Nov-Dec, 2015

Laboratory use of isotopes

Subtotal Start-up Phase

10.5 credits*

\section{2) Scientific Exposure}

- EPS PhD student days

EPS PhD Student Day, Wageningen University

EPS PhD Student Day, University of Amsterdam

EPS PhD Student Day, Leiden University

\section{$\underline{\text { date }}$}

May 20, 2011

Nov 30, 2012

Nov 29, 2013

EPS theme symposia

EPS theme 3 'Metabolism and Adaptation', Wageningen University

Apr 26, 2011

EPS theme 3 'Metabolism and Adaptation', Utrecht University

Apr 26, 2012

EPS theme 3 'Metabolism and Adaptation', Wageningen University

Mar 12, 2014

Lunteren days and other National Platforms

Annual Meeting Éxperimental Plant Sciences, Lunteren, NL

Apr 04-05, 2011

Annual Meeting Éxperimental Plant Sciences, Lunteren, NL

Apr 02-03, 2012

Annual Meeting Éxperimental Plant Sciences, Lunteren, NL

Apr 22-23, 2013 
Seminars (series), workshops and symposia

European Retreat of PhD Students in Experimental Plant Sciences, Paris,

Jul 05-08, 2011

France

European Retreat of PhD Students in Experimental Plant Sciences, Norwich,

UK

Plant Research day (Plant Breeding)

Aug 14-17, 2012

2010

Plant Research day (Plant Breeding)

Mar 08, 2011

\section{- Seminar plus}

- International symposia and congresses

VII International Symposium on In Vitro Culture and Horticultural Breeding: IVCHB, Ghent, Belgium

In Vitro Biology Meeting, Providence, Rhode Island, USA

Sep 18-22, 2011

Jun 15-19, 2013

\section{Presentations}

Rapid propagation of tulip in tissue culture ,TTIG symposium, NL (Poster)

Elucidation and improvment of bulb induction and bulb growth in tissue culture of lily, France (Poster)

Effect of GA and cold treatments on bulb growth of lily, Lunteren (Poster)

Lily bulb growth in tissue culture: the role of the explants, UK (Poster)

The role of photosynthesis on the growth of lily bulblets in vitro, USA (Poster)

Sep 21, 2011

July 05-08, 2011

Apr 02-03, 2012

Aug 14-17, 2012

Jun $15-19,2013$

\section{IAB interview}

Meeting with a member of the International Advisory Board of EPS

Nov 19, 2012

Excursions

Enza Zaden company

Jun 23, 2011

Flora Holland

2012

Subtotal Scientific Exposure

15.7 credits*

\begin{tabular}{|l|c|}
\hline 3) In-Depth Studies & $\frac{\text { date }}{}$ \\
$\quad$ EPS courses or other PhD courses & Sep 13-15 \& 20-21, \\
Basic Statistics & 2011 \\
Increasing photosynthesis in plants & Aug 21-26 2011 \\
Microscopy and spectroscopy in food and plant science & May 07-11 2012 \\
Natural variation in plants & Aug 21-24 2012 \\
$\quad$ Journal club & \\
Individual research training & \\
\hline Subtotal In-Depth Studies & 6.2 credits*
\end{tabular}




\section{4) Personal development}

\section{Skill training courses}

Summer School: English for IELTS

May-Aug 2012

Information Literacy $\mathrm{PhD}$ including EndNote Introduction

Jun 12-13, 2012

Academic writing 1

Mar-July 2012

Academic writing 2

The Art of Presenting Science

Scientific Wrtitng

Stress Identificatioan and Management

Sep 2012-Feb 2013

Reviewing a Scientific Paper

Apr 09, 18 \& May 07, 2013

Apr-Jun 2015

Jun 25, 2015

Sep 17, 2015

Organisation of PhD students day, course or conference

- Membership of Board, Committee or PhD council

\section{TOTAL NUMBER OF CREDIT POINTS*}

Herewith the Graduate School declares that the PhD candidate has complied with the educational requirements set by the Educational Committee of EPS which comprises of a minimum total of 30 ECTS credits

* A credit represents a normative study load of 28 hours of study. 